\title{
2. Kapitel: Prozedurales Recht: ein Konzept im Begriffsdreieck von Recht, Rationalität und Gesellschaft
}

Im folgenden sollen zunächst einige in der Diskussion befindliche Theorien zur Prozeduralisierung des Rechts vorgestellt werden. Angesichts der Vielzahl der Beiträge zum Thema beschränkt sich die Darstellung auf die aus Sicht des Verfassers wesentlichen Theorien (I.). Nach den theoretischen Grundannahmen sowie der groben Stoßrichtung, in die die Beiträge zielen, werden diese drei großen Richtungen zugeordnet, von denen die erste sich vornehmlich mit dem juristischen Diskurs befaßt (1.), während die zweite eine Theorie des politischen Diskurses einbezieht (2.). Die dritte, systemtheoretisch orientierte Richtung weitet die Analyse jenseits der aus der Rechtsstaatsdiskussion bekannten Dichotomie von Recht und Politik auf die gesamte Gesellschaft aus und richtet das Interesse auf die Abstimmung der Vielzahl von nebeneinander existierenden Diskursen in der Kommunikationsgesellschaft (3.). Die Unterschiede in den theoretischen Grundannahmen sowie die Verschiedenheit des Analysebereichs dieser Diskussionsstränge legen den Verdacht nahe, daß die Ansätze inkompatibel sind und abgesehen von dem gemeinsamen Schlagwort Prozeduralisierung über ganz unterschiedliche Dinge geredet wird (4.).

Um dennoch ein gemeinsames Substrat dieser Ansätze herausfiltern zu können, bedarf es eines Ausflugs in die abstrakten Höhen der Gesellschaftstheorie, innerhalb derer das Recht nicht mehr nur als System von Normen, sondern als Kommunikations- und Handlungssystem in einer Kommunikationsgesellschaft beschrieben und verstanden werden kann (II.). Als auf dem Begriff der Kommunikation aufbauende Gesellschaftstheorien werden dabei zunächst die Systemtheorie (1.) und sodann die Diskurstheorie (2.) befragt.

Ergebnis dieses Ausflugs ist eine Verortung des Begriffs "Prozedurales Recht" im Begriffsdreieck von Recht, Rationalität und Gesellschaft (III.), woraus abschließend ein Definitionsversuch prozeduralen Rechts in drei Dimensionen abgeleitet wird (IV.).

\section{Zu einigen Theorien der Prozeduralisierung des Rechts}

Zum Verhältnis von Recht, Gerechtigkeit, Rationalität und Verfahren liegen eine unüberschaubare Vielzahl von Theorien und Konstrukten vor, deren Darstellung den Rahmen dieser Untersuchung sprengen würde. Juristische Verfahrenstheorien sind dabei in der Regel sehr auf Verfahrensnormen fixiert, philosophischen Verfahrenstheorien fehlt nicht selten der Bezug zur konkreten gesellschaftlichen Institutionalisierung, während soziologische und psychologische Untersuchungen zur Verfahrensgerechtigkeit ihrem empirischen Wissenschaftsverständnis zufolge die normative Dimension ausblenden. Für die Suche nach einem der Risikogesellschaft und ihrem Präventionsstaat angemessenen Rechtsparadigma sind all diese Verfahrenstheorien deshalb nur von begrenztem Wert. ${ }^{1}$

1 S.o. Kap. 1, VI.; Daraus rechtfertigt sich, daß im folgenden auf die Darstellung rein normativer Ansätze, wie etwa J.Rawls Theorie der Gerechtigkeit, sowie rein sozialwissenschaftlicher Ansätze, wie etwa die sozialpsychologische procedural justice Forschung oder N.Luhmanns systemtheoretischer Ansatz der Legitimation durch Verfahren, und schließlich auch auf die Darstellung einer Vielzahl juristischer Verfahrenstheorien verzichtet wird. Ein Überblick über juristische Verfahrenstheorien fin- 
Dieser Einschätzung liegen drei Thesen zugrunde, die im Verlauf dieses Kapitels näher erläutert werden. Erstens setzt der Entwurf eines prozeduralen Rechtsparadigmas eine normative Teilnehmerperspektive voraus, die zwar nicht eine soziologische Aufklärung der eigenen Position, wohl aber ein Verharren in einer objektivierenden Beobachterperspektive ausschließt. Denn ein Rechtsparadigma als "juristisches Weltbild" kann im Rechtssystem nur dann konkret wirksam sein, wenn es aus einer teilnehmenden Perspektive entworfen und damit im Recht anschlußfähig ist.

Zweitens setzt ein den Problemen der modernen Risikogesellschaft gerecht werdendes Rechtsparadigma eine angemessene Beschreibung der Gesellschaft als Kommunikationsgesellschaft sowie des Rechts als Teilsystem in dieser Gesellschaft voraus. Denn im Gegensatz zu der abstrakt-philosophischen Frage nach dem Vernünftigen, Gerechten oder Guten an sich handelt eine Rechtstheorie von der Frage, wie Rationalität in der Gesellschaft praktisch institutionalisiert werden kann. Das setzt ein angemessenes Bild von der modernen Gesellschaft voraus und schließt eine rein normative Betrachtungsweise aus.

Drittens muß prozedurale Rationalität dem Selbstverständnis der modernen Gesellschaft als Kommunikations- und Informationsgesellschaft entsprechend als kommunikative Rationalität verstanden werden. Nur solche Entscheidungen können eine Vermutung für Vernünftigkeit in Anspruch nehmen, die sich als interimistisches Ergebnis einer in subjektlose Kommunikationskreisläufe ${ }^{2}$ eingelassenen, auf das regulative Ideal einer "final opinion" ausgerichteten rationalen Argumentation in freien Diskursen ausweisen. Solche Diskurse entziehen sich ihrer Logik nach, die jeden tatsächlich gefundenen Konsens und um so mehr jede faktisch getroffene Mehrheitsentscheidung als vorläufiges $Z$ wischenergebnis in einem unendlichen, aber zielgerichteten Lernprozeß $\beta$ auszeichnet, jeder Form der Institutionalisierung. Die in eine Vielzahl von Arenen und Foren der Meinungs- und Willensbildung eingelassene und deshalb "subjektlose" kommunikative Vernunft der Diskurse kann lediglich in Verfahren eingebettet werden, in denen kraft Entscheidung ein vorläufiges Zwischenergebnis als Arbeitsgrundlage gesellschaftlich verbindlich gemacht wird. Sind Diskurse aber nicht in Verfahren institutionalisierbar, so greift der auf Normen fixierte Blick vieler juristischer Verfahrenstheorien zu kurz. Eine Eins-zu-eins Übersetzung philosophischer Diskursregeln in juristisches Verfahrensrecht kann somit niemals zu einem dem Recht angemessenen und im Rechtssystem anschlußfähigen Rechtsparadigma führen.

Aus diesen drei Thesen ergeben sich Aufbau und Auswahl der folgenden Darstellung einiger Theorien zur Prozeduralisierung des Rechts recht zwanglos. Die Auswahl beschränkt sich auf Theorien, die ihr Augenmerk über die Normenebene hinaus auf kommunikative Aspekte im Recht richten, der Aufbau ergibt sich aus dem Fortschreiten vom Zentrum zur Peripherie des Rechts. Im ersten Schritt geht es um die Rationalität des juristischen Diskurses. Im zweiten Schritt wird der politische Diskurs einbezogen und, der traditionellen Rechtsstaatsdogmatik entsprechend, ins Verhältnis zum juristischen Diskurs gesetzt. Im dritten Schritt werden Theorien dargestellt, die über die Gren-

det sich bei R.Hoffmann, Verfahrensgerechtigkeit, S.53ff.; der normfixierte Blick juristischer Verfahrenstheorien tritt auch klar hervor in den Beiträgen in: K.Kroeschell (Hrsg.), Recht und Verfahren, Heidelberg 1993.

2 Zu dieser Formulierung von J.Habermas s.u. 2. b) und II. 2. 
zen von Recht und Politik hinaus den Stellenwert anderer Diskurse (Wirtschaft, Wissenschaft etc.) im gesamtgesellschaftlichen Allgemeinwohldiskurs problematisieren.

\section{Prozedurale Rationalität und juristische Argumentation: das Regel/Prinzipien/Prozedur-Modell des Rechtssystems}

Mit der Rationalität des zentralen Elements des Rechtssystems, nämlich dem richterlichen Urteil, hat sich unter kommunikativem Aspekt vor allem die juristische Argumentationstheorie beschäftigt. Während die als Lehre von der Textinterpretation noch relativ normfixierte juristische Hermeneutik zunächst zu dem Ergebnis gelangt war, daß sich ein Urteil nur in einem sehr schwachen Sinne aus einem Normtext herleiten läßt, und die Bedeutung des richterlichen Vorverständnisses betonte ${ }^{3}$, richtete die juristische Argumentationstheorie die Aufmerksamkeit auf die richterliche Begründung eines Urteils. Im Anschluß an die philosophische Argumentationstheorie etwa von Perelmann ${ }^{4}$ soll der Richter sein Urteil im Wege der rationalen Argumentation so gut begründen, daß er ein gedachtes juristisches Auditorium von der Richtigkeit des Urteils überzeugen kann.

Aus der Vielzahl juristischer Argumentationstheorien ${ }^{5}$ sticht unter dem Aspekt einer Prozeduralisierung des Rechts insbesondere Robert Alexys Theorie der juristischen Argumentation ${ }^{6}$ hervor, da Alexy den Begriff der rationalen juristischen Argumentation im Rahmen einer prozeduralen Theorie, nämlich der Theorie des rationalen Diskurses, expliziert $^{7}$ (a). Gleichsam um zwischen abstrakter Norm und juristischem Diskurs zu vermitteln, hat Alexy auf der Normebene die Unterscheidung von Regeln und Prinzipien eingeführt ${ }^{8}$, wobei Prinzipien einerseits als relativ offene Normen Optimierungsgebote enthalten, andererseits als Gründe für Abwägungen in der Argumentation Wirksamkeit entfalten $^{9}(\mathrm{~b})$. Aus diesen drei Elementen hat Alexy sodann ein Regel/Prinzipien/Prozedur-Modell des Rechtssystems zusammengefügt, das unter gegebenen Bedingungen ein Höchstmaß an praktischer Vernunft im Recht ermöglichen soll..$^{10}$ Ausführliche Analysen der Rechtsprechung des BVerfG zu den Grundrechten " führen Alexy zu der Annahme, daß die vielkritisierte Werteordnungsrechtsprechung des Verfassungsgerichts im Rahmen dieses Drei-Ebenen-Modells des Rechtssystems als eine Position des gemäBigten Konstitutionalismus rekonstruiert und auf eine tragfähige theoretische Grundlage gestellt werden kann ${ }^{12}$ (c). Nach der Diskussion einiger Probleme dieser Theorie (d) wird zusammengefasst, was für die hier zu entwerfende Theorie prozeduralen Rechts festgehalten werden kann (e).

3 Zur juristischen Hermeneutuk s.o. Kap. 1 V. 1.

4 S.o. Kap. 1 II 3. b).

5 Ein Überblick bei K.Larenz, Methodenlehre, S.35ff.

6 R.Alexy, Theorie der juristischen Argumentation (1978), Ffm 1983.

7 R.Alexy, Die Idee einer prozeduralen Theorie der juristischen Argumentation, in: ders., Recht, Vernunft, Diskurs (RVD), Ffm 1995, S.94ff.

8 R.Alexy, Zum Begriff des Rechtsprinzips, in: ders, RVD, S.177ff.; ders., Rechtsregeln und Rechtsprinzipien, S.13ff.

9 Zum Verständnis von Prinzipien als Gründe für Abwägungen vgl. J.-R.Sieckmann, Logische Eigenschaften von Prinzipien, Rechtstheorie 1994, S.163-189.

10 R.Alexy, Rechtssystem und praktische Vernunft, in: ders., RVD, S.213ff.

11 R.Alexy, Theorie der Grundrechte (1985), 2.Aufl., Ffm 1994.

12 R.Alexy, Rechtssystem, S.213ff.; Zum Begriff des Konstitutionalismus vgl. auch R.Dreier, Konsti-

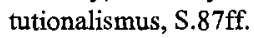




\section{a) Der Ausgangspunkt: die Idee einer prozeduralen Theorie der juristischen Argumentation}

Alexy hat die Chancen, die die linguistische Wende in der Moralphilosophie in bezug auf die Begründbarkeit von normativen (praktischen) Fragen auch für das Recht eröffnet hat, frühzeitig erkannt und systematisch für das Recht fruchtbar gemacht. ${ }^{13}$ Dabei hat er zunächst eine Reihe von Autoren auf ihren Beitrag zum Problem der rationalen Begründbarkeit von normativen Aussagen befragt und sodann, insbesondere in Anknüpfung an die Sprechakttheorie und Habermas' Diskurstheorie, eine Theorie des allgemeinen rationalen praktischen Diskurses entworfen. ${ }^{14}$

Diese Theorie bezeichnet er als prozedurale Theorie, weil ihr - wie allen prozeduralen Theorien - ein bestimmtes Verständnis des Verhältnisses von Richtigkeit und Verfahren zugrundeliegt. Nach einer prozeduralen Theorie ist eine normative Aussage genau dann richtig, wenn sie das Ergebnis einer bestimmten Prozedur sein kann ${ }^{15}$. Im Falle der Diskurstheorie besteht diese Prozedur in der Durchführung eines rationalen Diskurses, als dessen Ergebnis sich die Teilnehmer idealerweise kraft des besseren Arguments auf die Geltung einer bestimmten Norm einigen. Dabei ist nach Alexy nicht der Konsens an sich, sondern die Durchführung der Prozedur gemäß den Diskursregeln also die rationale Durcharbeitung der faktisch vorhandenen normativen Überzeugungen der Teilnehmer - das eigentliche Richtigkeitskriterium. ${ }^{16}$

Von anderen prozeduralen Theorien unterscheidet sich die Diskurstheorie im wesentlichen dadurch, daß die Prozedur zum einen nicht von einer einzelnen, idealen Person durchgeführt wird, sondern daß unbegrenzt viele Individuen in dem Zustand, in dem sie tatsächlich existieren, teilnehmen können. Im Gegensatz zu entscheidungstheoretischen Modellen ist die Diskurstheorie als argumentationstheoretisches Modell zum anderen dadurch gekennzeichnet, daß sich die faktisch vorhandenen normativen Überzeugungen der Individuen aufgrund der im Laufe der Prozedur vorgetragenen Argumente ändern können und sollen ${ }^{17}$. Der Diskurs ist daher wesentlich nicht-monologisch. ${ }^{18}$

Die Theorie des rationalen Diskurses kann nun, da sie keine besonderen Festlegungen hinsichtlich der Individuen und keine externen Vorgaben in bezug auf die Entscheidungsprämissen enthält, vollständig über Regeln formuliert werden. Alexy hat versucht, das System dieser Diskursregeln mit Hilfe von 28 Regeln möglichst vollständig zu erfassen ${ }^{19}$. Diese Regeln reichen von solchen, die Widerspruchsfreiheit, sprachliche Klarheit, empirische Wahrheit und Aufrichtigkeit fordern, über solche, die dem Gedanken

13 Ein Überblick über die Debatte um das Verhältnis von Recht und Diskurs findet sich bei R.Hoffmann, Verfahrensgerechtigkeit, S.186-200. Die folgende Darstellung beschränkt sich auf die Theorie von Alexy, weil dieser seine Theorie der juristischen Argumentation frühzeitig und systematisch entworfen hat, und im Anschluß konsequent zu einem umfassenden Modell der Rationalität des Rechts ausgebaut hat.

14 R.Alexy, Argumentation, Kap. A u. B.; Unter A diskutiert Alexy die Theorien Wittgensteins, Austins, Stevensons, Hares, Toulmins, Baiers, Habermas', Lorenzens, Schwemmers und Perelmans; zur Begründung der Diskurstheorie bei Habermas vgl. ausführlich unten Kap. 2 II. 2. a).

15 Ders., Idee, S.95.

16 Ders., Probleme der Diskurstheorie, in: ders., RVD, S.109ff., 120.

17 Ders., Idee, S.97.

18 Ders., Probleme, S.116; vgl. zur Unterscheidung von monologischen und dialogischen Theorien schon oben Kap. 1 II. 3. c) u. d).

19 Ders., Argumentation, S.234-255. 
der Verallgemeinerbarkeit etwa dadurch Ausdruck geben, daß Teilnahmerecht und Chancengleichheit eines jeden im Diskurs gesichert werden, bis zu solchen, die der Folgenargumentation, dem Abwägen und der Analyse der Entstehung normativer Überzeugungen gelten. Grob zusammengefaßt lassen sich vier Postulate prozeduraler praktischer Rationalität identifizieren: ${ }^{20}$ (1) Ein Höchstmaß an sprachlich-begrifflicher Klarheit; (2) ein Höchstmaß an empirischer Informiertheit; (3) ein Höchstmaß an Verallgemeinerbarkeit; (4) ein Höchstmaß an Vorurteilsfreiheit.

Das Problem der Diskurstheorie sieht Alexy nun darin, daß viele der Diskursregeln nur approximativ erfüllbar sind ${ }^{21}$. Faktisch stattfindende Diskussionen unterliegen einer Reihe von Einschränkungen im Hinblick auf die Zahl der Teilnehmer, deren kommunikative Kompetenz, die zur Verfügung stehende Zeit etc. Jeder zu einem bestimmten Zeitpunkt gefundene Konsens kann zudem in der Zukunft wieder in Frage gestellt werden. Die Ergebnisse tatsächlich durchgeführter Diskurse können daher immer nur als relativ richtig in bezug auf Teilnehmer, Zeitpunkt und approximative Erfüllung weiterer Diskursregeln gelten ${ }^{22}$. Nur wenige normative Aussagen, wie etwa eine Regel, nach der bestimmte Menschen als Sklaven von der diskursiven Willensbildung ausgeschlossen würden, die also gegen die Diskursregeln selbst verstoßen, können als diskursiv unmöglich ausgeschlossen werden. In Fällen, in denen zwei miteinander unvereinbare Normen ohne Verstoß gegen Diskursregeln begründet werden können, spricht Alexy hingegen vom Bereich des diskursiv Möglichen, in welchem es keine einzig richtige Antwort gibt. $^{23}$

In dem Verzicht auf einzig richtige Antworten sieht Alexy aber keineswegs einen Mangel. Der Richtigkeitsbegriff der Diskurstheorie bietet zwar weniger als derjenige material objektivistischer Moraltheorien, ist aber im Gegenzug frei von deren Problemen. Gleichzeitig wird im Hinblick auf die Richtigkeit mehr als im Rahmen relativistischer Theorien geboten, weil die Ergebnisse in dem Maße, in dem die Diskursregeln eingehalten werden, den Charakter rational erarbeiteter intersubjektiver Einsichten gewinnen ${ }^{24}$.

In den Grenzen der Ergebnisbestimmtheit der Theorie des allgemeinen rationalen praktischen Diskurses findet Alexy allerdings den entscheidenden Grund dafür, daß die Diskurstheorie in einer Theorie des Rechts und des Staats entfaltet werden muß. Denn dem weiten Raum des diskursiv Möglichen kann kein gleich weiter Raum des rechtlich Erlaubten entsprechen. Vielmehr sind Festlegungen im Raum des diskursiv Möglichen nötig, woraus sich der Bedarf nach einem Rechtssystem ergibt. Innerhalb dieses Rechtssystems sind drei weitere Prozeduren notwendig: die der staatlichen Rechtserzeugung, die der juristischen Argumentation sowie die des gerichtlichen Prozesses. Die konkreten Prozeduren der Rechtsetzung und des Gerichtsprozesses können dabei nach Alexy selbst Gegenstand allgemeiner rationaler Diskurse sein. Unter den denkbaren Formen der Institutionalisierung dieser Verfahren sind einige wiederum diskursiv unmöglich, andere hingegen nur im Bereich des diskursiv Möglichen. Einschränkungen des Diskursprin-

\footnotetext{
20 Ders., Rechtssystem, S.230.

21 Ders., Idee, S.99; ders., Probleme, S.113ff.

22 Zum Begriff der relativen Richtigkeit ders., Probleme, S.124ff.

23 Ders., Argumentation, S.255f.

24 Ders., Idee, S.102.
} 
zips etwa durch die Mehrheitsregel können dabei selbst wiederum diskursiv begründet werden. 25

Die Notwendigkeit der juristischen Argumentation begründet Alexy nun damit, daß kein Normensystem denkbar ist, aus dem sich fïr jeden Einzelfall ein einzig richtiges Urteil logisch ableiten lasse. Vielmehr gebe es zahlreiche Fälle, in denen bezogen auf die geltenden Rechtsnormen mehrere juristische Entscheidungen möglich sind. Zwar sorgt die Prozedur des Gerichtsprozesses dafür, daß immer eine Entscheidung getroffen wird, allerdings stellt sich die Frage, ob diese Entscheidung auch richtig ist. Die Aufgabe der Theorie der juristischen Argumentation besteht darin, diese Rationalitätslücke zu schließen. ${ }^{26}$

Die Begründung von Urteilen kann als rationaler Prozeß rekonstruiert werden, wenn die juristische Argumentation im Rahmen einer prozeduralen Theorie als rationaler Diskurs verstanden wird. Alexys Kernthese hierzu ist, daß der juristische Diskurs ein Sonderfall des allgemeinen praktischen Diskurses ist. ${ }^{27}$ Diese Sonderfallthese ergibt sich aus drei Argumenten. Um einen Diskurs handelt es sich bei der juristischen Argumentation deshalb, weil es in juristischen Diskussionen, zu denen Alexy neben der richterlichen Beratung auch die rechtswissenschaftliche (dogmatische) Erörterung, den Disput vor Gericht, die Behandlung juristischer Fragen in Gesetzgebungsorganen, Kommissionen und Ausschüssen, die Diskussion von Rechtsfragen zwischen Studenten, Anwälten, Wirtschafts- und Verwaltungsjuristen sowie den mit juristischen Argumenten ausgetragenen Streit um Rechtsprobleme in den Medien zählt, erstens um praktische Fragen, d.h. um die Begründung normativer Aussagen geht, und zweitens bezüglich dieser Aussagen ein Anspruch auf Richtigkeit erhoben wird. Um einen Sonderfall gegenüber dem allgemeinen praktischen Diskurs handele es sich drittens deshalb, weil der juristische Diskurs unter spezifischen Einschränkungen stattfindet, die sich aus der Bindung an das geltende Recht ergeben.

Der in juristischen Diskursen erhobene Anspmuch auf Richtigkeit unterscheidet sich dabei deutlich von dem des allgemeinen praktischen Diskurses. Es wird nicht beansprucht, daß die behauptete, vorgeschlagene oder als Urteil verkündete normative Aussage schlechthin vernünftig ist, sondern nur, daß sie erstens im Rahmen der geltenden Rechtsnormen, zweitens eingebunden in die von der institutionell betriebenen Rechtswissenschaft erarbeitete Dogmatik und drittens unter Berücksichtigung der Präjudizien richtig oder vernünftig begründbar ist ${ }^{28}$. $\mathrm{Da} ß$ aber überhaupt ein Anspruch auf Richtigkeit erhoben wird, ergibt sich aus der Tatsache, daß normative Aussagen im juristischen Diskurs begründet werden müssen. Für richterliche Urteile ist diese Begründungspflicht in den Prozeßordnungen verbindlich geregelt. Für die juristische Dogmatik ergibt sich dies aus dem Anspruch der Rechtswissenschaft als Wissenschaft, deren Hauptkriterium gerade die möglichst vollständige Auseinandersetzung mit allen denkbaren juristischen Argumenten ist ${ }^{29}$. Das gilt darüber hinaus aber auch für den anwaltlichen Disput vor Gericht. Zwar geht es den Parteien intern nicht um ein richtiges, sondern lediglich um ein 
vorteilhaftes Urteil. Allerdings können sie dieses Ziel nur durch eine Argumentation erreichen, die extern die eigene Rechtsposition als richtig ausweist ${ }^{30}$.

Neben diesen eher empirischen Argumenten ergibt sich der mit jeder normativen Aussage verbundene Anspruch auf Richtigkeit noch aus einer anderen Überlegung. Normen oder Urteile, die keinen Anspruch auf Richtigkeit erheben, verwickeln sich in einen performativen Widerspruch ${ }^{31}$. Dieser der Sprechakttheorie entstammende Begriff bezieht sich auf einen Widerspruch zwischen der in einem Satz enthaltenen Aussage (präpositionaler Satz) und der mit dem Satz vorgenommenen Handlung (performatorischer Ausdruck) ${ }^{32}$. Ein solcher Widerspruch besteht etwa in der Behauptung: "Die Kat-

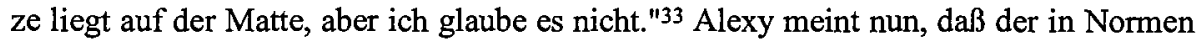
und Urteilen enthaltene Anspruch auf Richtigkeit im Bestreitensfalle in einen ebensolchen Widerspruch führt. Als Beispiel führt er die Verfassungsnorm "X ist eine souveräne, föderale und ungerechte Republik" sowie das Urteil "Im Namen des Volkes, der Angeklagte wird, was falsch ist (bzw. was eine falsche Interpretation des geltenden Rechts ist), zu lebenslanger Freiheitsstrafe verurteilt" ${ }^{34}$ Solche Normen und Urteile sind nach Alexy nicht nur sozial oder rechtlich regelwidrig, sondern begrifflich fehlerhaft, was zeige, daß mit dem Recht schon begrifflich ein Anspruch auf Richtigkeit verbunden sei.

Ist damit begründet, daß die juristische Argumentation als Diskurs verstanden werden kann, so ergeben sich die Einschränkungen gegenüber dem allgemeinen praktischen Diskurs aus den spezifischen Regeln und Formen der juristischen Argumentation, die die Bindung an Gesetz, Präjudiz und Dogmatik zum Ausdruck bringen. Nicht jedes Argument ist im juristischen Diskurs zulässig. ${ }^{35}$ Die zur Rechtfertigung von juristischen Urteilen zulässigen Argumentformen teilt Alexy in sechs Gruppen ein, denen er sodann bestimmte Regeln zuordnet. ${ }^{36}$ Den bereits erwähnten Argumentformen, die sich auf die Bindung an Gesetz, Präjudiz und Dogmatik beziehen, können die im wesentlichen bekannten Regeln der juristischen Methodenlehre zugeordnet werden. Eine weitere Gruppe bilden die bekannten juristischen Argumentformen der Analogie, des Umkehrschlusses etc. Sodann gibt es Regeln über die Ermittlung des Sachverhalts, die zum Teil in den Prozeßordnungen institutionalisiert sind. All diese Regeln reichen hingegen in vielen Fällen nicht aus, um zu einem eindeutigen Ergebnis zu führen. Innerhalb der bekannten juristischen Methoden besteht vielmehr ein breiter Raum des im juristischen Diskurs Möglichen (Vertretbaren).

Dieser Raum muß nach Alexy durch praktische Vernunft, also durch in allgemeinen praktischen Diskursen ebenfalls verwendbare rationale Argumente ausgefüllt werden. Der Übergang zwischen traditionellen juristischen Methoden und allgemeiner moralischer Argumentation ist dabei allerdings fließend. Denn in zahlreichen juristischen Argumentformen ist der Verweis auf allgemeine praktische Argumente bereits angelegt.

30 Ders., a.a.O., S.270f.

31 Ders., Begriff und Geltung des Rechts, Freiburg/München 1992, S.64ff., 69.

32 Vgl. dazu unten II. 2 a).

33 Beispiel bei R.Alexy, Argumentation, S.266; der Widerspruch liegt darin, daß mit einer empirischen Behauptung (Die Katze liegt auf der Matte) ein Wahrheitsanspruch erhoben wird, der mit dem Nachsatz (ich glaube es nicht) in Frage gestellt wird. Vgl. dazu ausführlich unten II. 2. a).

35 Ders., Idee, S.106f.

36 Ders., Argumentation, S.285ff. 
So verweist etwa die teleologische Auslegungsmethode schon auf die aus allgemeinen praktischen Diskursen bekannte Folgenberücksichtigung. Auch die allgemeinen juristischen Argumentformen der Analogie, des Umkehrschlusses etc. stellen einen Bezug zur allgemeinen praktischen Argumentation her. Für Alexy besteht insofern ein notwendiger Zusammenhang zwischen Recht und Moral, als der vom Recht erhobene Anspruch auf Richtigkeit im Bereich des nach den juristischen Methoden diskursiv Möglichen nur unter Rückgriff auf allgemeine moralische Argumente eingelöst werden kann. ${ }^{37}$

Besonders deutlich wird dies im Bereich der nach der juristischen Methodenlehre zulässigen contra-legem-Entscheidungen, in Fällen von Normkonflikten, für die das positive Recht keine Lösungen enthält, sowie für die verfassungsgerichtliche Normenkontrolle anhand der Grundrechte. Zur Analyse dieser sogenannten hard cases hat Alexy auf der Normenebene die Unterscheidung von Regeln und Prinzipien eingeführt, die nunmehr vorgestellt wird.

\section{b) Regeln und Prinzipien}

Die Prinzipientheorie unterscheidet zwei Arten von Normen: Regeln und Prinzipien. Damit wird an in der Rechtswissenschaft übliche Unterscheidungen zwischen Norm und Grundsatz ${ }^{38}$, Normen und Prinzipien ${ }^{39}$ oder Rechtsregeln und Rechtsgrundsätzen ${ }^{40}$ angeknüpft ${ }^{41}$. So vielfältig die Terminologie ist, so zahlreich sind auch die vorgeschlagenen Unterscheidungskriterien. So wird auf die Generalität oder Allgemeinheit der Normen, auf deren Bestimmtheit, auf die Bestimmbarkeit der Anwendungsfälle oder die Art der Geltungs- und Entstehungsweise abgestell ${ }^{42}$. Weiterhin wird nach der Explizitheit des Wertungsgehaltes, dem Bezug zur Rechtsidee oder danach unterschieden, ob es sich um Gründe für Regeln oder um Regeln selbst handelt ${ }^{43}$.

Es gibt nun drei mögliche Thesen über die Art der Trennung zwischen Prinzipien und Regeln. Zum einen wird eine solche Einteilung der Normen für verfehlt gehalten, da es an brauchbaren Unterscheidungskriterien fehle ${ }^{44}$. Zum anderen wird vertreten, Regeln und Prinzipien unterschieden sich nur dem Grade nach, eine strikte Abgrenzung sei allerdings unmöglich ${ }^{45}$. Alexy hingegen vertritt eine starke Trennungsthese, nach der ein qualitativer Unterschied zwischen Regeln und Prinzipien besteht ${ }^{46}$. In Anknüpfung an Dworkin ${ }^{47}$ findet er das ausschlaggebende Unterscheidungskriterium in der Normstruktur ${ }^{48}$. Prinzipien haben danach den Charakter von Optimierungsgeboten. Sie gebieten, daß etwas in einem relativ auf die rechtlichen und tatsächlichen Möglichkeiten mög-

37 Zum Zusammenhang zwischen Recht und Moral vgl. ausführlich R.Alexy, Begriff, insbes. zur Richtigkeitsthese S. 129ff; vgl. auch R.Dreier, Gerechtigkeit, S.8ff., $31 \mathrm{ff}$.

38 J.Esser, Norm und Grundsatz in der richterlichen Fortbildung des Privatrechts, 3. Aufl., Tübingen 1974.

39 BVerfGE 51, 324 (350).

40 U.Penski, Rechtsgrundsätze und Rechtsregeln, JZ 1989, S.105ff.

41 R.Alexy, Grundrechte, S.72f.

42 Vgl. die Nachweise bei U.Penski, Rechtsgrundsätze und Rechtsregeln, S.105.

43 R.Alexy, Rechtsregeln und Rechtsprinzipien, S.13ff. m.w.N.

44 A.Aarnio, Taking Rules Seriously, in ARSP-Beiheft 42 (1990), S.180ff.

45 U.Penski, Rechtsgrundsätze und Rechtsregehn, S.107f.

46 R.Alexy, Zum Begriff des Rechtsprinzips, S.177ff.

47 R.Dworkin, Taking Rights Seriously, 2. Aufl., London 1978, dt.: Bürgerrechte ernstgenommen, Ffm 1984.

48 Vgl. zum folgenden R.Alexy, Grundrechte, S.75ff. 
lichst hohen Maße verwirklicht wird. Der Bereich des rechtlich Möglichen wird dabei durch gegenläufige Prinzipien und Regeln bestimmt. Prinzipien können folglich in verschiedenen Graden verwirklicht werden. Demgegenüber sind Regeln Normen, die stets nur entweder erfüllt oder nicht erfüllt werden können. Wenn eine Regel gilt, dann ist es geboten, genau das zu tun, was sie verlangt, nicht mehr und nicht weniger. Regeln enthalten damit Festsetzungen im Raum des rechtlich und tatsächlich Möglichen, sie haben einen definitiven Charakter ${ }^{49}$.

Diese Differenz in der Normstruktur zeigt sich deutlich anhand des unterschiedlichen Kollisionsverhaltens von Regeln und Prinzipien. Führen zwei Regeln für sich genommen zu sich widersprechenden konkreten Sollensurteilen (Regelkonflikt), so wird dieser Konflikt gelöst, indem entweder in eine der Regeln eine Ausnahmeklausel eingefuigt wird oder aber eine der Regeln für ungültig erklärt wird. Letzteres geschieht durch Regeln wie Art. $31 \mathrm{GG}$ (Bundesrecht bricht Landesrecht) oder etwa die lex-posterior-Regel..$^{50} \mathrm{Im}$ Gegensatz dazu finden Prinzipienkollisionen nicht in der Dimension der Geltung, sondern in der Dimension des Gewichts statt. Sie werden durch eine Abwägung gelöst, bei der es darum geht, welchem der abstrakt gleichrangigen Belange im konkreten Fall das höhere Gewicht zukommt. Im Rahmen dieser Abwägung gilt das $A b w a ̈-$ gungsgesetz, nach dem das zulässige $\mathrm{Maß}$ der Nichterfüllung oder Beeinträchtigung des einen Prinzips vom Wichtigkeitsgrad der Erfuillung des anderen Prinzips abhängt, wobei sich die möglichen Abwägungsergebnisse in einer Indifferenzkurve darstellen lassen, die zum Ausdruck bringt, daß mit zunehmender Einschränkung des einen Prinzips ein immer größerer Zuwachs bei der Verwirklichung des anderen Prinzips nötig ist (Grenznutzen), so daß eine vollständige Nichtverwirklichung eines Prinzips ausgeschlossen erscheint. ${ }^{51}$

Das Ergebnis einer solchen Abwägung ist eine bedingte Vorrangrelation, die angibt, unter welchen Bedingungen das eine Prinzip dem anderen vorgeht. Nach dem Kollisionsgesetz bilden diese Bedingungen den Tatbestand einer Regel, die die Rechtsfolge des vorgehenden Prinzips ausspricht ${ }^{52}$. Aus der Struktur des Kollisionsgesetzes ergibt sich, $\mathrm{da} ß$ hinter jeder definitiven Regel eine Abwägung von Prinzipien steht. Dies gilt für die von der Rechtsprechung anhand der Entscheidung eines konkreten Einzelfalles erarbeitete Fallnorm ${ }^{53}$ ebenso wie für Gesetze, die den Charakter definitiver Regeln haben. Prinzipien sind insofern Gründe für Regeln und haben keinen definitiven, sondern nur einen prima facie verpflichtenden Charakter ${ }^{54}$. Als Gründe für Regeln sind Prinzipien damit wichtiger Bestandteil der juristischen Argumentation. Da Prinzipien aber häufig als Normen in der Rechtsordnung positiv verankert sind ${ }^{55}$, handelt es sich nicht um irgendwelche beliebigen Argumente. Prinzipien haben vielmehr eine normative Kraft, die den Rechtsanwender verbindlich anweist, einen durch das Prinzip ausgezeichneten $\mathrm{Zu}$ stand herbeizuführen oder ein bestimmtes Ziel zu verwirklichen. Mit Rücksicht auf die-

49 R.Alexy, Grundrechte, S.76.

50 R.Alexy, Grundrechte, S.77f.

51 R.Alexy, Grundrechte, S.146ff.

52 R.Alexy, Grundrechte, S.84.

53 Zum Begriff der Fallnorm bei Fikentscher vgl. K.Larenz, Methodenlehre, S.32; dieser Begriff entspricht im wesentlichen dem der konkreten Vorrangrelation bzw. der zugeordneten Grundrechtsnorm bei R.Alexy, Grundrechte, S.84f.

54 R.Alexy, Grundrechte, S.87-92.

55 R.Alexy, Grundrechte, S.117ff. 
sen normativen Charakter interpretiert Alexy Prinzipien nicht als bloße Argumente, sondern als Optimierungsgebote. Man kann daher sagen, daß Prinzipien eine vermittelnde Rolle zwischen abstrakter Regelebene und konkreter juristischer Argumentation spielen.

\section{c) Das Regel/Prinzipien/Prozedur-Modell des Rechts}

Aus den drei Elementen Regeln, Prinzipien und juristische Argumentation hat Alexy ein drei-Ebenen-Modell des Rechtssystems zusammengefügt, welches ein Höchstmaß an Rationalität im Recht gewährleisten sol156. Ein reines Regelmodell des Rechts ist danach im Hinblick auf die Rationalität unbefriedigend, da ein geschlossenes Regelsystem, aus dem sich für jeden Einzelfall eine einzig richtige Entscheidung ergibt, undenkbar ist. Um richterliche Willkür bei der Anwendung der Regeln zu vermeiden, muß es daher durch Prinzipien ergänzt werden, die dem Rechtsanwender im "Offenheitsbereich" des Rechts die Richtung vorgeben, in der die Antwort zu suchen ist..$^{57}$ Die im Rahmen des Prinzipienmodells vorzunehmenden Abwägungen sind zwar durch den Charakter der Prinzipien als Optimierungsgebote, aus dem sich das Abwägungsgesetz sowie das Kollisionsgesetz ergeben, rational vorstrukturiert, gewährleisten aber ebenfalls nicht für jeden Fall eine einzig richtige Antwort. Darüber hinaus führen Prinzipienabwägungen lediglich zu einem relativ engen Netz von konkreten Vorrangrelationen, die zudem durch die Methoden des distinguishing und overruling jederzeit situativ abänderbar $\operatorname{sind}^{58}$. Ein reines Prinzipienmodell würde daher zu untragbarer Unbestimmtheit des Rechts füh$\mathrm{ren}^{59}$. In einem kombinierten Regel/Prinzipien-Modell hingegen können sich nach Alexy die Vorteile beider Modelle vereinigen lassen, während sich die Nachteile beider Modelle durch gegenseitige Ergänzung auf ein Minimum reduzieren lassen. Um die Rationalitätslücke, die durch die Offenheit des Abwägungsergebnisses im Prinzipienmodell verbleibt, zu schließen, muß das Regel/Prinzipien-Modell noch durch die Prozeduren der Verfassungs- und Gesetzgebung, der Rechtsanwendung und des rationalen juristischen Diskurses ergänzt werden. Der weite Raum des diskursiv Möglichen wird also durch Regeln und Prinzipien eingeschränkt, die Offenheit des Rechts im Regel/Prinzipien-Modell wird durch den rationalen juristischen Diskurs geschlossen. Unter menschlichen Bedingungen ist nach Alexy ein Mehr an praktischer Vernunft im Recht nicht möglich ${ }^{60}$.

Dieses Regel/Prinzipien/Prozedur-Modell hat Alexy vornehmlich anhand der Rechtsprechung des BVerfG zu den Grundrechten erläutert ${ }^{61}$. Grundrechtsnormen haben nach Alexy einen Doppelcharakter: Einerseits sind Grundrechte Regeln, die an einen Tatbestand (Schutzbereich, Eingriff, Schranken) eine Rechtsfolge knüpfen. Andererseits muß den Grundrechten jedoch die normative Kraft von Optimierungsgeboten zukommen, weshalb sie gleichzeitig als Prinzipien verstanden werden müssen ${ }^{62}$. Ein reines Regel-

$56 \quad$ R.Alexy, Rechtssystem, S.213ff, 231.

57 Zum Begriff des "Offenheitsbereich" im postiven Recht vgl. R.Alexy, Begriff, S.118.

58 R.Alexy, Grundrechte, S.507.

59 R.Alexy, Grundrechte, S.104ff.; vgl. auch J.-R.Sieckmann, Regelmodelle und Prinzipienmodelle des Rechtssystems, Baden-Baden 1990.

60 R.Alexy, Rechtssystem, S.231.

61 R.Alexy, Grundrechte; ders., Die logische Analyse juristischer Entscheidungen, in: ders., RVD, S.13ff.

62 R.Alexy, Grundrechte, S.104-122. 
modell der Grundrechte würde nämlich angesichts der Gesetzesvorbehalte dazu führen, daß die Grundrechte bis auf einen schwer bestimmbaren Wesensgehalt zur freien Disposition des Gesetzgebers stünden. Das positive Recht der Bundesrepublik sieht aber in Art. $1 \mathrm{III}$ und Art. $20 \mathrm{III} \mathrm{GG}$ die Bindung auch des Gesetzgebers an die Grundrechte vor, und hat in Art. 93 GG auch eine richterliche Kontrolle dieser Bindung institutionalisiert. Wenn diese Kontrolle nicht weitgehend leerlaufen soll, so muß den Grundrechten eine positive Kraft gegeben werden, die auf Grundrechtsverwirklichung drängt. Das BVerfG hat dies mit der objektiven Wertordnungstheorie und dem sich daraus ergebenden Verhältnismäßigkeitsgrundsatz versucht. Alexy ist der Ansicht, daß dieses Werteordnungdsmodell im Rahmen seiner Prinzipientheorie von unhaltbaren Annahmen befreit und auf eine tragfähige theoretische Grundlage gestellt werden $\mathrm{kann}^{63}$. Die sich daraus ergebende Position bezeichnet er in Abgrenzung vom Legalismus (Positivismus) als die eines gemäßigten Konstitutionalismus ${ }^{64}$, die auf einem moralisch angereicherten Begriff des Rechts beruht ${ }^{65}$.

\section{d) Einige Probleme}

Die Prinzipientheorie wird vor allem unter zwei Gesichtspunkten kritisiert.66 Erstens wird die starke Trennungsthese von Alexy, nach der sich Prinzipien als Optimierungsgebote von definitiven Regeln ihrer Struktur nach unterscheiden, abgelehnt. Die hierauf bezogenen Beiträge laufen im wesentlichen darauf hinaus, daß eine Differenzierung nach verschieden Sollensqualitäten unhaltbar ist, Regeln und Prinzipien sich vielmehr lediglich durch die Art ihrer Anwendung unterscheiden. ${ }^{67}$ Auf diese normtheoretische Kritik soll hier nicht näher eingegangen werden ${ }^{68}$. Ein hohes Maß an Überzeugungskraft gewinnt Alexys Prinzipientheorie jedenfalls dadurch, daß sie die gegenwärtige Praxis der juristischen Argumentation zutreffend beschreibt und theoretisch strukturiert.

Für die hier geführte Diskussion interessanter ist die zweite, rechtsstaatliche Kritik an der Prinzipientheorie, die an die Kritik der Werteordnungstheorie des Verfassungsgerichts $^{69}$ anknüpft. Kernpunkte dieser Kritik sind die Abwertung der Grundrechte zu bloBen Abwägungsgesichtspunkten sowie das ungeklärte Verhältnis von richterlicher Prinzipienoptimierung und demokratischer Gesetzgebung. Was den ersten Kritikpunkt angeht, so liegt das Problem darin, daß in der Prinzipientheorie nicht nur den Grundrechten, sondern auch allen gegenläufigen, in der Abwägung zu berücksichtigenden Interessen der Charakter von Optimierungsgeboten zugesprochen wird. Dazu gehören neben

63 R.Alexy, Grundrechte, S.125-157.

64 R.Alexy, Rechtssystem, S.213ff.; vgl. auch R.Dreier, Rechtsstaat, S.73ff.; ders., Konstitutionalismus, S.87ff.

65 Vgl. dazu die Definition bei R.Alexy, Begriff, S.201ff.; sowie R.Dreier, Begriff des Rechts, S.95ff, $115 \mathrm{f}$.

66 Zur Kritik an Alexys Argumentationstheorie vgl, nur Alexys Antwort an einige Kritiker im Nachwort zur 2. Aufl.: R.Alexy, Argumentation, 2.Aufl. 1991, S.399ff.

67 Vgl. etwa U.Penski, Rechtsgrundsätze und Rechtsregeln, S.109; A.Aarnio, Taking Rules Seriously, S.187; K.Günther, Der Sinn für Angemessenheit, Ffm 1988, der insofern die Unterscheidung von Begründungs- und Anwendungsdiskursen einführt (S.257ff.); im Anschluß daran auch J.Habermas, FuG, S.309ff.

$68 \mathrm{Zu}$ einigen Gegenargumenten vgl. R.Alexy, Normenbegründung und Normanwendung, in: ders., RVD, S.52ff.; ders., Jürgen Habermas' Theorie des juristischen Diskurses, in: ders., RVD, S.165ff.

Vgl. oben Kap 1 V. 1. zur Krise des Rechtsstaats. 
kollidierenden Grundrechten Dritter auch die von Dworkin ${ }^{70}$ policies genannten Allgemeinwohlinteressen. Diese zur Begründung von Grundrechtsbeschränkungen genutzten Gesichtspunkte werden zum Teil aus normierten Rechtsgrundsätzen wie dem Rechtsstaats- oder dem Sozialstaatsprinzip oder gar aus Kompetenznormen hergeleitet ${ }^{71}$, zum Teil handelt es sich aber auch um politische Argumente, die keinerlei institutionelle Unterstützung im positiven Verfassungsrecht finden ${ }^{72}$. Da sich in der Praxis des BVerfG keine Abgrenzungskriterien finden, spricht Alexy jedem Interesse Prinzipienqualität zu, das zu Recht für oder gegen eine grundrechtliche Entscheidung angeführt werden $\mathrm{kann}^{73}$. Damit kommt jedem Interesse kraft Verwendung in grundrechtlichen Argumentationen Sollensqualität im Sinne eines Optimierungsgebotes zu.

$\mathrm{Da}$ alle Prinzipien abstrakt gleichrangig sind und ihr konkretes Gewicht erst situativ in der Abwägung bestimmt wird, führt die Prinzipientheorie zu einer Relativierung der Grundrechte im Hinblick auf gegenläufige Interessen, die - obwohl gerade nicht grundrechtlich verbürgt - abstrakt gleichrangiges Gewicht erhalten. Die Kritiker ${ }^{74}$ der Abwägungskonzeption führen nun an, daß der Grundrechtsschutz immer nur dann von Bedeutung sei, wenn eine Kollision mit gewichtigen gegenläufigen Interessen zu befürchten sei. Eine Kunst oder Meinungsäußerung, die niemanden störe, brauche keinen Grundrechtsschutz. Die Grundrechte, die aus historischen Konfliktlagen entstanden seien, wollten dem einzelnen gerade im Konflikt mit gewichtigen Interessen der Mehrheit absoluten Schutz gewähren. Das situative Abwägungsmodell, das die Grundrechte im Hinblick auf gegenläufige Interessen vom Zeitgeist abhängig mache, könne dem Bürger keine hinreichende Rechtssicherheit bezüglich dieses absoluten Grundrechtsschutzes geben ${ }^{75}$. Diesem Einwand begegnet Alexy, da er eine harte Vorrangordnung zwischen den Prinzipien für unmöglich hält, mit einem System von Vorrangbedingungen, Abwägungsstrukturen und prima-facie-Vorrängen, die die Grundrechte im Sinne einer Argumentationslastregel vor anderen Prinzipien auszeichnen ${ }^{76}$. Der entscheidende Mangel an dieser Kritik ist zudem, daß kein einleuchtendes Alternativkonzept zur Abwägung angeboten wird?7.

Aufmerksamkeit verdient hingegen der zweite Kritikpunkt, der sich auf den Machtzuwachs der Judikative gegenüber der Legislative bezieht ${ }^{78}$. Bei der Darstellung des Kollisionsgesetzes wurde bereits darauf verwiesen, daß die Struktur von Prinzipienabwägungen im wesentlichen der Struktur der Gesetzgebung entspricht, da das Ergebnis

70 R.Dworkin, Taking Rights Seriously, S.82, 90.

71 Z.B. wird der Grundsatz einer funktionstüchtigen Strafrechtspflege aus dem Rechtsstaatsprinzip, der Grundsatz der Funktionstüchtigkeit der Bundeswehr aus einer Kompetenznorm hergeleitet: vgl. R.Alexy, Grundrechte, S.118f.; kritisch dazu Dissenting Vote Böckenförde/Mahrenholz, BVerfGE $69,1,58 \mathrm{ff}$.

72 Zum Begriff der institutionellen Unterstützung vgl. A.Aarnio, Taking Rules Seriously, S.189f.

73 R.Alexy, Grundrechte, S.117ff.

74 Vgl. zum folgenden Dissenting Vote Böckenförde/Mahrenholz, BVerfGE 69, 1, 63ff.; U.Rühl, Das Grundrecht auf Gewissensfreiheit im politischen Konflikt, Ffm 1987, S.374ff.

75 U.Rühl, Gewissensfreiheit, S.369 m.w.N.

76 R.Alexy, Grundrechte, S.142f.

77 Zur Kritik verschiedener Entwürfe einer engen Tatbestandstheorie vgl. R.Alexy, Grundrechte, S.280ff.

78 Vgl. I.Maus, Aufklärung, S.298ff.; U.Rühl, Gewissensfreiheit, S.375f. m.w.N.; J.Habermas, FuG, S.309ff. m.w.N.; im Kern schon E.Forsthoff, Die Umbildung des Verfassungsgesetzes; s.o. Kap. 1 V. 1. zur Krise des Rechtsstaats. 
von Abwägungen in der Aufstellung einer definitiven Regel besteht, die in ihrem Tatbestand die Bedingungen angibt, unter denen die Rechtsfolge des einen Prinzips der des anderen Prinzips vorgeht. Abwägungen sind daher Regelsetzungen, die sich lediglich in dem Grad der Abstraktion der aufgestellten Regel von gesetzgeberischen Normbegründungsdiskursen unterscheiden. Diese Feststellung mag solange unproblematisch sein, wie sich der Unterschied zwischen juristischem und politischem Diskurs mit der Bindung an Gesetz, Präjudiz und Dogmatik erklären läßt, wie dies in Alexys Sonderfallthese ausgeführt wird.

Ein Legitimationsproblem ergibt sich aber dann, wenn diese für den juristischen Diskurs kennzeichnenden Bindungen an Gesetz und Dogmatik weitgehend unwirksam werden und sich die Rechtsprechung vornehmlich selbstreferentiell durch den Bezug auf Präjudizien legitimiert. Das ist im Bereich der Verfassungsrechtsprechung weitgehend der Fall. Denn dort sind die Gesetze nicht Maßstab, sondern selbst Gegenstand der Prüfung. Die Bindung an das positivierte Verfassungsgesetz hilft wegen dessen hoher Unbestimmtheit und Offenheit ebenfalls nicht weiter. ${ }^{79}$ Und die Bindung an die Dogmatik läuft weitgehend leer, wo diese selbst mehr Offenheit als Rechtssicherheit produziert.

Genau dies trifft für die aktuelle Grundrechtsdogmatik zu: Einerseits wird der Schutzbereich der Grundrechte sehr weit gefaßt, um möglichst viele Verhaltensweisen unter den Grundrechtsschutz zu bringen (weite Tatbestandstheorien) ${ }^{80}$. Gleichzeitig wird Art. 2 I GG als allgemeine Handlungsfreiheit interpretiert, die als Muttergrundrecht alle anderen Grundrechtsgewährleistungen umfasst und als Auffangtatbestand wirkt ${ }^{81}$. Im Ergebnis kann nahezu jedes gesellschaftliche Interesse als grundrechtlich geschützt dargestellt werden ${ }^{82}$. Auf der anderen Seite ist die Prinzipientheorie gegenüber allen gesellschaftlichen Interessen offen, die als gegenläufige Prinzipien dargestellt werden können. Der von Alexy betonte Regelcharakter, den die Grundrechte neben ihrem Prinzipiencharakter haben sollen, wird durch weite Tatbestandstheorien sowie durch die Lehre vom mittelbaren Eingriff und faktischen Grundrechtsbeeinträchtigungen tendenziell aufgelöst. Das Verständnis der Grundrechte als Leistungs- und Teilhaberechte, die Theorien der Drittwirkung der Grundrechte und der Schutzpflichten des Staates ermöglichen es zudem, die Grundrechte in alle Richtungen für und gegen jedermann zu richten. Insgesamt entsteht der Eindruck, daß jeder nur denkbare Interessenkonflikt als grundrechtliche Kollision darstellbar wird. "Die Rechtsordnung erhält damit den Charakter eines umfassenden Systems von Lösungen grundrechtlicher Kollisionen." 83

Der grundrechtliche Diskurs wird durch die Dogmatik also nicht nur in einem sehr eingeschränkten Sinne gebunden ${ }^{84}$, sondern der Gegenstandsbereich grundrechtlichen

$79 \mathrm{Zu}$ den Grenzen von Wortlaut und Wille bei der Grundrechtsinterpretation vgl. R.Alexy, Grundrechte, S.501ff.

80 R.Alexy, Grundrechte, S.273ff, $290 \mathrm{f}$.

81 R.Alexy, Grundrechte, S.309ff.

82 U.Rühl, Gewissensfreiheit, S.375.

83 R.Alexy, Grundrechte, S.296f.

84 Dies gilt selbst für die Bindung an Präjudizien. "Nahezu jede Position im (dogmatischen) Streit um die Grundrechte kann sich auf die eine oder andere Entscheidung und/oder grundsätzliche Stellungnahme des Gerichts berufen. ... Zur Offenheit der grundrechtlichen Normierung kommt also die Offenheit der Grundrechtsprechung." (R.Alexy, Grundrechte, S.18). Offenheit von Gesetz, Dogmatik und Präjudiz ergänzen sich also. 
Argumentierens wird ins Unendliche erstreckt, so daß er sich weitgehend mit dem Gegenstandsbereich des politischen Diskurses deckt. Da der grundrechtliche Diskurs dem Gesetzgebungsverfahren vorgeordnet is ${ }^{85}$, stellt sich die Frage nach den Kompetenzgrenzen eines Verfassungsgerichts, das durch Gesetz und Dogmatik weitgehend ungebunden allgemeine praktische Diskurse im gesamten Bereich der Politik führt ${ }^{86}$ und so die Gefahr einer Konstitutionalisierung der Tagespolitik heraufbeschwört ${ }^{87}$.

Alexy führt zur Lösung dieses Problems an, daß im Abwägungsprozeß neben materiellen Prinzipien auch formelle und prozedurale Prinzipien wie etwa die Entscheidungskompetenz des parlamentarischen Gesetzgebers zu berücksichtigen seien. ${ }^{88}$ Angesichts der Tatsache, daß eine richterliche Normenkontrolle im positiven Verfassungsrecht vorgesehen sei, könne die Frage allerdings nicht sein, $o b$ dem Verfassungsgericht eine Kontrollkompetenz zukomme, sondern nur, welchen Umfang diese habe. Die Kontrolldichte könne innerhalb der drei Stufen der Evidenzkontrolle, der Vertretbarkeitskontrolle und der intensivierten Inhaltskontrolle variieren. Dabei könne die Frage nach dem Umfang der Kontrolle durch drei verschiedene Ebenen der Argumentation entschieden werden. Auf der materiellen Ebene hänge die Kontrolldichte von der Wichtigkeit der betroffenen Prinzipien $a b$, auf der funktionellen Ebene würden Gründe für die Zuweisung grundrechtlicher Entscheidungskompetenzen wie etwa demokratische Legitimation, Sachnähe oder Unparteilichkeit diskutiert, auf der erkenntnistheoretischen Ebene gehe es um die rationale Entscheidbarkeit grundrechtlicher Fragen. Alexy ist allerdings der Meinung, daß immer dann, wenn sich mit hinreichender Sicherheit begründen lasse, daß ein gegen den Gesetzgeber gerichtetes subjektives Recht existiere, die gegen eine Kontrollkompetenz sprechenden Gründe zurücktreten müssten. ${ }^{89}$

Genau hier liegt m.E. das Hauptproblem der Prinzipientheorie. Formelle, prozedurale und materielle Prinzipien werden zum Gegenstand einer einheitlichen, umfassenden Gesamtabwägung gemacht. Bei dieser Abwägung drohen die formellen und prozeduralen Prinzipien, auf deren Ausarbeitung Alexy nur wenig Sorgfalt verwendet ${ }^{90}$, gegenüber den materiellen Prinzipien unterzugehen. Denn in der Prinzipientheorie ist bereits strukturell ein Vorrang des Materiellen angelegt, weil Optimierungsgebote selbst den Charakter definitiver Regeln haben: Entweder man optimiert oder eben nicht ${ }^{91}$. Normtheoretisch ist damit ein Entscheidungsspielraum bei der Grundrechtsanwendung ausgeschlossen, jede einfachgesetzliche Regelung ist, sofern verfassungsgemäß, zugleich auch verfassungsrechtlich geboten. Das Grundgesetz hat damit keinen Rahmencharakter, sondern verlangt einzig richtige Abwägungsergebnisse im Sinne einer Optimierung der beteiligten Interessen. ${ }^{92}$ Der Gefahr, daß der Rahmencharakter der Verfas-

85 R.Alexy, Grundrechte, S.501.

86 I.Maus, Die Trennung von Recht und Moral als Begrenzung des Rechts, in: dies., Aufklärung, S.308ff.

87 W.Schäuble, Weniger Demokratie wagen? Die Gefahr der Konstitutionalisierung der Tagespolitik, in: FAZ v. 13.09.1996, S.12.

88 R.Alexy, Grundrechte, S.89, 120, 267, 384; vgl. auch R.Dreier, Rechtsstaat, S.85ff.

89 R.Alexy, Grundrechte, S.496ff.

90 So wird etwa der Unterschied zwischen formellen und prozeduralen Prinzipien nicht erläutert. Alexy verwendet diese Begriffe als austauschbar. Einziges Beispiel für ein formelles Prinzip ist die Entscheidungskompetenz des parlamentarischen Gesetzgebers.

91 Vgl. A.Aarnio, Taking Rules Seriously, S.173.

92 Zu dieser Kritik ausführlich A.Scherzberg, Grundrechtsschutz und Eingriffsintensität, Berlin 1989, S. 105ff, 169ff. 
sung verlorengeht, wenn die Grundrechte als Prinzipien verstanden werden, begegnet Alexy zwar, indem er auch in der Grundrechtsabwägung einen weiten Raum des diskursiv Möglichen postuliert. Dadurch wird allerdings der entscheidungstheoretische Charakter von Prinzipien als Optimierungsgeboten in den argumentationstheoretischen sanften Zwang von guten Gründen gemindert.

Auf der materiellen Argumentationsebene kommen formelle Prinzipien nur dann zum Zuge, wenn die betroffenen Rechtsgüter von eher geringer Bedeutung sind. Der Gesetzgeber entscheidet dann nur das Unwichtige ${ }^{93}$, was schon dem formellen Prinzip, da $ß$ gerade die grundlegenden Entscheidungen dem parlamentarischen Gesetzgeber überlassen sein sollen ${ }^{94}$, widerspricht. Es besteht zudem die Gefahr, daß die Grundsätze der richterlichen Zurückhaltung bei Vorliegen einer Einschätzungsprärogative des Gesetzgebers oder eines Beurteilungsspielraums der Verwaltung etwa zur Abkürzung der Begründung von Urteilen des Verfassungsgerichts lediglich dann hervorgeholt werden, wenn eine materielle Vorprüfung im Stillen ergeben hat, daß an der gesetzgeberischen Abwägung nichts auszusetzen ist. Das Problem der formellen Prinzipien liegt darin, daß diese eigentlich gar nicht mit den materiellen Prinzipien kollidieren, sondern im Widerspruch zu der an die Richter gerichteten Optimierungsanweisung selbst stehen. Die Frage lautet nicht Grundrechtsverwirklichung oder gesetzgeberischer Entscheidungsspielraum, also nicht etwa Eigentum oder Demokratie, sondern wer optimiert, also Grundrechtsverwirklichung durch Gesetzgeber oder Richter? In materiellen Abwägungen können formelle Prinzipien daher gar nicht oder nur zum Schein stechen.

Das formelle Prinzip der Entscheidungsprärogative des demokratischen Gesetzgebers verlangt vom Verfassungsgericht, die materiellen Prinzipien gerade nicht (selbst) zu optimieren, sondern die Optimierung dem Gesetzgeber zu überlassen. Eine Lösung der Kompetenzfrage im Wege der Abwägung ist daher nur möglich, wenn die Optimierungsgebote selbst als formelle Prinzipien verstanden werden ${ }^{95}$. Ein solches Verständnis der nur noch prinzipiellen Geltung der Optimierungsgebote stellt Alexys Grundrechtstheorie aber vor ungeklärte Fragen, da Optimierungsgebote nach Alexy gerade den definitiven Sollensgehalt von Prinzipien ausdrücken, die Optimierungsanweisung selbst also Regelcharakter hat. ${ }^{96}$ Der Vorschlag von Sieckmann, diesem Problem durch eine "Iteration von Geltungsgeboten" zu entgehen, so daß prinzipielle Geltungsgebote selbst wiederum als Prinzip angesehen werden ${ }^{97}$, scheint im Ergebnis zu dem von Kelsens Stufenbau der Rechtsordnung her bekannten Problem eines infiniten Regresses zu führen, der durch eine logische Grundnorm bzw. hier durch ein Grundprinzip abgebrochen werden müßte.

Auf diese Problemlage wird bei der Ausarbeitung einer Theorie des prozeduralen Rechtsstaats im dritten Kapitel zurückzukommen sein. Hier kann lediglich festgehalten

93 Alexys Formel für die Kompetenzabgrenzung, nach der es auf das "vom Standpunkt des Verfassungsrecht" Wichtige ankomme (R.Alexy, Grundrechte, S.406ff., 408) ist m.E. eine Leerformel, die in einen Zirkel führt, weil die formelle Frage der Optimierungskompetenz (Gesetzgeber oder Richter) durch Vorgriff auf die erst im Anschluß an die Klärung der Kompetenzfrage vorzunehmende Optimierung der materiellen Prinzipien geklärt wird.

94 Zum Parlamentsvorbehalt und zur Wesentlichkeitstheorie des BVerfGs vgl. nur C.E.Eberle, Gesetzesvorbehalt und Parlamentsvorbehalt, DÖV 1984, S.485ff.

95 So auch A.Scherzberg, Grundrechtsschutz, S.175.

96 Vgl. dazu J.Sieckmann, Rechtssystem und praktische Vernunft, ARSP 78 (1992), S.151.

97 J.Sieckmann, Logische Eigenschaften von Prinzipien, S.163ff. 
werden, daß die Frage der Kompetenzabgrenzung durch formelle und prozedurale Prinzipien ungeklärt ist.

\section{e) Festzuhaltendes: der juristische Diskurs}

Im Ergebnis kann festgehalten werden, daß das Recht jenseits der Normebene als $S y$ stem von Prozeduren verstanden werden kann. Als System von Prozeduren ist das Rechtssystem ein System von durch Regeln und Prinzipien geleiteten Handlungen, durch die Normen gesetzt, begründet, interpretiert, angewandt und durchgesetzt werden. ${ }^{88}$ Neben den klassischen Rechtsverfahren der Gesetzgebung, des Gerichtsprozesses und des Verwaltungsverfahrens gehört zu diesen Prozeduren auch der juristische Diskurs, der aus allen Sprechakten besteht, die normative Aussagen zum Gegenstand haben und einen Anspruch auf Richtigkeit im Rahmen des geltenden Rechts, also in den Grenzen von Gesetz, Präjudiz und Dogmatik, erheben. Dieser juristische Diskurs, in dem ausschließlich das bessere Argument zählt, ist weder zeitlich noch örtlich oder persönlich an bestimmte Institutionen oder Rechtsverfahren gebunden, sondern vollzieht sich in einer Vielzahl von Arenen und Foren des kommunikativen Ringens um das richtige Recht und ist als in der Zeit verlaufender, unendlicher Lernprozeß mit dem Ziel der Gerechtigkeit zu verstehen. Der juristische Diskurs ist in die rechtlich geregelten Prozeduren der Gesetzgebung, des Verwaltungsverfahrens und des Gerichtsprozesses eingebettet. Im Zentrum des Rechts ist es etwa das Gerichtsverfahren, das den offenen juristischen Diskurs in einem hierarchisch geordneten Instanzenzug auf Mehrheitsentscheidungen hin ordnet. Die so produzierten Urteile haben über ihre auf die Einhaltung der Prozeßrechtsregeln gegründete juristische Geltung hinaus eine Vermutung der Richtigkeit für sich, soweit sie unter Berücksichtung von Gesetz, Dogmatik und Präjudiz, also dem "Stand der Rechtswissenschaft" gemäß begründet und damit im Bereich des im juristischen Diskurs Möglichen liegen. Soweit die Bindung an die geltenden Gesetze reicht, ist die Rationalität eines Urteils allerdings immer relativ auf die Rationalität der Gesetze bezogen. ${ }^{99}$ Innerhalb des im Rahmen der Gesetze diskursiv Möglichen ist die Argumentation nicht völlig frei. Der Raum des diskursiv Möglichen wird vielmehr einerseits durch die Regeln der juristischen Methodenlehre, nach der nur bestimmte Argumentformen juristisch möglich sind, eingeschränkt. Andererseits wird der juristische Diskurs durch Prinzipien gebunden, die als normative Argumente aus relativ ungesättigten Normen folgen, die bestimmte Ziele oder Zustände als im Sinne einer Optimierung zu verwirklichende normativ auszeichnen. Darüber hinaus finden die allgemein für praktische Argumentationen geltenden Diskursregeln Anwendung.

\section{Prozedurale Rationalität und politischer Diskurs: Volkssouveränität als Verfahren}

Kann die Rechtsanwendung im Rahmen einer Theorie des juristischen Diskurses als rationaler Prozeß verstanden werden, so bleibt die Vernünftigkeit der juristischen Argumentation in dem Umfang, in dem sie durch die Gesetze determiniert wird, relativ auf die Vernünftigkeit der Gesetzgebung. Um auch diesen Aspekt zu erfassen, müßte nach Alexy die Theorie des allgemeinen praktischen Diskurses zu einer Theorie der Gesetz-

98 R.Alexy, Begriff, S.46.

99 R.Alexy, Argumentation, S.351f. 
gebung und diese zu einer normativen Theorie der Gesellschaft erweitert werden, von der die Theorie des juristischen Diskurses ein Teilstück wäre ${ }^{100}$. Alexys Ziele sind beschränkter, er hat sich auf die Ausarbeitung einer Theorie der rationalen Rechtsanwendung konzentriert. Um die bereits angesprochenen Kompetenzabgrenzungsprobleme zwischen Recht und Politik zu lösen, bedarf es allerdings einer Theorie des politischen Diskurses. Im folgenden werden einige Ansätze vorgestellt, die über das Konzept prozeduraler Rationalität die demokratische Politik als rationalen Prozeß rekonstruieren. Im Mittelpunkt stehen dabei die Begriffe der Zivilgesellschaft und der deliberativen Politik.

\section{a) Die Ausgangslage: Demokratie und Rationalität}

In der Tradition des mit dem juristischen Positivismus jedenfalls in Deutschland verbundenen Wertrelativismus wird bis in die heutige Zeit hinein fortwirkend ein Gegensatz zwischen Demokratie und Rationalität gesehen. ${ }^{101}$ Paradigmatisch ist diese Position in der reinen Rechtslehre von Kelsen ausgearbeitet. ${ }^{102}$ Rationalität ist nach Kelsen auf den Bereich der vom Prinzip der Kausalität beherrschten Naturwissenschaften (Empirie) sowie auf den Bereich der formalen Logik (Mathematik) beschränkt. Moral und Politik sind demgegenüber als "Metaphysik" nur subjektiven Bekenntnissen zugänglich. Demokratische Rechtsetzang und richterliche Rechtsanwendung sind daher, soweit nicht formallogisch gebunden oder durch empirisch gesicherte Zweck/Mittel-Empfehlungen angeleitet, irrationale Wertbekenntnisse. Da unterschiedliche subjektive Wertvorstellungen rational nicht voreinander ausgezeichnet werden können, meint Kelsen die Demokratie wertrelativistisch begründen zu können. Denn da alle Wertbekenntnisse rational gleichwertig seien, gelte das Prinzip der Toleranz gegenüber andersartigen Vorstellungen. Politisch könne diese relativistische Meinungsvielfalt nur durch demokratische Abstimmungen zu einem Staatswillen zusammengefüht werden ${ }^{103}$. Demokratie ist hiernach lediglich die beste Methode der friedlichen Abstimmung von einer Vielzahl von irrationalen Wertbekenntnissen in einer Gesellschaft. Demokratie steht damit in einem Spannungsverhältnis zur Rationalität.

Nach den Erfahrungen mit dem nationalsozialistischen gesetzlichen Unrecht sowie mit der Wehrlosigkeit der Weimarer Demokratie gegenüber der Hitlerdiktatur, die in der Selbstabschaffung der Demokratie durch das Ermächtigungsgesetz gipfelte, bestand in der Bundesrepublik ein starkes Bedürfnis, die demokratische Politik verbindlich an die Grundlagen der christlich-abendländischen Tradition und des rationalistischen Vernunftrechts zu binden. Im Grundgesetz hat sich dieses Mißtrauen gegenüber demokratischer Politik insbesondere in Form der verfassungsrichterlichen Kontrolle der Grundrechtsbindung des Gesetzgebers niedergeschlagen. Das Spannungsverhältnis von Demokratie und Rationalität ist damit als Spannungsverhältnis zwischen Gesetz und Recht, wie es in Art. $20 \mathrm{III} \mathrm{GG} \mathrm{zum} \mathrm{Ausdruck} \mathrm{kommt,} \mathrm{in} \mathrm{die} \mathrm{Verfassung} \mathrm{eingelassen}{ }^{104}$. Dieser Lage entsprechend werden Rationalität und Demokratie als unterschiedliche, aber funktional äquivalente politische Organisationsprinzipien verstanden, die sich gegenseitig

100 R.Alexy, Argumentation, S.351f.

101 So etwa wieder K.Hohmann, Rationalität und Demokratie, Tübingen 1988.

102 H.Kelsen, Reine Rechtslehre; vgl. dazu R.Dreier, Sein und Sollen, Bemerkungen zu reinen Rechtslehre Hans Kelsens, JZ 1972, S.329ff.

103 Vgl. dazu ausführlich H.Dreier, Rechtslehre, S.249ff.

104 R.Dreier, Rechtsstaat, S.73, $78 \mathrm{ff}$. 
ergänzen. Das Gewicht, das dem einen Prinzip gegenüber dem anderen zukommt, wird dabei in Abhängigkeit von den spezifischen Problemlagen und Rahmenbedingungen einer konkreten Gesellschaft gesehen, so daß historisch mal die Demokratie, mal die Rationalität als dominantes politisches Organisationsprinzip hervortritt ${ }^{105}$.

Soweit in diesem Kontext die Aufgabe der Rechtsprechung, insbesondere des BVerfG als "Hüter der Grundrechte", darin gesehen wird, im Wege der Kontrolle des demokratischen Gesetzgebers dem politischen Organisationsprinzip der Rationalität Geltung zu verschaffen, bestand ein Problem lange darin, die Rationalität gerade der Verfassungsrechtsprechung $z u$ begründen. Im wertrelativistischen Modell von Kelsen etwa wurde nämlich nicht nur die politische Gesetzgebung, sondern auch die richterliche Normkonkretisierung durch Urteil in den Bereich der "Metaphysik" verwiesen. 106 Die Werteordnungslehre des BVerfG konnte in dieser Hinsicht kaum überzeugen.107 Alexy sieht die Prinzipientheorie nun als eine von unhaltbaren Annahmen gereinigte Werttheorie an und meint mit dem Regel/Prinzipien/Prozedur-Modell des Rechtssystems eine Theorie der Rechtsanwendung entwickelt zu haben, die ein Höchstmaß an praktischer Vernunft gewährleistet, wenn sie auch nicht für jeden denkbaren Fall eine einzig richtige Antwort gewährleisten könne. ${ }^{108}$

Aus der so begründeten Rationalität der Rechtsprechung können wiederum Rückschlüsse für die Frage der Kompetenzabgrenzung zwischen Rechtsprechung und Gesetzgeber gezogen werden. ${ }^{109}$ Denn bei der Abwägung zwischen materiellen Prinzipien und den formalen Prinzipien der Demokratie und Gewaltenteilung geht es auf der methodologischen und erkenntnistheoretischen Ebene um die Frage der rationalen Begründbarkeit grundrechtlicher Entscheidungen. ${ }^{110}$ Kann die Grundrechtsrechtsprechung als rationaler Prozeß verstanden werden, so spricht dies tendentiell für eine Ausweitung richterlicher Kompetenzen. ${ }^{111}$ Die unter dem Stichwort der "Krise des Rechtsstaats" beschriebene Tendenz des Übergangs von der Herrschaft der Gesetze zum Justizstaat ${ }^{112}$ wird so erkenntnistheoretisch legitimiert.

Dieser These vom Vorrang der Justiz vor der demokratischen Gesetzgebung würde die erkenntnistheoretische Grundlage allerdings dann entzogen, wenn sich demokratische Politik ebenfalls als rationaler Prozeß verstehen ließe. ${ }^{113} \mathrm{Im}$ folgenden werden einige Ansätze vorgestellt, die am Begriff der prozeduralen Rationalität orientiert ihr Erkenntnisinteresse auf eine Rekonstruktion des demokratischen Rechtsstaats richten. Dabei geht es vor allem darum, dem Konzept der Volkssouveränität eine Fassung zu ge-

105 Vgl. K.Hohmann, Rationalität und Demokratie, S.234ff.

106 H.Dreier, Rechtslehre, S.145ff.

107 Vgl. die Diskussion bei R.Alexy, Grundrechte, S.134ff.

108 R.Alexy, Rechtssystem, S.213ff.

109 Alexy zieht die folgenden Rückschlüsse nicht. Sie werden aber an einigen im folgenden zitierten Stellen impliziert. Vorliegend geht es nicht darum, Alexy anti-demokratische Tendenzen zu unterstellen, sondern um den Verweis auf potentiell implizierte Schlußfolgerungen aus einer Theorie als folgenorientiertes Argument gegen bestimmte Aspekte dieser Theorie.

110 R.Alexy, Grundrechte, S.497.

111 Dies ergibt sich im Umkehrschluß aus folgendem Statement: "Solite sich herausstellen, daß es so etwas wie rationale Argumentation nicht gibt ..., wird man den Umfang richterlicher Kompetenz eher zu begrenzen versuchen." (R.Alexy, Argumentation, S.45).

112 S.o. Kap. 1 V. 1.

113 Auf die Notwendigkeit einer Diskurstheorie der Gesetzgebung verweist auch R.Alexy, Argumentation, Einleitung. 
ben, die dessen Institutionalisierung unter modernen gesellschaftlichen Bedingungen der Komplexität als aussichtsreich erscheinen läßt.

\section{b) Volkssouveränität als Verfahren}

Im Zuge der Materialisierung des Rechtsstaats ist das soeben beschriebene Spannungsverhältnis zwischen Demokratie und Rationalität vielfach aus einem Gegensatz zwischen Volkssouveränität und Grundrechten erklärt worden, der schon in der liberalen Staatstheorie der Aufklärung angelegt gewesen sei. Die durch die Menschenrechte verbürgte individuelle Freiheit drohe gegenüber der vom Prinzip der Gleichheit geleiteten Volkssouveränität unterzugehen. Gegenüber den dezisionistisch-totalitären Tendenzen der Demokratie gelte es daher die Grundrechte als vor- und überstaatliche Rechte zur Geltung zu bringen, die die Minderheit vor dem Totalitarismus des Mehrheitsentscheids schützen sollen ${ }^{14}$. Demgegenüber hat Ingeborg Maus in ihrer Kantinterpretation dargelegt, daß die Demokratietheorie der Aufklärung die Spannung zwischen individueller Freiheit und staatlicher Gesetzgebung im Modell des demokratischen Rechtsstaats gerade aufgehoben habe. Das demokratische Gesetzgebungsverfahren, das jede Freiheitsbeschränkung von der vorherigen Zustimmung aller Betroffenen abhängig mache, werde von einem Automatismus getragen, der strukturell die Universalisierbarkeit seiner Ergebnisse garantiere. Das Volk der Volkssouveränität kontrolliere sich daher selbst und könne nicht noch einmal - etwa durch ein Verfassungsgericht - kontrolliert werden, weil dies zum einen zu einem infiniten Regress führe, zum anderen die Souveränität nicht mehr beim Volk, sondern beim Kontrolleur liegen würde. Bei Kant werde durch die Verlagerung des Freiheitsschutzes in die Verfahrensbedingungen des demokratischen Rechtsstaats der Schritt von einem materialen Naturrecht zu einem rein prozeduralen Vernunftrecht vollzogen. ${ }^{115}$

Ralf Dreier hat dieses Modell als Gesetzgebungsmodell prozeduraler Gerechtigkeit bezeichnet, das die Erzeugung gerechten staatlichen Rechts betreffe. Diesem Modell stellt er das argumentationstheoretische Modell prozeduraler Gerechtigkeit gegenüber, welches - etwa in Form der Theorie des juristischen Diskurses von Alexy - der Begründung und Rechtfertigung von konkreten Gerechtigkeitsurteilen diene und am Modell der wissenschaftlichen Wahrheitsfindung orientiert sei ${ }^{116}$. Diese Unterscheidung erhellt ein Problem der Demokratietheorie der Aufklärung, welches sich insbesondere innerhalb des Rousseauschen Modells der direkten Demokratie stellt. Denn Volksgesetzgebung durch Volksentscheid leidet wegen der Anonymität und Größe, wegen fehlender Bildung, Zeit oder Interesse der Teilnehmer an einem Mangel an Kommunikation. Die Teilnehmer kommen mit ihren vorhandenen Einstellungen zu einer Versammlung und stimmen über eine auf Ja/Nein-Stellungnahmen reduzierte Fragestellung ab. Was fehlt, ist die diskursive Überarbeitung der vorgefundenen Präferenzen der Teilnehmer im Wege der rationalen Argumentation, bei der über einen universellen Rollentausch vermittelt die besseren Gründe entscheiden.

114 Vgl. W.Kägi, Rechtsstaat und Demokratie, S.127ff.; ausführlich s.o. Kap. 1. II. 3.

115 I.Maus, Aufklärung, insbes. Kap. 8, 9.; ausführlich dazu s.o. Kap. 1 II. 3.

116 R.Dreier, Gerechtigkeit, S.8ff, $23 \mathrm{ff}$. 
Jürgen Habermas hat nun versucht, Gesetzgebungsmodell und Argumentationsmodell der prozeduralen Gerechtigkeit im Begriff der deliberativen Politik zu vereinen. ${ }^{117}$ Mit diesem englischen Lehnwort ist eine Politik bezeichnet, die sich aus einer sorgfältigen Abwägung aller für oder gegen eine Entscheidung sprechenden Gründe in Diskussionsprozessen legitimiert ${ }^{118}$. Ein solches Verständnis von Politik als Diskurs kann allerdings nur dann überzeugen, wenn sich Elemente einer kommunikativen Vernunft auch in den faktischen Praktiken der Politik identifizieren lassen. ${ }^{119}$ Dazu ist es nötig, den Begriff der Volkssouveränität - jenseits der konkretistischen Vorstellung einer örtlich, zeitlich und persönlich gebundenen Verkörperung des Volkes im Parlament als Versammlung von Repräsentanten - vollständig zu prozeduralisieren. ${ }^{120} \mathrm{Zwar}$ schließt die tatsächliche Dominanz von strategischen Verhandlungen im parlamentarischen Gesetzgebungsverfahren ein diskursives Verständnis der Politik nicht aus, da auch Kompromisse als rational angesehen werden können, soweit die Bedingungen, unter denen diese ausgehandelt werden, selbst in einem diskursiven Verfahren rechtfertigungsfähig und damit fair sind. ${ }^{121}$ Allerdings entziehen sich Argumentationsprozesse in ihrer Binnenstruktur einer Institutionalisierung in Rechtsverfahren ${ }^{122}$, weshalb der auf das rechtlich regulierte Verfahren der Gesetzgebung konzentrierte Blick bei der Suche nach der kommunikativen Vernunft in der Politik zu kurz greift.

Zum politischen Diskurs gehören vielmehr alle Kommunikationen, die sich auf eine legitime Regelung des gesellschaftlichen Zusammenlebens mit den Mitteln der Politik beziehen. Der politische Diskurs vollzieht sich ungebunden an Zeit, Ort oder Personen in einem dezentrierten Netzwerk von subjektlosen Kommunikationen, die gesellschaftsweit in einer Vielzahl von Foren und Arenen der Beratung, der Meinungs- und Willensbildung kursieren. Im Zentrum der Politik ist dieser Diskurs in Rechtsverfahren eingebettet, die diesen einerseits gewissen zeitlichen, sachlichen und sozialen Beschränkungen unterwerfen, indem sie den Diskurs auf Entscheidung fokussieren, andererseits durch Anhörungs- und Begründungspflichten, Verteilung von Rede- und Stimmrechten, Regeln über die Öffentlichkeit etc. die Spielräume definieren, schützen und strukturieren, in denen Argumentationen stattfinden können, und so die formalpragmatischen Bedingungen einer deliberativen Politik verkörpern. ${ }^{123}$

Dieser institutionalisierte Kern der auf Beschlußfassung programmierten Körperschaften ist allerdings angewiesen auf eine nicht institutionalisierte politische Öffent-

117 J.Habermas, FuG, Kap. VII.; an dieser Stelle wird nur das Modell des politischen Diskurses erläutert, aufgrund dessen Habermas das prozeduralistische Rechtsparadigma entfaltet. Die Diskurstheorie als Gesellschaftstheorie wird demgegenüber unten unter II. 2. ausführlich erläutert. Vorliegend geht es also um Habermas' Vorschläge zur Prozeduralisierung des Rechts, während es später um seine Gesellschaftstheorie geht. Wegen der Abgrenzungsschwierigkeiten lassen sich Wiederholungen nicht gänzlich vermeiden.

118 Vgl. Webster's Third New International Dictionary: 1. deliberate (adj.): characterized by or resulting from slow careful thorough calculation and consideration of effects and consequences (a deliberate judgement). 2. deliberation: a) the act of weighing and examining the reasons for and against a choice or measure; careful consideration; mature reflection. b) a discussion by a number of persons. 3. deliberative: relating to or marked by deliberation; proceeding or acting by discussion.

119 J.Habermas, FuG, S.349.

120 J.Habermas, FuG, S.359ff, 365.

121 J.Habermas, FuG, S.204ff.

122 J.Habermas, FuG, S.219.

123 J.Habermas, FuG, S.219, 347, $370 \mathrm{ff}$. 
lichkeit, deren Meinungsbildung sich in einem Netzwerk sich überlappender subkultureller ${ }^{124}$ Öffentlichkeiten mit fließenden Grenzen vollzieht, und deren Strukturen sich, innerhalb eines grundrechtlich garantierten Rahmens, mehr oder weniger spontan bilden ${ }^{125}$. Die politische Öffentlichkeit findet ihre gesellschaftliche Basis in einer Zivilgesellschaft, welche sich aus Vereinigungen, Organisationen und Bewegungen zusammensetzt, die gesellschaftliche Problemlagen aufnehmen, kondensieren und lautverstärkend an die politische Öffentlichkeit weiterleiten. ${ }^{126}$ Vermittelt über Massenmedien, "public interest groups", Kirchen, Verbände und Parteien nimmt diese Peripherie Einfluß auf den institutionellen Kern der Politik und vermittelt diesem Legitimität. Die zivilgesellschaftliche Peripherie bildet so den Kontext, in welchem sich deliberative Politik erst entfalten kann.

Legitime Rechtsetzung setzt dabei ein Zusammenspiel von Zentrum und Peripherie voraus. Zivilgesellschaft und politische Öffentlichkeit sind wegen ihrer anarchischen Struktur einerseits den Repressions- und Ausschließungseffekten von ungleich verteilter sozialer Macht, struktureller Gewalt und verzerrter Kommunikation schutzloser ausgesetzt als die organisierten Öffentlichkeiten des parlamentarischen Komplexes. Nach dem Schleusenmodell müssen bindende Entscheidungen daher durch die engen Kanäle des institutionalisierten Kernbereichs hindurchgeleitet werden, um in den auf Chancengleichheit angelegten demokratischen Rechtsverfahren im Hinblick auf Universalisierbarkeit gefiltert zu werden. Andererseits läuft der Großteil der Operationen im Kernbereich des politischen Systems nach Routinen ab. Demgegenüber bietet die politische Öffentlichkeit den Vorteil institutionell uneingeschränkter Kommunikationsmöglichkeiten. Innovation und Lernfähigkeit werden deshalb strukturell eher dezentriert in der Zivilgesellschaft bevorratet. Dieser fällt daher die Aufgabe zu, über die Medien vermittelt für bestimmte Themen eine erhöhte öffentliche Aufmerksamkeit zu schaffen und neue Themen in das politische System so einzuführen, daß dessen Routinemodus gestört wird. Erst dieser Druck der öffentlichen Meinung löst nämlich einen deliberativen Problemverarbeitungsmechanismus im Parlament aus. ${ }^{127}$

Bedingung deliberativer Politik ist damit zum einen, daß grundrechtlich geschützte Freiräume offengehalten werden, in denen sich die spontanen Kommunikationskreisläufe einer Zivilgesellschaft entfalten können, zum anderen, daß die von Massenmedien dominierte politische Öffentlichkeit sowie der institutionalisierte politische Entscheidungskomplex strukturell für die zivilgesellschaftlichen Kommunikationen durchlässig gehalten werden. Volkssouveränität als Verfahren zieht sich damit in die demokratischen Verfahren und in die rechtliche Implementierung ihrer anspruchsvollen Kommunikationsvoraussetzungen zurück, die den Fluß der diskursiven Meinungs- und Willens-

124 Eigentlich besser "kulturell". Die Vorsilbe "sub" verdankt sich wohl einer Voreingenommenheit sich als "links" verstehender Theoretiker für sich selbst kontrafaktisch als "subkulturell" bezeichnende Gruppen.

125 J.Habermas, FuG, S.373; I.Maus, Basisdemokratische Aktivitäten und rechtsstaatliche Verfassung. Zum Verhältnis institutionalisierter und nichtinstitutionalisierter Volkssouveränität, in: T.Kreuder (Hrsg.), Der orientierungslose Leviathan. Beiträge zur Steuerungsfunktion des Rechts und zur Notwendigkeit einer neuen Verfassung, Marburg 1992.

126 J.Habermas, FuG, S.443f; zur anläßlich des Umbruchs in Mittel- und Osteuropa aufgelebten Debatte um die Zivil- oder Bürgergesellschaft vgl. J.v.Soosten, Civil Society, Literaturbericht, ZfEvEthik 1993, S.139ff.

127 J.Habermas, FuG, S.374, 430ff. 
bildung so regulieren, daß ihre falliblen Ergebnisse die Vermutung der Vernünftigkeit für sich haben ${ }^{128}$.

\section{c) Das prozeduralistische Paradigma}

Den demokratischen Rechtsstaat interpretiert Habermas als das Ergebnis eines Diskurses zwischen freien Rechtsgenossen, die ihr Zusammenleben mit den Mitteln des Rechts legitim regeln wollen. Individuelle Menschenrechte und Demokratieprinzip entstehen dabei gleichursprünglich aus der privaten sowie der öffentlichen Autonomie der Rechtsgenossen, sind also zwei Seiten derselben Medaille. ${ }^{129}$ Ein legitimes Rechtssystem setzt ein System der Rechte voraus, die sich die Bürger gegenseitig einräumen müssen. Dazu gehören (1.) Freiheitsrechte, (2.) Mitgliedschaftsrechte, (3.) Prozeßgrundrechte, (4.) Rechte auf chancengleiche Teilhabe an Prozessen der Meinungs- und Willensbildung und (5.) soziale und ökologische Grundrechte. Bei diesen Rechten handelt es sich um ungesättigte Prinzipien, die von einem politischen Gesetzgeber je nach Umständen interpretiert und ausgestaltet werden müssen. An dieser Ausgestaltung der im System der Rechte zunächst abstrakt gesetzten privaten Autonomie wirken die Rechtsgenossen mittels der diskursiven Ausübung ihrer öffentlichen Autonomie mit. 130

In Anknüpfung an Kants Gleichsetzung von Freiheit, Autonomie und Selbstgesetzgebung ${ }^{131}$ versteht Habermas den demokratischen Rechtsstaat als ein Modell, welches Prozeduren zur Verfügung stellt, in denen sich private und öffentliche Autonomie gleichberechtigt entfalten. Dieses prozedurale Verständnis des Rechts verdichtet Habermas zu einem prozeduralistischen Rechtsparadigma, welches er in Abgrenzung zum formal-liberalen sowie zum material-sozialstaatlichen Paradigma entwickelt ${ }^{132}$. Im Lichte dieses am Projekt der individuellen Selbstbestimmung orientierten Paradigmas erhalten Rechte einen prozeduralen Sinn: Rechte sind weder individuelle Güter, die man besitzen kann, noch kollektive Güter, die man gemeinsam verzehrt; Rechte lassen sich nur "genießen", indem man sie ausübt ${ }^{133}$. Über die gleiche Verteilung von Rechten können daher nur die Rechtsgenossen selbst bestimmen. Der Streit um Gleichheit und Ungleichheit, um die Interpretation von Bedürfnissen kann nicht an Richter und Beamte, nicht einmal an den Gesetzgeber delegiert werden. Das prozedurale Rechtsparadigma weist über die Begriffe der deliberativen Politik und der Zivilgesellschaft lediglich die Arenen und Foren aus, in denen dieser Streit vernünftig ausgetragen werden kann. Die Verwirklichung von Grundrechten ist damit ein Prozeß, der die private Autonomie gleichberechtigter Bürger nur im Gleichschritt mit der Aktivierung ihrer staatsbürgerlichen Autonomie sichert ${ }^{134}$.

Aus dieser Begründung des Rechts ergibt sich für Habermas ein prinzipieller Vorrang des politischen Diskurses vor dem in den rechtsanwendenden Instanzen geführten

128 J.Habermas, FuG, S.365; Ders., Volkssouveränität als Verfahren (1988), FuG, S.600ff., 626.

129 J.Habermas, FuG, S.112ff.

130 J.Habermas, FuG, S.151ff, 154, 159.

131 S.o. Kap. 1 II. 3. b); Kant, GMS, WW IV, S. 86: "... Freiheit und eigene Gesetzgebung des Willens sind beides Autonomie, mithin Wechselbegriffe...". An dieser Stelle mag angemerkt werden, daß das von Habermas entfaltete prozedurale Verständnis des demokratischen Rechtsstaats in weiten Teilen auf der prozeduralen Interpretation der Demokratietheorie von Kant durch I.Maus (Aufklärung, insbes. Kap. 8-12) aufbaut.

132 J.Habermas, FuG, S.468ff.

133 J.Habermas, FuG, S.505.

134 J.Habermas, FuG, S.514f. 
Diskursen. Gewaltenteilung spezifiziert er als Prinzip, nach dem Gesetzgebung, Verwaltung und Rechtsprechung über unterschiedliche Sorten von Gründen verfügen dürfen. Moralische und ethisch-politische Fragen sollen grundsätzlich dem politischen Diskurs vorbehalten sein. Die Verwaltung soll bei der Ausübung administrativer Macht an die normativen Vorgaben der Politik gebunden sein. Sie darf daher nur über pragmatische Gründe verfügen, die empirisches Wissen auf gegebene Präferenzen und gesetzte Zwecke beziehen 135 .

Für die Rechtsprechung gilt dies nur in eingeschränktem Rahmen. Juristische Diskurse sind zwar von Haus aus auf das demokratisch gesatzte Recht bezogen, wegen der Unbestimmtheit des Rechts muß die Rechtsprechung aber auch über moralische Gründe verfügen. Den Unterschied zwischen politischen und juristischen Diskursen erklärt Habermas in Anknüpfung an Klaus Günther ${ }^{136}$ mit der Verschiedenheit von Gegenstand und Ziel dieser Diskurse. Politische Normbegründungsdiskurse sind auf die unparteiliche Begründung von abstrakt-generellen Normen ausgerichtet. Aufgrund der damit verbundenen Abstraktion und wegen der Unvorhersehbarkeit künftiger Situationen sind die gültigen Normen nur prima facie anwendbar, so daß in einem Anwendungsdiskurs geprüft werden muß, welche von mehreren gültigen Normen in einem konkreten Fall unter Berücksichtigung aller Umstände der Situation angemessen ist. Der politische Diskurs betrifft also die Gültigkeit, der juristische Diskurs die Angemessenheit einer Norm. Aufgrund dieser unterschiedlichen Ausrichtung sind politischer und juristischer Diskurs in völlig verschiedene Rechtsverfahren eingebettet. Das Gesetzgebungsverfahren ist mit dem Grundsatz der Repräsentativität auf die abstrakte Begründung universalisierbarer Normen in Unkenntnis zukünftiger Anwendungsfälle durch Übereinkunft aller Betroffenen ausgerichtet. Das Gerichtsverfahren ist mit dem Grundsatz der Unabhängigkeit des Richters auf die Findung einer angemessenen Norm unter Berücksichtigung aller Umstände des konkreten Einzelfalls durch einen neutralen Dritten zugeschnitten. ${ }^{137}$

Aus dem prozeduralistischen Verständnis des Rechts ergeben sich insbesondere Schlußfolgerungen für die Grundrechtsrechtsprechung des Verfassungsgerichts. Das prozedurale Verständnis individueller Rechte als Kompetenzen, die man ausüben muß, tritt mit dem materialen Verständnis von Rechten als optimierbaren Gütern, die man besitzt oder verzehrt, in Konflikt. Denn die Wertejudikatur ist von einem Selbstverständnis getragen, nach dem die Eliten im Recht den Grundrechtsträgern dasjenige, was ihnen zukommt, sozial-autoritär zuteilen. Dieser paternalistische Charakter widerspricht der Idee eines der privaten und öffentlichen Autonomie der Rechtsgenossen entspringenden Systems der Rechte. Dem autorisierenden Sinn der Grundrechte entspricht daher nicht ein teleologisches bzw. axiologisches Verständnis von Rechten als Ziele oder Werte, sondern ein deontologisches Verständnis als ungesättigte, aber unbedingt verbindliche Normen ${ }^{138}$.

135 J.Habermas, FuG, S.198, 235f.

136 K.Günther, Der Sinn für Angemessenheit, Ffrn 1988.

137 J.Habermas, FuG, Kap. V., insbes. S.266ff., 287ff.; vgl. auch die am EHI in Florenz geführte Debatte zwischen K.Günther (Critical Remarks on Robert Alexy's Special case Thesis, Ratio Juris 1993, S.143ff.) und R.Alexy (Justification and Application of Norms, Ratio Juris 1993, S. 157ff.; deutsch in R.Alexy, RVD, S. 52ff). Vgl. auch J.Habermas, Anhang zu Faktizität und Geltung, in: ders., Die Einbeziehung des Anderen, S.309ff., 366ff., 370.

138 J.Habermas, FuG, S.309ff. 
Dem Verfassungsgericht kommt in diesem prozeduralistischen Verfassungsverständnis die Rolle eines Hüters der deliberativen Politik zu. In Anlehnung an den representation reenforcing approach des amerikanischen Verfassungsrechtlers Ely139 bestimmt Habermas die Aufgabe des Verfassungsgerichts dahin, jene Freiräume und Verfahrensbedingungen zu schützen und zu gewährleisten, die für den demokratischen Prozeß im ganzen die Vermutung begründen, vernünftige Ergebnisse zu ermöglichen. Für den verrechtlichten Teil des politischen Diskurses im institutionalisierten Zentrum des politischen Systems bedeutet dies eine Konzentration auf die Kontrolle jener Kompetenz-, Organisations- und Verfahrensregeln, die die Freiräume schützen, in denen sich auf Universalisierung ausgerichtete Argumentationen entfalten können. Für die nicht verrechtlichte und auch nicht institutionalisierbare Peripherie der in der Zivilgesellschaft basierten politischen Öffentlichkeit bedeutet dies, daß die Kommunikations- und Teilhaberechte eine privilegierte Stellung gewinnen. Versammlungs-, Vereins- und Meinungsfreiheit grenzen die Freiräume aus, in denen sich die Zivilgesellschaft spontan entfalten kann. Rundfunk- und Pressefreiheit sichern die mediale Infrastruktur der öffentlichen Kommunikation. Politische Parteien und Wahlen verschränken das politische System mit Öffentlichkeit und Zivilgesellschaft. Das Verfassungsgericht hat darauf zu achten, daß der Kommunikationsfluß von der Peripherie zum Zentrum strukturell gewährleistet wird ${ }^{140}$.

Die hervorgehobene Stellung der politischen Rechte soll das Gewicht der Individualgrundrechte jedoch nicht verkürzen. Denn die Idee des demokratischen Rechtsstaats setzt voraus, daß die Staatsbürger den Status von Rechtspersonen haben, die Träger einklagbarer subjektiver Rechte sind. Die öffentliche Autonomie ist aus dieser Sicht das Medium, über das die Bürger ihre subjektiven Freiheiten aufeinander abstimmen, die Privatautonomie konstituiert umgekehrt erst das Medium (Recht), in dem sich die demokratische Idee der Selbstgesetzgebung entfaltet. Private und öffentliche Autonomie, Grundrechte und Volkssouveränität, Rechtsstaat und Demokratie sind daher zwei Seiten derselben Medaille, von denen keine einen Primat beanspruchen kann ${ }^{141}$.

\section{d) Probleme: Krise des Rechtsstaats und Prozeduralisierung}

Eine so allumfassende Rechtstheorie wie Habermas' Diskurstheorie des Rechts steht naturgemäß vor einer Unzahl von Problemen. Die integrative Doppelperspektive zwischen soziologischer Beobachtung und normativer Teilnahme führt dazu, daß Habermas es niemandem ganz recht macht. Auf die bisher vorgetragene Kritik kann an dieser Stelle nicht eingegangen werden ${ }^{142}$. Vor dem Hintergrund der im ersten Kapitel entfalteten Fragestellung nach Auswegen aus dem krisenhaften Trilemma des modernen Rechts durch eine wie auch immer geartete Prozeduralisierung des Rechts besteht das Hauptproblem von Habermas' Rechtstheorie darin, daß die unter dem Stichwort der Krise des

139 J.H.Ely, Democracy and Distrust, A Theory of Judicial Review, Cambridge, Mass. 1980. Ely beschreibt die Aufgaben eines Verfassungsgerichts schlagwortartig mit: a) clearing the channels of political change, b) facilitating the representation of minorities.

140 J.Habermas, FuG, S.321ff, $333 \mathrm{ff}, 445 \mathrm{ff}$; vgl. auch I.Maus, Aufklärung, S.236ff., $298 \mathrm{ff}$.

141 J.Habermas, Über den internen Zusammenhang von Rechtsstaat und Demokratie, in: ders., Einbeziehung, S.293ff, $301 \mathrm{ff}$.

142 Vgl, zu den Beiträgen eines Symposiums der Cardozo Law School die Replik von J.Habermas, Anhang zu Faktizität und Geltung, in: ders., Einbeziehung, S.309ff. 
Rechtsstaats angesprochenen Phänomene lediglich kursorisch gestreift werden, die unter dem Gesichtspunkt der Steuerungskrise des Rechts entfaltete Sicht sogar als verfehlt zurückgewiesen wird, um den Blick auf Legitimationsprobleme zu lenken ${ }^{143}$.

Faktizität und Geltung beschränkt sich auf eine - allerdings dringend nötige - Rekonstruktion des klassischen Modells des demokratischen Rechtsstaats, wobei der Kantschen Position eine kommunikative Wendung gegeben wird, die es erlaubt, demokratische Gesetzgebung als rational zu verstehen. Das prozeduralistische Rechtsparadigma bleibt hingegen auf die Einbettung des politischen Diskurses in das parlamentarische Gesetzgebungsverfahren fixiert, orientiert sich also an der Herrschaft des Gesetzes. Daß die aus der Entformalisierung des Rechts und dem Zusammenbruch funktionsspezifischer Gewaltenteilung resultierende weitgehende Wirkungslosigkeit demokratischer Willensbildung ${ }^{144}$ nicht nur auf ein unrichtiges, nämlich materiales, paradigmatisches Verständnis des Rechts zurückzuführen ist, das lediglich durch ein neues, prozedurales Paradigma ersetzt werden müßte, wird nur unwillig zur Kenntnis genommen ${ }^{145}$.

Habermas sieht zwar, daß sich die Probleme der Gesetzesbindung und der Rechtssicherheit im Zusammenhang mit der Ausweitung der Staatsaufgaben in der Risikogesellschaft dramatisch zuspitzen. Er meint aber, daß die an der Steuerungskrise des Rechts orientierte Literatur den Gesichtspunkt der Effektivität des Rechts in unzulässiger Weise gleichberechtigt neben den der Legitimität des Rechts stelle. Demgegenüber gelte es angesichts der Tatsache, daß sich wegen der zunehmenden Unbestimmtheit des Rechts die richterliche Rechtsfortbildung zur impliziten Gesetzgebung ausweite und die Verwaltung im Vollzug eigene Programme entwickle, die demokratische Genese des Rechts durch Institutionalisierung rechtsstaatlicher Prinzipien sicherzustellen. Dazu müsse der Gewaltenteilungsgrundsatz abstrakter gefasst werden. Das abstrakt-generelle Gesetz könne nicht mehr das Scharnier bilden, um das sich die institutionelle Trennung der gesetzgebenden, -anwendenden und vollziehenden Instanzen dreht. "Die konkretistische Rede von Gesetzgeber, Justiz und Verwaltung verschleiert die Logik einer rechtsstaatlichen Gewaltenteilung, die auf einer anderen Abstraktionsebene die Verfügung über verschiedene Sorten von Gründen und die Art des Umgangs mit ihnen regelt. Sie verlangt die Institutionalisierung verschiedener Diskurse und entsprechender Kommunikationsformen, die - gleichviel in welchem Kontext - Zugriffsmöglichkeiten auf entsprechende Sorten von Gründen eröffnen"146.

Der Gesetzgeber müsse zunächst auf einer Metaebene darüber entscheiden, ob er überhaupt entscheiden wolle, wer an seiner Stelle entscheiden könnte und, falls er entscheiden wolle, welche Folgen sich für die legitime Verarbeitung seiner Programme ergäben. Dabei stelle sich die Frage, ob sich der Gesetzgeber durch eine Dezentralisierung zugleich funktional spezifizierter Gesetzgebungskompetenzen von Entscheidungen entlasten könne, die er selbst nicht mit hinreichender Bestimmtheit treffen könne. Verwende der Gesetzgeber hingegen materiales (unbestimmtes) Recht, so müßten dort, wo Verwaltung und Justiz nicht nur Recht vollziehen und anwenden, sondern darüber hin-

143 J.Habermas, FuG, Krise des Rechtsstaats und prozeduralistisches Rechtsverständnis, S.516-537. Das sind in Seitenzahlen ca. $4 \%$ der Arbeit. Man kann daher sagen, daß Faktizität und Geltung mit einem kursorischen Ausblick dort aufhört, wo die vorliegende Untersuchung anfängt.

144 S.o. Kap.1 V. 1. zur Krise des Rechtsstaats; vgl. auch I.Maus, Verrechtlichung, S.279.

145 J.Habermas, FuG, S.518.

146 J.Habermas, FuG, S.528f. 
aus normbegründend tätig werden, mit Hilfe prozeduralen Rechts zusätzliche Legtimationsfilter eingebaut werden. Als Beispiele für solche Filter nennt Habermas eine Reihe von unspezifizierten Stichwörtern wie die Institutionalisierung einer justizkritischen Rechtsöffentlichkeit sowie eine als Demokratisierung verstandene Bürgerbeteiligung an Verwaltungsverfahren, Ombudsleute, Anhörungen etc., wobei er diese Vorschläge keineswegs für originell hältt14.

Dieser Selbsteinschätzung kann man sich nur unbedingt anschließen. Habermas gibt bestenfalls eine Richtung vor, in der Antworten zu suchen wären. Daß mit dem Stichwort der Prozeduralisierung des Rechts keinesfalls eine bloße prozeduralistische Rekonstruktion der Herrschaft des Gesetzes gemeint sein kann, hat bereits Klaus Eder herausgearbeitet ${ }^{148}$. Denn die Erkenntnis, da $\beta$ das Recht sich weitgehend über prozedurales Recht i.S.v. Kompetenz-, Organisations- und Verfahrensregeln selbst festlegt, ist nach Eder nicht neu. Neu ist hingegen eine Zunahme prozeduralen Rechts im Prozeß der fortschreitenden Verrechtlichung der Gesellschaft sowie eine damit verbundene verstärkte Abhängigkeit der Legitimität des Rechts von Gesichtspunkten prozeduraler Rationalität. Während formales Recht mit dem Begriff der Zweckrationalität verbunden war, an deren Stelle im Rahmen der Materialisierung des Rechts die Idee der Wertrationalität getreten ist, geht es bei der Prozeduralisierung des Rechts um die Institutionalisierung kommunikativer Rationalität. Das entscheidende Phänomen, auf das das Recht heute reagieren muß, ist die Multiplikation kollektiver Akteure und die kommunikative Verflüssigung von Standards materieller Rationalität, was Eder als den Beginn der Kommunikationsgesellschaft deutet ${ }^{149}$.

Wo es keine substantiellen Grundlagen mehr für Rationalitätsannahmen gibt, müssen diese in der Gesellschaft selbst gesucht werden. Prozeduralisierung des Rechts bedeutet daher eine Vergesellschaftung von Recht, so daß die Standards materialer Rationalität selbst erst in rechtlich konstituierten Prozeduren sozialer Auseinandersetzungen festgelegt werden. Angesichts der Vervielfältigung von Kommunikation und der Dezentralisierung des Wissens, die zu einer Zunahme von Unsicherheit und so zu einer Verstetigung von Dissens führen, kann Recht nicht mehr am Paradigma des Konsens und der Widerspruchsfreiheit ausgerichtet werden. Es gilt vielmehr, rechtliche Kommunikation als Koordination von Dissens zu organisieren. An die Stelle von an Universalisierung und Konsens ausgerichteten virtuellen oder repräsentativ-advokatorischen Diskursen tritt die Institutionalisierung realer Diskurse als prozedurale Verfassung einer Kommunikations- und Streitgesellschaft. Ein prozeduralisiertes Recht begreift Eder als lernfähiges Recht, das unter Verzicht auf interventionistische Strategien des Staates, die auf zentral ausgearbeiteten materiellen Vorgaben beruhen, lediglich durch prozedurales Recht die normativen Voraussetzungen für Auseinandersetzungen um Selektionen herstellt und so institutionelle Lemprozesse auslöst und unterstützt. Das Problem ist die Herstellung einer disputing society unter Bedingungen hoher Komplexität ${ }^{150}$.

Wenn Eder die Aufmerksamkeit auch in die richtige Richtung leitet, so enthalten seine Beiträge doch keinerlei Hinweise auf konkrete institutionelle Arrangements, in denen

147 J.Habermas, FuG, S.529ff, 535.

148 K.Eder, Prozedurale Rationalität, S.1ff.; ders., Prozedurales Recht und Prozeduralisierung des Rechts, in: D.Grimm (Hrsg.), Wachsende Staatsaufgaben, 1990, S.155-185.

149 K.Eder, Prozedurales Recht, S.167.

150 K.Eder, Prozedurale Rationalität, S.28. 
sich das lernfähige Recht entfalten könnte. Hinweise in dieser Richtung finden sich insbesondere bei Ingeborg Maus, die mit Habermas das Interesse an einer Reformulierung der Idee des demokratischen Rechtsstaats unter modernen gesellschaftlichen Bedingungen der Komplexität teilt151. Maus entwickelt den Gedanken, daß, wenn das Modell einer monokausalen Herrschaft des Gesetzes angesichts der Komplexität der modernen Gesellschaft nicht mehr greift, neue Formen der Institutionalisienung der Grundprinzipien des demokratischen Rechtsstaats gefunden werden müssen ${ }^{152}$. Dazu wird in zwei Schritten vorgegangen: erstens müssen die Grundprinzipien des demokratischen Rechtsstaats im Wege der Abstraktion aus den überlieferten Institutionen des Rechtsstaats herausgearbeitet werden. Zweitens bedarf es eines großen Ausmaßes an institutioneller Phantasie und Kreativität, um neue Formen der gesellschaftlichen Selbststeuerung zu finden, in denen die abstrakten Prinzipien des demokratischen Rechtstaats entfaltet werden können.

Rechtssicherheit, Gewaltenteilung und demokratische Legitimation werden im liberalen Rechtsstaatsmodell über das Gesetz vermittelt $t^{153}$. Dieses Gesetzgebungsmodell der Gerechtigkeit zerfällt mit der Materialisierung des Rechts, die es den rechtsanwendenden Instanzen erlaubt, die Inhalte unbestimmten Rechts weitgehend selbst zu definieren. Rechtssicherheit wandelt sich zur Rechtsgütersicherheit und funktionale Gewaltenteilung wird durch ein System der polyzentrischen Rechtserzeugung ersetzt, in welchem die Frage nach der demokratischen Legitimation offen bleibt ${ }^{154}$. Im Gegensatz zu Habermas verschließt Maus den Blick jedoch nicht vor den Veränderungen von Gesellschaft und Staatsaufgaben sowie den daraus resultierenden Steuerungsproblemen des Rechts, die die gegenwärtigen Entformalisierungstendenzen eher als irreversibel erscheinen lassen 155 .

Das Gesetzgebungsmodell der Gerechtigkeit bei Rousseau und Kant beruht auf einer Reihe von Annahmen, die heute problematisch geworden sind. Erstens setzt der Begriff der Volkssouveränität neben einer Einheit des Volkes, die sich in einem Volkswillen äußert, einen souveränen Staat voraus, der als zentrales Entscheidungszentrum die Einheit der Gesellschaft garantiert. Heute kann dem Volksbegriff angesichts der Regionalisierung und Pluralisierung aller gesellschaftlichen Problemlagen und der fortgeschrittenen Entwicklung zu einer multikulturellen Gesellschaft keine kompakte Bedeutung mehr zugeordnet werden. Souveränität scheint durch die Tatsache widerlegt, daß politische Entscheidungsprozesse zunehmend mit ihren gesellschaftlichen Regelungsbereichen in einer Weise vernetzt sind, daß eindeutige Zuständigkeiten und Verantwortlichkeiten nicht mehr ausfindig zu machen sind. Die explosionsartige Vermehrung hochspeziellen Wissens in den ausdifferenzierten gesellschaftlichen Teilbereichen verbunden mit der informationellen Unterlegenheit zentraler Instanzen machen die Rede von einem souveränen staatlichen Entscheidungszentrum illusorisch. "Was wir noch als Staat bezeichnen, ist das jeweilige Ergebnis der Kommunikation zwischen verschiedenen fragmen-

151 I.Maus, Aufklärung, S.224; dies., Verrechtlichung, S.315ff.; dies., Perspektiven reflexiven Rechts, S.390ff., 400; dies., Volkssouveränität, S.137ff.

152 I.Maus, Aufklärung, S.297.

153 S.o. Kap. 1 III. 1.

154 S.o. Kap. 1 V. 1.; I.Maus, Verrechtlichung, S.278ff.; D.Grimm, Wandel, S.296ff.

155 S.o. Kap. IIV und V 3. u. 4.; Maus, Aufklärung, S.224. 
tierten Staatsapparaten, die ihrerseits informationsabhängig mit ihren gesellschaftlichen 'Umwelten' untrennbar vernetzt sind."156

Zweitens ging die Demokratietheorie des 18. Jahrhunderts von einem geringen rechtlichen Regelungsbedarf der Gesellschaft aus, so daß etwa Rousseau das "Allgemeine" der volonté générale als den kleinsten gemeinsamen Nenner der besonderen Interessen verstehen konnte ${ }^{157}$. Der heutige Präventionsstaat mit seinem System offener Staatsaufgaben kennt demgegenüber prinzipiell keine Grenzen rechtlichen Steuerungsbedarfs ${ }^{158}$. Dabei wird die Verrechtlichung der Gesellschaft mit entformalisierten Rechtsformen vorangetrieben, die in Anpassung an den Bedarf an Prävention sowie ständiger Nachsteuerung generalklauselartig flexibel und unbestimmt gehalten werden und folglich die Bindung von Verwaltung und Justiz an den demokratischen Volkswillen nicht mehr leisten können. Weil die Gesetze aufgrund ihres feinsteuernden Charakters immer speziellere Materien regeln und einen immer kleineren Adressatenkreis betreffen, kann selbst in einem symbolischen Sinne nicht mehr die Rede davon sein, daß alle über alle das Gleiche beschließen, sondern es entscheiden wenige über wenige Besonderes ${ }^{159}$.

Das Konzept der Freiheitssicherung durch demokratische Legitimation, inhaltliche Allgemeinheit und Anwendungsgleichheit des Gesetzes scheitert damit am Zustand der gegenwärtigen Gesellschaft. Gesellschaftliche Differenzierung, staatliche Detailregulierung und die Intensität der Verrechtlichung haben in einem Ausmaß zugenommen, das sämtliche Voraussetzungen der legitimatorischen Trias gesetzlicher Allgemeinheit entfallen läßt. Die Normenflut hat drittens zur Folge, daß das Konzept der Rechtssicherheit in Frage gestellt wird, da selbst den Betroffenen immer weniger Gesetze bekannt sind, zumal deren unbestimmter Inhalt häufig erst im Anwendungsprozeß festgelegt wird ${ }^{160}$.

Für Maus stellt sich damit die Frage, wie die wesentlichen Intentionen der Theorie des demokratischen Rechtsstaats unter den heute gegebenen gesellschaftlichen Bedingungen zu rekonstruieren sind ${ }^{161}$. Als den abstrakten Kern der Volkssouveränitätstheorie bestimmt Maus die schlichte Forderung, daß Souveränität ausschließlich denen zukomme, die von Entscheidungen selbst betroffen sind, und nicht etwa den Verwaltern delegierter, rechtsanwendender Macht, also die Idee der "Freiheit als Autonomie als Selbstgesetzgebung" im Sinne von Kant ${ }^{162}$. Den abstrakten Kern der Rechtsstaatsidee entwickelt Maus hingegen in Anlehnung an eine Terminologie Luhmanns am Begriff der reflexiven Institutionalisierung. Reflexivität meint bei Luhmann die Anwendung eines Prozesses auf sich selbst ${ }^{163}$, also Normieren der Normierung, Planen der Planung, Entscheiden über Entscheidungsprämissen, in diesem Zusammenhang Institutionalisierung der Institutionalisierung ${ }^{164}$.

Die politisch-rechtliche Integration der modernen Gesellschaft wird nach Luhmann über eine reflexive Institutionalisierung geleistet, die sich zunächst auf institutionalisie-

156 I.Maus, Volkssouveränität, S.137, 144, wobei ausdrücklich an U.Becks Analyse der "Niemandsherrschaft der Risikogesellschaft" (U.Beck, Risikogesellschaft, S.253, 305f.) angeschlossen wird.

157 S.o. Kap. 1 II. 3., IV. 1.

158 S.o. Kap. 1 IV. 3.

159 I.Maus, Aufklärung, S.221f.

160 I.Maus, Verrechtlichung, S.322.

161 I.Maus, Aufklärung, S.224, 296f.

162 I.Maus, Aufklärung, S.218.

163 N.Luhmann, Soziale Systeme, S.601,610ff.

164 I.Maus, Verrechtlichung, S.280; dies., Perspektiven reflexiven Rechts, S.393. 
rende Verfahren und erst sekundär auf sachliche Rechtsentscheidungen bezieht. Auf der Ebene der Normierung der Normsetzung konstituieren sich rechtsetzende, -anwendende und -vollziehende Institutionen wesentlich durch Organisations- und Verfahrensrecht. Die Stabilität dieses institutionellen Arrangements bei prinzipieller Abänderbarkeit allen Rechts beruht Luhmann zufolge auf dieser Differenzierung zwischen institutionalisierenden Entscheidungen über Entscheidungsprämissen und den inhaltlichen Entscheidungen selbst, sowie auf der Differenzierung zwischen den Entscheidungsverfahren: Im laufenden Entscheidungsprozeß darf nicht zugleich über die Spielregeln dieses Prozesses mitentschieden werden; im laufenden (einfachen) Gesetgebungsverfahren darf die prinzipiell änderbare Verfassung nicht durchbrochen werden, im Gerichtsverfahren dürfen die ansonsten permanent zu ändernden Rechtsnormen nicht geändert werden. Die systemischen Stabilitätsbedingungen positiven Rechts liegen mithin darin, daß nicht alles auf einmal geändert werden kann. ${ }^{165}$

Maus hat nun herausgearbeitet, daß dieses Auseinanderziehen von Entscheidungen über Entscheidungsprämissen und Entscheidungen über Inhalte ein Prinzip enthält, das der rechtsstaatlichen Institutionalisierung von Gewaltenteilung überhaupt zugrundeliegt. ${ }^{66}$ Im Anschluß an Kants Begründung der Gewaltenteilung als repräsentativer (Absonderung der ausführenden Regierungsgewalt von der gesetzgebenden Gewalt) gegenüber einer despotischen Regierungsart (Gesetzgebung und Vollziehung sind in einer Person vereinigt) ${ }^{167}$, sieht Maus den Sinn rechtsstaatlicher Gewaltenteilung in der strukturellen Gewährleistung einer gestuften Unkenntnis materieller Interessen für die jeweils nächste Entscheidungsebene, der die Funktion einer vernünftigen Selbstüberlistung interessierter Egoisten zukommt. Die rechtsstaatlichen Verfahrenstrennungen sind künstlich errichtete Sichtblenden, die Ralws' "Schleier des Nichtwissens" im Rechtsfindungsprozeß institutionalisieren. Richter sollen "ohne Ansehen der Person" entscheiden, Rechtsetzung über Verfahren oder Inhalte soll in Unkenntnis zukünftiger Anwendungsfälle und materieller Betroffenheiten stattfinden. ${ }^{168}$

In der modernen dezentrierten Gesellschaft können diese wesentlichen Intentionen der Theorie des demokratischen Rechtsstaats nach Maus nur über das Experiment einer dezentralisierten Gesetzgebung, die die parlamentarische ergänzt, rekonstruiert werden. "Angesichts der fortgeschrittenen Partikularisierung der Gesellschaft und der Spezialisierung des Rechts ist die Identität der Gesetzgebenden und der Gesetzesadressaten, also Selbstgesetzgebung, ganz überwiegend nur noch in den Binnenräumen gesellschaftlicher Teileinheiten herzustellen. Dies bedeutet aus der Perspektive des Rechts: Je begrenzter die Zahl der Rechtsadressaten oder der Regelungsbereich einer Norm ist, desto eher kann diese in Rechtsetzungsarrangements beraten und verabschiedet werden, in denen die betroffenen konfligierenden Interessen einander direkt konfrontiert werden. Je allgemeiner Rechtsnormen noch sind, desto mehr eignen sie sich für Entscheidungsprozesse, die entweder im parlamentarischen Verfahren oder in zentral veranstalteten Plebisziten (oder in Kombination beider) realisiert werden. Dies setzt voraus, daß die legislative Zentrale für die allgemeinste Funktion zuständig bleibt: die Setzung von Ver-

165 Vgl. N.Luhmann, Rechtssoziologie, S.214, 234ff.; I.Maus, Verrechtlichung, S.280f.

166 I.Maus, Perspektiven reflexiven Rechts, S.392.

167 I.Kant, ZeF, WW VI, S.206f.; s.o. Kap. 1 bei FN 146.

168 I.Maus, Aufklärung, S.294f.; vgl. dazu schon oben Kap. 1 II. 1. 
fahrensnormen, nach denen in zentral-plebiszitären wie in dezentralen Rechtsetzungsprozessen die inhaltlichen Normen erst zustande kommen." 169

Die Allgemeinheit des Rechts verkörpert sich angesichts der extremen inhaltlichen Parzellierung der Gesellschaft nur noch in prozeduralen Organisations- und Verfahrensvorschriften. Dieses prozedurale Recht, das die Asymmetrien gesellschaftlicher Macht durch Verteilung symmetrischer Verhandlungspositionen rechtlich kompensiert, muß allerdings selbst hinreichend bestimmt sein. Denn ein Mindestma $\beta$ an Fairneß ist von Verfahrensnormen nur zu erwarten, wenn diese nicht ihrerseits situativ flexibel sondern in Unkenntnis der jeweils konkreten gesellschaftlichen Interessenkonflikte vorab festgelegt werden. Rechtssicherheit bezieht sich dann zwar nicht mehr auf die Kenntnis inhaltlicher Normen, kann aber an dem Vorhandensein unverbrüchlicher Partizipationsund Teilhabechancen im Prozeß der inhaltlichen Rechtsetzung festgemacht werden. ${ }^{170}$

Dem Prinzip der reflexiven Institutionalisierung werden demgegenüber jene Konzepte nicht gerecht, die das legitimatorische Defizit von zunehmend Normbegründungsdiskurse führender Verwaltung und Rechtsprechung bloß durch Einbau legitimatorischer Filter kompensieren wollen. Denn auch eine durch Bürgerbeteiligung demokratisierte Exekutive, die rechtsetzende gleichzeitig mit rechtsanwendenden Funktionen wahrnimmt, zerreißt den strukturellen "Schleier des Nichtwissens" reflexiver Institutionalisierung. ${ }^{171}$ Im Sinne von Kant bleibt eine demokratische Vollziehung "notwendig ein Despotism, weil sie eine exekutive Gewalt gründet, da alle über und allenfalls auch wider Einen (der also nicht mit einstimmt), mithin alle, die doch nicht alle sind, beschließen". ${ }^{172}$

Mit dem Konzept dezentralisierter Gesetzgebung knüpft Maus an Habermas' Verständnis von Recht als Institution an, das im Gegensatz zum Recht als Medium den geregelten gesellschaftlichen Teilbereichen keine detaillierten inhaltlichen Vorgaben macht, sondern lediglich eine äußere Verfassung vorgibt, innerhalb derer Raum für bereichsinterne Prozesse der diskursiven Willensbildung bleibt, wobei Maus allerdings meint, daß sich solche Institutionen der Freiheit nicht nur in lebensweltlichen sondern auch in systemischen Bereichen errichten lassen. ${ }^{173}$ In diesem Kontext hat Dieter Suhr für die Grundrechtsdogmatik ein neues Paradigma der Freiheit durch Geselligkeit entworfen, anhand dessen er die begrifflich-systematischen Zusammenhänge von Institut, Teilhabe, Organisation und Verfahren erläutert. ${ }^{174}$ Mit diesem Konzept erfindet Suhr die Grundrechtsdogmatik nicht etwa neu. Er weist aber zutreffend darauf hin, daß Freiheit für den einzelnen weitestgehend nur in der sozialen Dimension, also im Bezug auf andere Menschen Bedeutung hat. Die selbständig und nebeneinander entwickelten Begriffe der Grundrechtsdogmatik Institut, Teilhabe, Organisation und Verfahren finden darin etwas Gemeinsames, daß Freiheit in der Gesellschaft durch staatliche Einrichtung von Institutionen und Verfahren gesichert oder erst hergestellt werden muß. Für die hier zu diskutierende Idee einer Prozeduralisierung des Rechts durch Delegation von Rechtsetzungsbefugnissen an ausdifferenzierte gesellschaftliche Teilbereiche ist dies deshalb

169 I.Maus, Aufklärung, S.224f.

170 I.Maus, Perspektiven reflexiven Rechts, S.402, 404f.

171 I.Maus, Aufklärung, S.201f.

172 I.Kant, ZeF, WW VI, S.206f.

173 I.Maus, Verrechtlichung, S.316.; Zur Unterscheidung von Lebenswelt und System s.u. II. 2. c).

174 D.Suhr, Freiheit durch Geselligkeit, Institut, Teilhabe, Verfahren und Organisation im systematischen Raster eines neuen Paradigmas, EuGRZ 1984, S.529ff. 
interessant, weil Suhr darauf hinweist, daß sich die rechtlich zu schaffende äußere Verfassung der gesellschaftlichen Teilbereiche auch an den Grundrechten messen lassen muß. Grundrechte sind damit Kriterien für prozedurales Recht.

Was dies im einzelnen bedeutet, muß der Ausarbeitung einer Theorie des prozeduralen Rechtsstaats im dritten Kapitel vorbehalten bleiben. An dieser Stelle kann festgehalten werden, daß sich Kriterien für eine Prozeduralisierung des Rechts im Sinne einer Dezentralisierung und Vergesellschaftung der Rechtsfindung sowohl aus dem Demokratie- und Rechtsstaatsprinzip, als auch aus den individuellen Grundrechten herleiten lassen, was die von Habermas herausgearbeitete Gleichursprünglichkeit von privater und öffentlicher Autonomie unterstreicht. Festgestellt werden muß andererseits aber auch, daß sich die institutionelle Phantasie der bis hierher dargestellten Autoren in Grenzen hält. Die in diesem Abschnitt vorgestellten Beiträge, die von dem Interesse an einer normativen Rekonstruktion der Prinzipien des demokratischen Rechtsstaats unter Bedingungen gesteigerter gesellschaftlicher Komplexität zusammengehalten werden, geben normative Kriterien vor. Wie eine Prozeduralisierung des Rechts konkret aussehen soll, bleibt hingegen offen.

\section{e) Festzuhaltendes: der politische Diskurs}

Im Ergebnis kann festgehalten werden, daß sich demokratische Politik als rationaler Prozeß verstehen läßt, sofern Volkssouveränität jenseits der konkretistischen Idee einer Repräsentation des Volkes im Parlament vollständig prozeduralisiert als dezentrierter Diskurs verstanden wird, dessen subjektlose Kommunikationen in einer Vielzahl von Arenen und Foren der Meinungs- und Willensbildung zirkulieren. Der politische Diskurs gliedert sich in eine nichtinstitutionalisierte Peripherie der politischen Öffentlichkeit, die ihre Basis in den spontanen Assoziationen einer Zivilgesellschaft findet, sowie in einen institutionalisierten Kern, in welchem der Diskurs im Modus deliberativer Politik in Rechtsverfahren eingebettet ist, die Entscheidungen ermöglichen. Die im Gesetzgebungsverfahren begründeten Normen haben neben ihrer durch die Einhaltung der rechtlichen Verfahrensregeln feststellbaren Geltung eine Vermutung der Vernünftigkeit für sich, soweit sie sich als interimistisches Zwischenergebnis eines als in der Zeit verlaufenden Lernprozesses verstandenen politischen Diskurses auszeichnen, dessen Zentrum von der Peripherie gespeist wird.

Während der politische Diskurs in das auf universalistische Normbegründung angelegte Gesetzgebungsverfahren eingebettet ist, ist der juristische Diskurs in das auf unparteiliche Normanwendung anläßlich der konkreten Streitentscheidung durch einen neutralen Dritten angelegte Gerichtsverfahren eingebettet. Aus diesem Unterschied erklärt sich die Unterordnung des juristischen unter den politischen Diskurs insofern, als dies in der Bindung an das Gesetz zum Ausdruck kommt. Soweit der politische Diskurs vom juristischen Diskurs unter verfassungsrechtlichem Aspekt kontrolliert wird, gilt diese Kontrolle vornehmlich der Sicherung der prozedural-rationalen Legitimitätsbedingungen der Politik. Diese Kontrolle rechtfertigt sich aus der Tendenz des professionellorganisatorischen Kerns der Politik, sich gegenüber der zivilgesellschaftlich basierten politischen Öffentlichkeit zu verselbständigen und so die formalpragmatischen Bedingungen deliberativer Politik zu unterlaufen.

Angesichts des Bedeutungs- und Bindungsverlustes des allgemeinen und bestimmten Parlamentsgesetzes in der Risikogesellschaft mit ihrem Präventionsstaat gilt es darüber 
hinaus, neue Formen der Institutionalisierung der öffentlichen und privaten Autonomie der Bürger zu entwickeln, die die Prinzipien des demokratischen Rechtsstaats auch unter Bedingungen gesteigerter gesellschaftlicher Komplexität verwirklichen. Prozeduralisierung des Rechts bedeutet in diesem Zusammenhang eine Vervielfältigung und Dezentralisierung von Rechtsetzungsverfahren, in die der politische Diskurs eingebettet wird. Dezentralisierung darf dabei weniger im regional-föderalistischen Sinne, wie sie dem traditionell hierarchischen Staatsaufbau entspricht, als vielmehr der gegenwärtig dominanten Logik der funktionalen Differenzierung der Gesellschaft entsprechend als Delegation funktional spezifizierter Kompetenzen an autonome Teilbereiche der Gesellschaft verstanden werden. Die dezentrierte öffentliche Autonomie der Bürger entfaltet sich dabei entsprechend dem Prinzip reflexiver Institutionalisierung eher in Verfahren der dezentralisierten Selbstgesetzgebung, die private Autonomie der Bürger verwirklicht sich tendenziell in Form von Teilhabe- und Verfahrensrechten in rechtlich organisierten Institutionen der Freiheit.

\section{Prozedurale Rationalität und gesellschaftliche Diskursvielfalt: Reflexives Recht und Prozeduralisierung}

Die bisher vorgestellten Theorien beschäftigen sich aus normativer Sicht mit der Bedeutung prozeduraler Rationalität für Recht und Politik. Die entscheidenden Anstöße für die Diskussion um eine Prozeduralisierung des Rechts sind jedoch von einer Reihe von Autoren ausgegangen, die aus einer eher beschreibenden Perspektive das im ersten Kapitel erläuterte Phänomen der Steuerungskrise des Rechts erklären und Auswege aufzeigen wollen. Vor dem Hintergrund eines systemtheoretischen Verständnisses von Steuerung werden dabei teils bekannte Rechtsentwicklungen neu interpretiert, vor allem aber neue Modelle und Formen der politischen Steuerung der Gesellschaft entwickelt, die angesichts des soeben festgestellten Bedarfs an institutioneller Phantasie von großem Interesse sind. Während Habermas Legitimität vermittelnde Diskurse lediglich in den traditionell staatlichen Bereichen von Recht und Politik verortet, wird hier davon ausgegangen, daß in einer zentrumslosen Kommunikationsgesellschaft potentiell an jedem Ort Diskurse stattfinden und durch prozedurales Recht institutionalisiert werden können. Die hier zu begründende Hypothese lautet, daß der etwa von Habermas behauptete Widerspruch zwischen Effizienz und Legitimität des Rechts in der modernen Gesellschaft aufgehoben wird: die Risiken und Probleme der Wissenschafts- und Kommunikationsgesellschaft lassen sich nur durch Formen der indirekten Steuerung bewältigen, die auf eine strukturelle Gewährleistung und prozedurale Überformung der diskursiven Selbststeuerung relativ autonomer gesellschaftlicher Teilbereiche zielen. Das ausgeschlossene Andere, die gesellschaftliche Diskursvielfalt wird einbezogen.

\section{a) Die Ausgangslage: neue Metaphern zur Beschreibung der Gesellschaft und die Entzauberung des Staates}

Angesichts der Komplexität ihres Gegenstandes leben Staatsphilosophie und Gesellschaftstheorie von Bildern, Gleichnissen und Metaphern. Bekanntes Beispiel ist etwa die Beschreibung der Gesellschaft als Mensch, in der der Staat als Kopf die Glieder der Gesellschaft steuert, wobei die Glieder nur reflexartig das zuvor im Kopf intelektuell erarbeitete Programm ausführen. Die Idee vom Interventionsstaat wird von einer Variante 
dieses Gleichnisses getragen: der Maschinenmetapher. Der rasante technische Fortschritt im Industriezeitalter speist den Glauben an die technische Machbarkeit auch der sozialen Verhältnisse, Politik wird als social engineering verstanden. Der Staat gibt inputs, die nach mechanischen Gesetzen der Kausalität zu gewissen gesellschaftlichen outputs führen. Steuerungsversagen ist ein Zeichen dafür, daß die Kausalzusammenhänge nicht hinreichend durchschaut wurden und kann durch eine verbesserte Steuerungsmechanik beseitigt werden. Grundsätzlich wird davon ausgegangen, daß jeder Steuerungsablauf in seinen Kausalitäten transparent und damit einseitig planbar gemacht werden kann. ${ }^{175}$

Die These der systemtheoretisch orientierten Autoren ist nun, daß die Maschinenmetapher keine angemessene Beschreibung der modernen Kommunikationsgesellschaft mehr liefert ${ }^{176}$. Zur Beschreibung der Gesellschaft wird vielmehr auf neue, insbesondere der Biologie und der Informatik entlehnte Metaphern zurückgegriffen. Von v.Foerster stammt die Metapher von der "nicht-trivialen Maschine"177. Im Gegensatz zu trivialen Maschinen, die gemäß einer feststehenden Wirkungsfunktion auf eine bestimmte Eingabe mit einer gewissen Ausgabe reagieren, sind nicht-triviale Maschinen analytisch unbestimmbar und ihre Reaktionen sind nicht voraussagbar, weil diese von den inneren Zuständen der Maschine, also von ihrer Vergangenheit abhängen, so daß derselbe input im Verlauf der Zeit durch Zustandsveränderungen der Maschine unterschiedliche outputs nach sich ziehen kann. Für den Außenstehenden erscheinen solche Maschinen als blackbox. Als Metapher für die Gesellschaftstheorie soll damit gesagt werden, daß die moderne Gesellschaft ein System nicht-trivialer Maschinen ist, deren Verhalten zueinander nicht nach einfachen Kausalgesetzen berechenbar ist. Nicht-triviale Maschinen tendieren allerdings im Verlauf ihrer Operationen auf Eigenwerte hin, die zu einer Verfestigung ihres Zustands führen ${ }^{178}$. In einem System von nicht-trivialen Maschinen werden so durch das unendliche Anknüpfen von Reaktionen an Aktionen in der Zeit Gleichgewichtszustände erreicht. Dabei ist es allerdings unmöglich vorherzusehen, welche Folgen etwa ein politischer Eingriff in einen solchen Gleichgewichtszustand am Ende haben wird. Für die Aufgabe der politischen Steuerung der Gesellschaft bedeutet dies eine Absage an linear-kausale Planungsmodelle im input/output-Schema ${ }^{179}$.

Aus der Zellbiologie stammt das Bild der Autopoiese ${ }^{180}$. Danach können Zellen nicht von ihrer Umwelt im Sinne kausaler Beeinflussung verändert werden. Zellen steuern sich vielmehr selbst, indem sie sich in einem fortlaufenden Prozeß der Autopoiese aus ihren eigenen Elementen reproduzieren. Umwelteinflüße wirken nicht kausal auf diesen geschlossenen Produktionsprozeß ein, sondern induzieren lediglich Selbstveränderun-

175 Vgl. F.Scharpf, Die Handlungsfähigkeit des Staates am Ende des zwanzigsten Jahrhunderts, PVS 1991, S.621-634.

176 H.Willke, Entzauberung des Staates, Überlegungen zu einer gesellschaftlichen Steuerungstheorie, Königstein/Ts. 1983.

177 Vgl. etwa H.von Foerster, Abbau und Aufbau, in: F.B.Simon (Hrsg.), Lebende Systeme, Berlin u.a. 1988, S.19-33.

178 H.von Foerster, Erkenntnistheorien und Selbstorganisation, in: S.J.Schmidt (Hrsg.), Der Diskurs des Radikalen Konstruktivismus, Ffm 1987, S.133ff.

179 H.Willke, Ironie, S.168; G.Teubner, Recht als autopoietisches System, S.8f.

180 Ein lustig geschriebener Überblick über die Herkunft des Begriffs Autopoiese und dessen Rezeption durch die Sozialwissenschaften findet sich bei J.Nocke, Autopoiesis - Rechtssoziologie in seltsamen Schleifen, KJ 1986, S.364ff. 
gen $^{181}$. Von dieser Metapher lebt die autopoietische Systemtheorie ${ }^{182}$. Auf die Gesellschaft übertragen meint sie, daß diese aus einer Vielzahl ausdifferenzierter Teilsysteme wie etwa Wirtschaft, Gesundheit, Wissenschaft, Medien, Erziehung, Recht, Familie besteht, die sich in einem Ausmaß spezialisiert und ausdifferenziert haben, das ihnen einen hohes $\mathrm{Ma}$ an Autonomie gewährleistet. Einer Zelle vergleichbar reproduzieren sich diese Subsysteme selbst, indem sie sich immer wieder auf sich selbst beziehen (Selbstreferenz), an vorhandenes Wissen und selbstgemachte Ereignisse anknüpfen und immer unwahrscheinlichere Strukturen ausbilden. Die Politik, die selbst nur ein Subsystem unter anderen ist, kann operativ geschlossene Systeme nicht kausal steuern, sondern lediglich Selbständerungen anregen. ${ }^{183}$

Während die Autopoiesemetapher die operative Geschlossenheit eines Systems betrifft, das seine Operationen in zirkulärer Kausalität selbst bestimmt, bezieht sich die order-from-noise-Metapher auf die Offenheit dieser Systeme für Informationen aus ihrer Umwelt. Nach der Erkenntnistheorie des Radikalen Konstruktivismus ${ }^{184}$ werden alle Informationen eines Systems über seine Umwelt ausschließlich systemintern generiert. Dabei wird das Bild eines Systems über die Wirklichkeit seiner Umwelt entscheidend von den systeminternen Wahrnehmungsstrukturen geprägt. So hat ein Beobachter, der einen Adler sieht, keineswegs einen Kontakt zur Realität außerhalb seiner selbst. Vielmehr wird das im Gehirn entstehende Bild, dem die Bedeutung Adler zugewiesen wird, erst aus einer Unzahl von Umwelteinflüssen vom Gehirn selektiert und konstruiert. Die Augen selektieren bestimmte Lichtwellen aus der Unzahl vorhandener Wellen und das Gehirn setzt diese zu einem Bild zusammen, das entscheidend erfahrungsgeprägt ist und aus der Erinnerung intern ergänzt wird. Die Lichtwellen selbst sind zunächst nur bedeutungsloser Lärm in der Umwelt. Aus der Vielzahl von Lärm filtert das System intern einige Informationen heraus und konstruiert daraus eine Ordnung. Information entsteht also erst durch systeminterne Bedeutungszuweisung. In diesem Sinne erfindet sich jedes System seine Umwelt, indem es aus externem Lärm interne Ordnung herstellt. Orderfrom-noise meint, daß der Erkennende und das Erkannte in einem Zirkel der wechselseitigen Ko-Spezifizierung und des ko-abhängigen Entstehens gebunden sind ${ }^{185}$. Auf die Gesellschaft übertragen bedeutet dies, $\mathrm{da} \beta$ verschiedene Subsysteme füreinander zunächst nichts als Lärm produzieren. Jedes System konstruiert aus dem Umweltlärm je seine streng systemrelative Wirklichkeit. Dabei entstehen Kommunikationsprobleme aus der unterschiedlichen Struktur der Systeme. Die Wirtschaft mißversteht das Recht, weil Normen auf den "Bildschirmen" der Wirtschaft als Preise erscheinen. Das Recht erfindet sich sein Bild von der Wirtschaft anhand seiner internen Strukturen, etwa anhand von Tatbestandsmerkmalen, die nichts mit der Wirklichkeit der Wirtschaft zu tun haben (müssen). Die Politik versteht ein Gerichtsurteil, mit dem das Recht Einzelfallge-

181 Vgl. F.J.Varela, Autonomie und Autopoiese, in: S.J.Schmidt (Hrsg.), Der Diskurs des Radikalen Konstruktivismus, S.119ff.; H.R.Maturana/F.J.Varela, Der Baum der Erkenntnis, München 1987. Diese verkürzte Darstellung erhebt keinen Anspruch auf biologische Korrektheit. Da es sich bei der sozialen Autopoiesetheorie lediglich um eine Metapher handelt, kommt es nur darauf an, die Metapher zu umschreiben.

182 Siehe dazu ausführlich unten II. 1.

183 H.Willke, Ironie, S.43ff, 60ff.; G.Teubner, Recht als autopoietisches System, S.21ff, 87.

184 S.J.Schmidt, Der Radikale Konstruktivismus, S.11ff.

185 Vgl. zum Adlerbeispiel F.J.Varela, Erkenntnis und Leben, in: F.B.Simon (Hrsg.), Lebende Systeme, S.34-46. 
rechtigkeit produziert, als politische Ohrfeige für die Regierung, etc.. Mit der orderfrom-noise-Metapher werden also Steuerungsprobleme als strukturnotwendige Verständigungsprobleme zwischen ausdifferenzierten Teilsystemen erklärt ${ }^{186}$.

Erwähnung bedarf schließlich noch die "Netzwerk"-Metapher, die aus den Kommunikationswissenschaften einerseits ${ }^{187}$, aus der Gehirnforschung andererseits bekannt ist ${ }^{188}$. Die Struktur der modernen Kommunikationsgesellschaft kann nicht länger im Bild der Hierarchie zwischen Kopf und Gliedern eingefangen werden. Information und Innovation werden dezentral produziert und bevorratet und die Kommunikationsstränge verlaufen nicht von der Peripherie zum Zentrum sondern durch ein weitverzweigtes Netz von Quer- und Seitenverbindungen. In diesem Netzwerk gibt es zwar einige Knotenpunkte aber kein Zentrum, in welchem alle Informationen zusammenlaufen und verarbeitet würden. Eine solche zentrale Instanz würde schon an der bloßen Menge an Informationen scheitern, die eine zentrale Verarbeitung schlicht unmöglich macht ${ }^{189}$. Komplexe Netzwerke sind vielmehr polyzentrisch und heterarchisch organisiert. Heterarchie kann dabei verstanden werden als Prinzip der potentiellen Führung: in einem komplexen Netzwerk liegt die Autorität zur Führung oder Steuerung des Ganzen bei dem Teil, welcher in der gegebenen Situation über optimale Informationen verfügt ${ }^{190}$. Versteht man die moderne Gesellschaft im Sinne dieser Metapher als hochkomplexes Kommunikationsnetzwerk, so verliert der Staat seine Rolle als benevolenter Vater, der im hierarchischen Zentrum der Gesellschaft das Ganze repräsentiert. In einer polyzentrischen Gesellschaft ist der Staat vielmehr nur noch ein Spieler unter vielen, der mit gleichgeordneten Partnern verhandelt und Kompromisse schließt $\mathrm{t}^{191}$. Er ist Mittler und Makler zwischen kollidierenden autonomen Teilbereichen der Gesellschaft oder bestenfalls - wie Helmut Willke es ausdrückt - Supervisor für sich selbst steuernde Systeme, der diese zu Selbständerungen und zu reflexiver Rücksichtnahme auf die Bedürfnisse anderer Systeme anregt ${ }^{192}$.

Zusammenfassend erscheint die Gesellschaft als polyzentrisch und heterarchisch organisiertes Kommunikationsnetzwerk, innerhalb dessen sich anhand von bestimmten Funktionen operativ geschlossene Subsysteme ausdifferenziert haben. Diese Subsysteme reproduzieren sich über ihre codierten Kommunikationen selbst, verfügen über systemintern konstruierte Wirklichkeiten und bilden Teilrationalitäten aus, die wechselseitig nicht ohne weiteres kompatibel sind. Trotz funktionaler Abhängigkeiten kommt den Subsystemen ein hohes $\mathrm{Ma} \beta$ an Autonomie $z \mathfrak{u}$, das linear-kausale Steuerungsbeziehungen zwischen den Systemen ausschließt. Intersystembeziehungen finden lediglich in Form von Ko-Evolution statt. Recht und Politik sind selbst autopoietische Systeme, die keine per se übergeordnete Stellung in der Gesellschaft beanspruchen können. Vor diesem Hintergrund stellt sich die Frage, wie politisch induzierte Gesellschaftssteuerung durch Recht möglich ist.

186 G.Teubner, Recht als autopoietisches System, S.96ff.; ders., Steuerung durch plurales Recht, S.530ff.

187 Vgl. etwa M.Schenk, Kommunikationsstrukturen in Bürgerinitiativen, Tübingen 1982.

188 Wo etwa von Netzwerken neuronaler Felder die Rede ist: vgl. H.Willke, Ironie, S.65.

189 Zur Unmöglichkeit zentraler Informationsverarbeitung in hochkomplexen Kommunikationssystemen vgl. G.Wersig, Die kommunikative Revolution, S.53ff.; H.Willke, Ironie, S.68.

190 H.Willke, Ironie, S.62ff., 65.

191 F.W.Scharpf, Die Handlungsfähigkeit des Staates, S.621ff.

192 H.Willke, Ironie, S.335ff. 


\section{b) Kontext und Autonomie: Steuerung von Selbststeuerung}

Folgt man dieser Gesellschaftsbeschreibung, so liegt das Problem von Steuerung in der dreifachen Autopoiese der beteiligten Systeme Politik, Recht und reguliertes System ${ }^{193}$. Hochgetriebene politische Interventionsansprüche führen, wenn die auf Selbstreferentialität beruhende Autonomie der beteiligten Systeme mißachtet wird, immer tiefer in das regulatorische Trilemma ${ }^{194}$. Unter Autonomie versteht Teubner dabei nicht nur Autopoiese im engeren Sinne der Selbstreproduktion der Elemente eines Systems, sondern soziale Selbstreferenz schlechthin: wo immer in der sozialen Realität eine Operation, ein Prozeß, ein System auf sich selbst trifft, entsteht eine Beziehung der Selbstbestimmung, die von außen nicht bestimmt werden kann - eben Autonomie ${ }^{195}$.

Autonomie sozialer Systeme meint dabei allerdings nicht eine monadische AbschlieBung des Systems gegenüber seiner Umwelt im Sinne von Autarkie. Vielmehr bezieht sich Autonomie auf die Zirkularität der Operationen des Systems und ist demgemäß ein gradualisiertes, also steigerungsfähiges Konzept: "Gesellschaftliche Teilsysteme gewinnen an Autonomie, wenn im Subsystem die Systemkomponenten (Element, Struktur, Prozeß, Identität, Grenze, Umwelt) selbstreferentiell definiert sind (= Selbstbeobachtung), wenn zusätzlich diese Selbstbeobachtungen im System operativ verwendet werden (= Selbstkonstitution) und wenn schließlich in einem Hyperzyklus die selbstkonstituierten Systemkomponenten als einander wechselseitig produzierend miteinander verkettet werden (= Autopoiesis)." 196

Dieses Autonomiekonzept soll am Beispiel des Rechts erläutert werden. Dazu werden Teubners Ausführungen zum Recht als autopoietisches System in zwei Tabellen vereinfachend zusammengefasst. In Tabelle 1 werden zunächst die Systemkomponenten des Rechts aufgelistet:

Tabelle 1: Systemkomponenten des Rechts ${ }^{197}$

\begin{tabular}{|l|l|l|l|l|l|}
\hline System & Element & Struktur & Prozeß & $\begin{array}{l}\text { Identität / } \\
\text { Grenze }\end{array}$ & Umwelt \\
\hline Rechtssystem & $\begin{array}{l}\text { Rechtsakt: } \\
\text { Gesetz, } \\
\text { Vertrag, } \\
\text { Urteil }\end{array}$ & Rechtsnormen & $\begin{array}{l}\text { Rechtliche } \\
\text { Verfahren }\end{array}$ & $\begin{array}{l}\text { Rechts- } \\
\text { dogmatik, } \\
\text { Rechtstheorie }\end{array}$ & $\begin{array}{l}\text { 1. Unwelt der } \\
\text { Gesellschaft } \\
\text { 2. Innergesell- } \\
\text { schaftliche } \\
\text { Umwelt }\end{array}$ \\
\hline
\end{tabular}

In Tabelle 2 sind die verschiedenen selbstreferentiellen Operationen des Rechts anhand von Beispielen erläutert, die Teubner selbst anführt. Einen relativ unklaren Status hat dabei allerdings der sogenannte „Hyperzyklus“, dem die Funktion der Verkettung der Systemkomponenten zukommen soll. Dem Hyperzyklus läßt sich daher kein konkretes Beispiel aus dem Recht zuordnen:

193 G.Teubner, Recht als autopoietisches System, S.89.

194 S.o. Kap. 1 V. 4.

195 G.Teubner, Recht als autopoietisches System, S.88, 94ff.

196 G.Teubner, Recht als autopoietisches System, S.44.

197 Zusammengestellt nach G.Teubner, Recht als autopoietisches System, S.36ff. 
Tabelle 2: Selbstreferentielle Rechtsoperationen ${ }^{198}$

\begin{tabular}{|l|l|l|}
\hline Operation & Definition & Beispiel im Recht \\
\hline Selbstbeobachtung & $\begin{array}{l}\text { Aussage des Systems über sich } \\
\text { selbst }\end{array}$ & $\begin{array}{l}\text { Theorie, begriffliche Erfassung } \\
\text { eines Rechtsproblems }\end{array}$ \\
\hline Selbstbeschreibung & $\begin{array}{l}\text { Systematische, dauerhafte Selbst- } \\
\text { beobachtung }\end{array}$ & $\begin{array}{l}\text { Als Rechtsdogmatik an den Uni- } \\
\text { versitäten institutionalisiert }\end{array}$ \\
\hline Selbstorganisation & $\begin{array}{l}\text { Systeminterne Identifizierung der } \\
\text { Struktur }\end{array}$ & $\begin{array}{l}\text { Erkennen gültiger Normen über } \\
\text { "rules of recognition" }\end{array}$ \\
\hline Selbststeuerung & $\begin{array}{l}\text { Systeminterne Steuerung von } \\
\text { Strukturänderung }\end{array}$ & $\begin{array}{l}\text { Positivierung des Rechts durch } \\
\text { rechtliche Regulierung der Nor- } \\
\text { mänderung }\end{array}$ \\
\hline Selbstreflexion & $\begin{array}{l}\text { Festlegung von Identität und } \\
\text { Grenzen des Systems durch } \\
\text { Selbstbezeichnung anhand der } \\
\text { Unterscheidung System/Umwelt }\end{array}$ & Rechtstheorie \\
\hline $\begin{array}{l}\text { Selbstproduktion, } \\
\text { Selbstreproduktion, } \\
\text { Selbstherstellung }\end{array}$ & $\begin{array}{l}\text { Verknüpfung von Systemopera- } \\
\text { tionen über Selbstverweisungen in } \\
\text { der Weise, daß sie sich selbst pro- } \\
\text { duzieren }\end{array}$ & $\begin{array}{l}\text { Präjudizienverweis, Rechtsände- } \\
\text { rungsregeln: Norm- } \\
\text { Entscheidung-Norm-... }\end{array}$ \\
\hline Selbstkonstitution & $\begin{array}{l}\text { Verwendung von Selbstbeschrei- } \\
\text { bungen und Selbstreflexion in den } \\
\text { Systemoperationen }\end{array}$ & $\begin{array}{l}\text { BGH-Zitat einer juristischen } \\
\text { Theoric; Professorale Beratung } \\
\text { von Gericht/Gesetzgeber }\end{array}$ \\
\hline Selbsterhaltung & $\begin{array}{l}\text { Systeminterne Aufrechterhaltung } \\
\text { der Bedingungen der Selbstpro- } \\
\text { duktion in einem Hyperzyklus }\end{array}$ & $\begin{array}{l}\text { Zirkuläre Verknüpfung von } \\
\text { Norm, Entscheidung, Verfahren, } \\
\text { Dogmatik }\end{array}$ \\
\hline $\begin{array}{l}\text { Selbstbeobachtung-Selbstkonsti- } \\
\text { tution-Selbstproduktion- Hyper- } \\
\text { zyklus }\end{array}$ & Autopoiese & \\
\hline
\end{tabular}

Nach diesem gradualisierten Konzept der Autopoiese ${ }^{199}$ nimmt die Autonomie sozialer Systeme mit der zunehmenden Verwendung selbstreferentieller Operationen zu. Autopoiese als Produktion von Rechtskommunikationen durch Rechtskommunikationen über das Netzwerk von Rechtserwartungen, gesteuert durch Rechtsdogmatik und Rechtsverfahren, stellt demnach lediglich den vorläufigen Höhepunkt eines evolutionären Prozesses dar, in welchem sich die funktional spezialisierten Subsysteme immer weiter aus dem allgemeinen gesellschaftlichen Kommunikationskreislauf ausdifferenzieren. Mit der Steigerung von Selbstreferenz werden die Operationen der Subsysteme zunehmend vom inneren Zustand dieser Systeme bestimmt, also vergangenheitsabhängig und deshalb im Sinne nicht-trivialer Maschinen extern nicht vorhersehbar. Autopoietische Geschlossenheit bezeichnet daher einen Zustand, der erst mit der extremen Steigerung von Eigenkomplexität der Subsysteme in der modernen Kommunikationsgesellschaft entsteht. Die Subsysteme werden dadurch immer leistungsfähiger, für die Gesellschaft aber

198 Zusammengestellt nach G.Teubner, Recht als autopoietisches System, S.48ff., 52ff;; die Angaben in der ersten und zweiten Spalte gelten dabei grundsätzlich für alle gesellschaftlichen Subsysteme, müßten für die Wirtschaft, die Wissenschaft, die Politik also jeweils nur mit spezifischen Beispielen in der dritten Spalte belegt werden.

199 G.Teubner, Recht als autopoietisches System, S.38ff. 
auch immer undurchschaubarer. ${ }^{200}$ Damit entsteht für die Politik ein neuartiges Steuerungsproblem: wenn autopoietische Systeme von außen nicht steuerbar sind, dann ist Gesellschaftssteuerung nur noch als Steuerung von Selbststeuerung denkbar.

Nach dem Prinzip des order-from-noise ist eine externe Induzierung von Selbstveränderung im Wege der Ko-Evolution von Systemen durch gegenseitige Beobachtung möglich. Wenn das Recht sich etwa durch eine Rechtsprechungsänderung selbst verändert, erscheint dies aus Sicht der Wirtschaft als eine Veränderung in der Umwelt (Lärm), auf die die Wirtschaft mit Anpassung durch Selbstveränderung reagiert (Perturbation). Wegen der selektiven Wahrnehmungsstruktur ist allerdings nicht vorhersehbar, mit welcher Art von Selbstveränderung die Wirtschaft auf den rechtlichen Umweltlärm reagieren wird. ${ }^{201}$ Will man über diese kaum als intentionale Steuerung za bezeichnende Form blinder Ko-Evolution von Systemen im Sinne von "Gesellschaftsordnung durch Gesetzgebungslärm"202 hinaus, so stellt sich die Frage nach Umwegen, Schleichwegen und Ausweichstrategien.203

In das Zentrum solcher Überlegungen haben Teubner und Willke den Begriff des reflexiven Rechts gestellt.204 Reflexives Recht bezieht sich zunächst auf Reflexion, d.h. auf die Ausbildung einer Identität des Rechts unter Bedingungen funktionaler Differenzierung der Gesellschaft. Reflexives Recht bezeichnet insoweit ein Rechtssystem, das sich als autopoietisches System in einer Welt von autopoietischen Systemen identifiziert und daraus operative Konsequenzen zieht. ${ }^{205}$ Eine mögliche Konsequenz ist dabei die Steigerung von Reflexivität im Recht, also die Verlagerung des Schwergewichts der Normsetzung von der materiellen auf die reflexive Ebene des Normierens des Normierens. Denn Kompetenz-, Organisations- und Verfahrensvorschriften als prozedurale Normen sind das klassische Mittel zur rechtlichen Steuerung von Selbststeuerung.

Das Schlüsselwort zur Ermöglichung von prozeduraler Steuerung ist dabei Interferenz. Interferenz meint den ereignishaften Gleichlauf zweier geschlossener Systeme, über den strukturelle Kopplungen zwischen diesen stattfinden können. Teubner hat dies beispielhaft an der Institution des Vertrags herausgearbeitet. ${ }^{206}$ Der Vertragsschluß ist uno actu wirtschaftliche und rechtliche Kommunikation, Zahlung und Rechtsakt. Das Recht stellt der Wirtschaft ein Instrument der Selbststeuerung zur Verfügung, das die Autonomie der Wirtschaft in Form der Privatautonomie respektiert und der Wirtschaft gleichzeitig Vorteile, etwa den der Rechtssicherheit, bietet. Deshalb läßt sich die Wirtschaft auf das rechtliche Angebot ein. Gleichzeitig knüpft das Recht vornehmlich prozedurale, aber in Form des nichtdispositiven Rechts auch materiale Bedingungen an die Wahrnehmung des Angebots und sichert sich so Einfluß auf die Wirtschaft. Der Witz dieses Arrangements liegt in der freiwilligen Selbst-Einbindung der Wirtschaft in das

$200 \mathrm{Zu}$ den Unterschieden zu N.Luhmanns Begriff von Autopoiese s.u. II. 1. und III.1.; vgl. auch M.Blecher, Zu einer Ethik der Selbstreferenz oder Theorie als Compassion: Möglichkeitsbedingungen einer autopoietischen Gesellschafts- und Rechtstheorie, Berlin 1991, S.123ff.

201 G.Teubner, Steuerung durch plurales Recht, S.530ff., wo Teubner beispielhaft sieben unterschiedliche mögliche wirtschaftseigene Lektüren einer rechtlichen Preisbindung darstellt.

202 G.Teubner, Gesellschaftsordnung durch Gesetzgebungslärm, S.45ff.

203 G.Teubner, Recht als autopoietisches System, S.96ff.

204 G.Teubner, Reflexives Recht, ARSP 1982, S.13ff.; G.Teubner/H.Willke, Kontext und Autonomie: Gesellschaftliche Selbststeuerung durch reflexives Recht, ZfRSoz 1984, S.4ff.

205 G.Teubner, Recht als autopoietisches System, S.87.

206 G.Teubner, Recht als autopoietisches System, S.102ff., $106 \mathrm{ff}$. 
rechtliche Korsett, was im Verlauf der Zeit von Ereignis zu Ereignis zu einem relativ konstanten Strukturabgleich zwischen Recht und Wirtschaft führt. Erkauft wird diese Steuerungsmöglichkeit allerdings mit einem hohen $\mathrm{Maß}$ an Autonomie des regulierten Systems, der Einfluß des Rechts ist sehr indirekt und im seinem Umfang begrenzt. Denn die strukturelle Kopplung funktioniert nur solange, wie die vertragliche Bindung aus Sicht der Wirtschaft als Selbstbindung erscheint.207

Dieses Modell der indirekten Steuerung durch Systeminterferenz wird nun generalisiert. Es geht also um das Aufspüren von Selbststeuerungsmechanismen im zu regulierenden System, um diese sodann durch prozedurales Recht überformen zu können. Dem regulierten System wird Autonomie angeboten, wobei der Kontext, innerhalb dessen diese Autonomie ausgeübt wird, vom Staat bestimmt wird. Damit ist eine Rücknahme staatlicher Steuerungsansprüche von materiellen Detailvorgaben auf prozedurale Kontextsteuerung verbunden, die eine neue Bescheidenheit von Politik und Recht zum Ausdruck bringt. ${ }^{208}$ Die dahinterstehende Idee ist, daß Vollzugsdefizite, kontraproduktive Folgen und Nebenwirkungen staatlicher Steuerung nur durch eine Einbeziehung des regulierten Feldes in Formulierung und Vollzug der jeweiligen Politiken vermieden werden können. Das setzt voraus, daß sich die Spezialkommunikationen in den zu regulierenden Subsystemen einerseits über formale Organisation in einer Weise verdichtet haben, die Ansatzpunkte für eine prozedurale Überformung durch Recht bieten, und daß diese systeminternen Diskurse andererseits gegenüber Belangen des Allgemeinwohls sensibilisiert werden können. ${ }^{209}$ Ersteres soll durch eine staatlich geförderte Konstitutionalisierung der Subsysteme erreicht werden, letzteres bezeichnet die Reflexionsfähigkeit der Subsysteme, die der Staat in seiner Rolle als Supervisor in Verhandlungssystemen steigern helfen soll. 210

Sind damit die Möglichkeiten von politisch-rechtlicher Steuerung in einer heterarchisch organisierten Kommunikationsgesellschaft abstrakt umrissen, so sollen im folgenden einige konkretere Vorstellungen über mögliche Formen der Prozeduralisierung des Rechts, wie sie von einer Vielzahl von Autoren vorgeschlagen wurden, nach den klassischen Bereichen Gesetzgebung, Verwaltung und Rechtsprechung sortiert vorgestellt werden.

\section{c) Gesetzgebung}

Mit konkreten Vorschlägen für die Gesetzgebung tun sich die hier vorgestellten Autoren generell schwer, im folgenden muß daher versucht werden, aus deren mehr oder weniger dunklen Andeutungen Gehalt zu schöpfen. M.E. lassen sich grob drei verschiedene Strategien reflexiver Gesetzgebung unterscheiden.

Die erste Strategie zielt darauf, aus der blinden Ko-Evolution der Systeme eine "einäugige" zu machen. Görlitz hat diese Strategie als "Mediales Recht" bezeichnet. ${ }^{211} \mathrm{Da}$ -

207 G.Teubner, Steuerung durch plurales Recht, S.539ff., $546 \mathrm{f}$.

208 H.Willke, Ironie, S.316.

209 G.Teubner, Steuerung durch Plurales Recht, S.543ff.; H.Willke, Ironie, S.335ff., $359 \mathrm{ff}$.

$210 \mathrm{H}$.Willke, Ironie, S.300ff., 335ff, $359 \mathrm{f}$.

211 A.Görlitz, Mediales Recht als Politisches Steuerungskonzept, in: ders. (Hrsg.), Politische Steuerung sozialer Systeme, Pfaffenweiler 1989, S.13; ders., Mediales Recht, in: ders./R.Voigt (Hrsg.), Postinterventionistisches Recht, Jahresschrift für Rechtspolitologie 4, Pfaffenweiler 1990, S.151-163. 
mit ist gemeint, daß das Recht zur Umwelt (Medium) ${ }^{212}$ des gesteuerten Systems gehört und deshalb durch Selbständerungen nach dem Prinzip des order-from-noise Selbständerungen des regulierten Systems perturbieren kann. Wegen des fehlenden Wissens über die internen Kausalabläufe im regulierten System empfiehlt es sich, dieses schlicht als black box zu betrachten und auf politische Eingriffe in die internen Detailabläufe des regulierten Systems zu verzichten. Anstattdessen sollen im Sinne einer Globalsteuerung lediglich die politischen Rahmenbedingungen vorgegeben werden, innerhalb derer das zu regulierende System dann eigenständig Problemlösungen entwickelt. Der Schritt von der blinden zur einäugigen Ko-Evolution besteht nun darin, daß die Politik anhand extrem vereinfachter Annahmen über das Funktionieren des regulierten Systems beim Setzen der Rahmenbedingungen darauf achtet, daß diese in einer für das regulierte System verständlichen Sprache formuliert sind.213

Für das Beispiel einer Regulierung der Wirtschaft bedeutet dies, daß man in der Sprache des Geldes spricht. Verändert werden also die politischen Rahmenbedingungen, innerhalb derer die Wirtschaft dann nach Gewinn streben kann. Solche Ansätze der Globalsteuerung sind aus der Umweltpolitik unter dem Stichwort der ökologischen Marktwirtschaft, der Internalisierung externer Kosten sowie der Ökosteuern ${ }^{214}$ ebenso bekannt wie aus dem Bereich der Arbeitspolitik, wo um die Senkung der Lohnnebenkosten gerungen wird. Anstatt also Grenzwerte festzulegen, technische Standards vorzuschreiben, Arbeitsplätze in konkreten Unternehmen zu subventionieren oder über Arbeitsbeschaffungsmaßnahmen und Beschäftigungsgesellschaften künstlich Arbeitsplätze zu schaffen, werden lediglich die politischen Rahmenbedingungen für ökonomisches Handeln geändert. Wo, wie und wann Energie gespart, Filter eingebaut oder Arbeitsplätze geschaffen werden, bleibt den Selbstregulierungsmechanismen der Wirtschaft überlassen. Zählen tut lediglich der Output. Wie dieser aufgrund des Inputs systemintern erreicht wurde, ist im black-box Modell egal.

Das hat den großen Vorteil, daß sich Recht und Politik bei der Implementation der Programme nicht mit ökonomischen Detailfragen auseinandersetzen müssen, die durch Recht und Politik nicht beantwortbar sind: nämlich ob etwa die Nachrüstung einer konkreten Industrieanlage mit einem modernen Filter wirtschaftlich vertretbar ist ${ }^{215}$, oder ob die Subventionierung eines konkreten Betriebes zum ökonomischen turnaround führt oder den notwendigen Strukturwandel bloß verschleppt. Mediales Recht kommt demgegenüber mit wenigen vereinfachten Grundannahmen über das Funktionieren der Wirtschaft aus, indem es sich im Sinne einer Globalsteuerung auf die Veränderung der politisch gemachten Rahmenbedingungen des Wirtschaftens (Steuergesetzgebung; Sozialgesetzgebung, etc.) beschränkt. ${ }^{216}$

Die zweite Strategie setzt auf eine Konstitutionalisierung der Subssysteme mit dem Ziel, deren Reflexionsfähigkeit durch Kompetenz-, Organisations- und Verfahrensvor-

212 Der Begriff Mediales Recht meint etwas anderes als etwa Recht als Medium (vs. Recht als Institution) bei Habermas. Medium meint hier Umwelt so wie etwa der Fisch im "Medium" Wasser lebt.

213 H.Willke, Ironie des Staates, S.190ff.

214 Vgl. M.Kloepfer, Zu den neuen umweltrechtlichen Handlungsformen des Staates, JZ 1991, 737ff.; W.Köck, Umweltrechtsentwicklung und ökonomische Analyse, NuR 1992, S. $412 \mathrm{ff}$.

215 S.o. Kap. 1 V. 3. a).

$216 \mathrm{Zu}$ den Problemen auch derart vereinfachter Annahmen über das Funktionieren der Wirtschaft vgl. G.Teubner, Steuerung durch plurales Recht, S.531ff. 
schriften zu erhöhen. ${ }^{217}$ Beispiel hierfür ist das rechtlich ausgestaltete System der Tarifautonomie ${ }^{218}$, das der Wirtschaft einen Rahmen bietet, innerhalb dessen innersystemische Interessenkonflikte auf zivilisierte Art im Interesse aller Beteiligten und unter Berücksichtigung des Allgemeinwohls (Vermeidung von andauernden Streiks) gelöst werden können. Das Tarifvertragsrecht bietet ein Beispiel dafür, wie vorrechtlich bestehende formale Organisationen innerhalb des Wirtschaftssystems (Gewerkschaften, Arbeitgeberverbände) durch reflexives Recht einerseits durch Einräumung von Sozialautonomie unterstützt und verfestigt, andererseits durch prozedurale Spielregeln (Friedenspflicht, Schlichtungsverfahren, Aussperrungs- und Streikverbote) auf politische Ziele hin verpflichtet werden können. Im Sinne einer Optionenpolitik ${ }^{219}$ beruht die Wirksamkeit dieses Arrangements auf der Freiwilligkeit der Teilnahme (Verbandsmitgliedschaft) sowie auf den mit der Verrechtlichung der Tarifautonomie verbundenen Vorteilen (Anerkennung der Verbände, rechtliche Verbindlichkeit und Durchsetzbarkeit der Vereinbarungen, Möglichkeit der Allgemeinverbindlichkeitserklärung etc.), die aus Sicht der Beteiligten die Nachteile (rechtliche Überformung und Kontrolle) überwiegen müssen. Aufgabe der Politik ist es dabei, über prozedurale Regeln das Machtgleichgewicht der Verhandlungspartner sicherzustellen, sowie das System so flexibel zu halten, $\mathrm{da} ß$ es als Option auch unter geänderten ökonomischen Bedingungen attraktiv bleibt.220

Weitere Beispiele dieser Strategie sind etwa die Gesetzgebung zur Mitbestimmung ${ }^{221}$, die Einrichtung von Betriebsbeauftragten für Umweltschutz, biologische Sicherheit etc., die Einführung eines Öko-Audit-Systems und dessen Ausbau zu einem Umweltmanagementsystem (Ecological-Quality-Management) ${ }^{222}$ sowie die Einrichtung von Kommissionen für Biologische Sicherheit oder die Verrechtlichung medizinischer Ethikkommissionen. ${ }^{223}$ All diese Maßnahmen zielen darauf, durch prozedurale Regeln den im jeweils regulierten System stattfindenden Diskurs auf Belange des Allgemeinwohls hin auszurichten und so die Reflexionsfähigkeit der Systeme zu erhöhen.224

217 H.Willke, Ironie, S.198ff., 306ff., 327ff., 357ff.; G.Teubner, Recht als autopoietisches System, S.117ff.

218 Vgl. H.Willke, Strategien der Intervention in autonome Systeme, in: D.Baecker et al. (Hrsg.) Theorie als Passion. Niklas Luhmann zum 60. Geburtstag, Ffm 1987; ders., Systemtheorie entwickelter Gesellschaften, Weinheim 1989, Kap. 4.

219 Vgl. dazu N.Luhmann, Einige Probleme mit "reflexivem Recht", ZfRSoz 1985, S.1ff, 11; G.Teubner, Recht als autopoietisches System, S.115ff.

220 Zum Problem der zunehmenden Verlagerung der Auseinandersetzungen von der tariflichen auf die betriebliche Ebene vgl. schon M.Hartmann, Reflexives Recht am Ende? Zum Eindringen materialen Rechts in die Tarifautonomie, ZISoziologie 1987, S.16ff., sowie die Antwort von G.Teubner, Recht als autopoietisches System, S.84f.

$221 \mathrm{Vgl}$. G.Teubner, Recht als autopoietisches System, S.119.

222 Vgl. zur Diskussion von prozeduralen Steuerungsmöglichkeiten im Umweltrecht E.Rehbinder, Reflexives Recht und Praxis: Der Betriebsbeauftragte für Umweltschutz als Beispiel, in: Jahrbuch für RSoz u. RTheorie XIII. (1988), S.109-128; W.Köck, Indirekte Steuerung im Umweltrecht, DVB1. 1994, S.27ff.; E.Hagenah, Neue Instrumente für eine neue Staatsaufgabe: Zur Leistungsfähigkeit prozeduralen Rechts im Umweltschutz, in: D.Grimm (Hrsg.), Staatsaufgaben, 1994, S.487ff,; K.H.Ladeur, Das Umweltrecht in der Wissensgesellschaft: von der Gefahrenabwehr zum Risikomanagement, Berlin 1995, S.243ff., $257 \mathrm{ff}$.

223 Siehe dazu ausfiuhrlich unten Kap. 3 IV.

224 Vgl. z.B. M.Blecher, Ecological Responsibility of Enterprise: Environmental Officers in an Ecological-Quality-Organisation, in: G.Teubner (Ed.), Ecological Responsibility of Enterprise, Oxford UP 1993. 
Die dritte Strategie setzt auf die Einrichtung von Intersystembeziehungen in Form von Verhandlungssystemen, in denen im Gespräch zwischen Politik, Recht und den betroffenen regulierten Systemen Probleme definiert, Ziele formuliert, Lösungen ausgehandelt und Kompromisse geschlossen werden. ${ }^{225}$ Strukturelle Kopplung findet in diesen Verhandlungen über die Angleichung von Sichtweisen und Wirklichkeitswahrnehmungen und die Abstimmung von Programmen statt. Der Staat kann in solchen Verhandlungen die von Willke betonte Rolle eines Supervisors spielen, der die zu regulierenden Systeme für die Belange des Allgemeinwohls sensibilisiert und so deren Reflexionsfähigkeit erhöht. ${ }^{226}$ Diese Gespräche können von einmaligen Zusammenkünften über lockere Konversationskreise, runde Tische, konzertierte Aktionen bis hin zu formal organisierten und institutionalisierten Gremien, wie etwa dem Wissenschaftsrat, reichen. ${ }^{227}$ Recht erhält in diesem Zusammenhang die Funktion eines zielgerichtet eingesetzen "Katalysators für systemeigene Veränderungsprozesse"228, wobei die prozedurale Qualität des Rechts im Vordergrund steht. Im Rahmen der Intersystembeziehungen ist es Garant für bestimmte Spielregeln des Prozessierens von Widersprüchen, der Konflikterhaltung und -behandlung, die das strategische Spiel der gesellschaftlichen Subsysteme auf die Reflexion der gesellschaftlichen Bedingungen ihrer Möglichkeit zurückbinden. Als reflexives Recht wird es zum Medium der reflexiven Abstimmung widersprüchlicher Teilsystemrationalitäten. ${ }^{229}$ Die spezifische Form, die das Recht in $\mathrm{Zu}$ sammenhang mit dieser prozeduralen Funktion der Strukturierung von Intersystembeziehungen annimmt, benennt Willke in Abgrenzung vom formalen Konditionalprogramm sowie vom materialen Zweckprogramm als Relationierungsprogramm. 230

Solche Intersystembeziehungen stehen allerdings vor einem doppelten Problem. ${ }^{231}$ $\mathrm{Da}$ die Subsysteme insgesamt nicht wie Personen miteinander sprechen können, sind sie nur über formale Organisation möglich. Es kann also nicht die Politik mit der Wirtschaft sprechen, sondern es können lediglich Repräsentanten formaler Organisationen innerhalb der Teilsysteme, also etwa Regierungsvertreter mit Vertretern der Gewerkschaften und Wirtschaftsverbände, miteinander ins Gespräch kommen. Die Intersystembeziehungen sind daher einerseits nur ein vermitteltes Gespräch der Systeme ohne Garantie dafür, daß das Besprochene von den Systemen insgesamt übernommen wird (Beispiel Lehrstellengarantie). Andererseits sind solche Intersystembeziehungen selbst wieder Systeme, die, je formaler sie organisiert und je dauerhafter sie institutionalisiert sind, einer Tendenz zur Verselbständigung folgen und mitunter ohne Rücksicht auf ihr Ziel der Systemverständigung einen Selbsterhaltungstrieb entwickeln. ${ }^{232}$ Hutter, der solche Intersystembeziehungen anhand des Beispiels von Gesprächen zwischen Wirtschaft und Recht

225 H.Willke, Ironie, S.198ff.

226 H.Willke, Ironie, S.335ff., $349 \mathrm{ff}$.

$227 \mathrm{Zu}$ Verhandlungssystemen im Bereich des Umweltschutzes vgl. E.Hagenah, Zur Leistungsfähigkeit prozeduralen Rechts im Umweltschutz, S.503ff.; Zu einer partizipativen Technikfolgenabschätzung vgl. A.Bora, Gesellschaftliche Integration durch Verfahren - Zur Funktion von Verfahrensgerechtigkeit in der Technikfolgenabschätzung und -bewertung, ZfRSoz 1993, S. 55ff;; zum Wissenschaftsrat vgl. H.Willke, Politische Steuerung der Wissensgesellschaft?, ZfRSoz 1995, S.94ff.

228 H.Willke, Ironie, S.203.

229 H.Willke, Ironie, S.205.

230 H.Willke, Ironie, S.179ff.

231 G.Teubner, Recht als autopoietisches System, S.103f., $112 \mathrm{f}$.

232 Vgl. G.Teubner, Die Fremdproduktion von Recht. Oder: Wie die Wirtschaft das Recht zur KoEvolution überredet, ZfRSoz 1991, S.161ff, 166. 
im Rahmen des Arzneimittelpatentrechts untersucht hat, kommt deshalb zu dem Schluß, daß lockere Konversationskreise institutionalisierten Foren vorzuziehen sind. ${ }^{233}$

\section{d) Verwaltung}

Auf der Ebene der Verwaltung ist das Phänomen der zunehmenden Angewiesenheit von Recht und Politik auf die Mitwirkung des regulierten Systems bei der Formulierung und Implementation von Steuerungsprogrammen, das Teubner und Willke mit der Ausdifferenzierung autopoietischer Subsysteme und dem Übergang zu einer polyzentrischen, heterarchisch organisierten Kommunikationsgesellschaft erklären, inzwischen unter dem Stichwort vom kooperativen Staat recht ausführlich beschrieben worden. ${ }^{234}$ Durch Informationsrechte, Anhörungen, konzertierte Aktionen und Bürgerbeteiligungen sind die Betroffenen bei der Normsetzung und Planerstellung ebenso beteiligt, wie beim Verwaltungsvollzug im Einzelfall zwischen Antragsteller und Behörde Verhandlungen stattfinden und Absprachen getroffen werden. Dabei gewinnt insbesondere der öffentlich-rechtliche Vertrag als Instrument konsensuellen Verwaltungshandelns an Bedeutung. ${ }^{235}$ Ein Großteil des kooperativen Verwaltungshandelns findet allerdings in einem rechtlich nicht regulierten Graubereich statt, weshalb auch von informalem Verwaltungshandeln die Rede ist. ${ }^{236}$ Informationsaustausch, Vorverhandlungen, Vorabzuleitung von Entscheidungsentwürfen und "gentlemen's agreements" finden vor allem dort Anwendung, wo das Verwaltungshandeln durch unbestimmte Rechtsbegriffe und Ermessensspielräume gesetzlich nicht ausreichend programmiert ist. ${ }^{237}$ Der gegenseitige Kooperationswille bei der Ausfüllung solcher Spielräume kommt dabei einerseits durch die Drohung der Verwaltung, bei Verweigerung auf einseitig hoheitliches Handeln zurückzugreifen, andererseits durch die Drohung der Regelungsadressaten mit Vollzugsverhinderung oder -verschleppung bis in die letzte Gerichtsinstanz zustande. ${ }^{238}$ Mit Hilfe der einseitig-hoheitlichen Rechtsinstrumente wird dann nur noch gewissermaßen als "Erfüllungsgeschäft" realisiert, was in kooperativ gestalteten "Kausalgeschäften" zuvor abgestimmt und vereinbart war. ${ }^{239}$

Die Vorteile kooperativen Verwaltungshandelns liegen vor allem in der Mobilisierung von Sachverstand und der Gewinnung von Informationen, die nur von den Betroffenen selbst eingebracht werden können, in der Erreichbarkeit von Steuerungszielen, die - weil über das gesetzlich Gebotene hinausgehend - durch einseitiges Handeln nicht er-

233 M.Hutter, Die Produktion von Recht: Eine selbstreferentielle Theorie der Wirtschaft, angewandt auf den Fall des Arzneimittelpatentrechts, Tübingen 1989, S.90ff., 126.

234 Vgl. nur E.-H.Ritter, Staatliche Steuerung bei vermindertem Rationalitätsanspruch? in: Jahrbuch zur Staats- und Verwaltungswissenschaft 1987, S.321ff.; ders., Das Recht als Steuerungsmedium im kooperativen Staat, in: D.Grimm (Hrsg.), Wachsende Staatsaufgaben, 1990, S.69ff.; M.Bullinger, Kooperatives Verwaltungshandeln (Vorverhandlungen, Arrangements, Agreements und Verträge) in der Verwaltungspraxis, DÖV 1989, S.277ff.; J.Ipsen, Die Bewältigung der wissenschaftlichen und technischen Entwicklungen durch das Verwaltungsrecht, VVDStRL 48, 1990, S.178ff, 193ff.; N.Dose/R.Voigt (Hrsg.), Kooperatives Recht, 1995; Trute, Die Verwaltung und das Verwaltungsrecht zwischen gesellschaftlicher Selbstregulierung und staatlicher Steuerung, DVBl 1996, 950ff.

235 So z.B. P.Arnold, Die Arbeit mit öffentlich-rechtlichen Verträgen im Umweltschutz beim Regierungspräsidium Stuttgart, Verwaltungs-Archiv 1989, S.125-142.

236 E.Bohne, Der informale Rechtsstaat, 1981.

237 Vgl. dazu schon oben Kap. 1 V. 3. a) zu Vollzugsdefiziten bei unbestimmten Normen.

238 N.Dose/R.Voigt, Kooperatives Recht: Norm und Praxis, S.11.

239 E.-H.Ritter, Recht als Steuerungsmedium, S.84. 
reicht werden könnten, im Zeitgewinn bei der Abwicklung von komplexen Verfahren durch frühzeitige Einbindung der Betroffenen und Ausräumung von Bedenken, im Gewinn an funktionaler Legitimität und Akzeptanz sowie in der Vermeidung von Vollzugsdefiziten durch Selbstbindung der Regelungsadressaten. Die Gefahren liegen hingegen in einer Selektivität der Interessenberücksichtigung, in einem Ungleichgewicht der Verhandlungspositionen, sofern der Staat immer mit einseitiger Rechtsdurchsetzung drohen kann, in der Gefährdung der Verfahrensteilhabe Dritter sowie in einer Erschwerung von rechtsstaatlicher Kontrolle und effektivem Rechtsschutz. ${ }^{240}$ Das informale Verwaltungshandeln ist deshalb aus rechtsstaatlicher Sicht in die Kritik geraten. ${ }^{241}$ Ritter hat daher vorgeschlagen, das kooperative Staatshandeln durch prozedurale Regeln zu formalisieren und damit rechtsstaatlicher Kontrolle zugänglich zu machen. Nötig seien etwa Regelungen über die Organisation und Konstitution der Akteure und deren Kompetenzen, die staatliche Vorgabe von Zielen sowie die Setzung von äußeren Grenzen, die Angabe von Abwägungsgesichtspunkten und Entscheidungskriterien, Regeln über die Zulässigkeit von Mitteln, über die Haftung, über die Verbindlichmachung der Ergebnisse von Kooperationsprozessen, über das Verfahren sowie schließlich Transparenzregeln, die eine öffentliche Kontrolle ermöglichen. ${ }^{242}$

Was die Rolle der Verwaltung in diesem Prozeß der kooperativen Normkonkretisierung und -vollziehung betrifft, so hat Ladeur den situativ-flexiblen Umgang mit Recht durch Abwägung zum neuen Paradigma des Verwaltungsrechts erhoben ${ }^{243}$. Vor dem Hintergrund der postmodernen Verunsicherung der Wissenschaft ${ }^{24}$ hat Ladeur insbesondere am Beispiel des Umweltrechts herausgearbeitet, daß der Informationsbedarf des Rechtssystems derart gesteigert worden ist, daß er nicht mehr in allgemeinen Rechtssätzen verarbeitet werden kann. Rechtsfortbildung in der Rechtsanwendung erfolgt nicht mehr implizit durch Interpretation, sondern explizit, proaktiv und systematisch, das Recht ist situativ flexibel. ${ }^{245}$ Das Problem des Rechts besteht dabei im Umgang mit Ungewißheit, in der Unvollständigkeit des Wissens über Gefahren und Risiken neuer Techniken, aber auch über die Risiken der Risikoregulierung. Wo jede Entscheidung der Verwaltung unter Ungewißheitsbedingungen selbst ein Risiko ist ${ }^{246}$, muß die Arbeitsweise der Verwaltung auf eine prozedurale Rationalität des Provisorischen umgestellt werden. ${ }^{247}$ Damit meint Ladeur die Orientierung des staatlichen Handelns an Lernfähigkeit. Angesichts einer ungewissen Zukunft müssen Entscheidungen revisibel sein, Handlungsoptionen müssen offengehalten werden und Alternativenreichtum sowie In-

240 Vgl. etwa die Aufstellung von Vor- und Nachteilen bei E.-H.Ritter, Recht als Steuerungsmedium, S.78ff.

241 Vgl. W.Brohm, Rechtsstaatliche Vorgaben für informelles Verwaltungshandeln, DVBl. 1994, S.133ff. m.w.N.; H.Schulze-Fielitz, Kooperatives Recht im Spannungsfeld von Rechtsstaatsprinzip unf Verfahrensökonomie, in: N.Dose/R.Voigt (Hrsg.), Kooperatives Recht, 1995, S.225ff. m.w.N.

242 E.-H.Ritter, Recht als Steuerungsmedium, S.87f.

243 K.-H.Ladeur, Abwägung - Ein neues Paradigma des Verwaltungsrechts, Ffm 1984.

244 Vgl. K.-H.Ladeur, Perspektiven einer post-modernen Rechtstheorie, Rechtstheorie 1985, S.383-427; ders., Postmoderne Rechtstheorie: Selbstreferenz - Selbstorganisation - Prozeduralisierung, Berlin 1992.

245 K.-H.Ladeur, "Prozedurale Rationalität" - Steigerung der Legitimationsfähigkeit oder der Leistungsfähigkeit des Rechtssystems?, ZfRSoz 1986, S.265ff, 269; vgl. dazu auch E.Denninger, Technologische Rationalität, S.123ff.

246 S.o. Kap.1 IV. 3. Risikogesellschaft und Präventionsstaat.

247 Ders., Das Umweltrecht in der Wissensgesellschaft, S.131ff. 
novationsfähigkeit müssen gesteigert werden. Zudem müssen begleitende Beobachtungs- und Kontrollpflichten festgelegt werden, die auf eine ständige Korrektur des unter Ungewißheitsbedingungen stets vorläufigen Verwaltungshandelns zielen. ${ }^{248}$ Rechtliches Entscheiden muß also einerseits auf prozeßhafte Selbstrevision angelegt werden (Lernfähigkeit des Rechts), andererseits soll das Recht durch die Konstruktion "kommunikativer Unterbrecher" und den Einbau von "Stopregeln" gegen sich selbst verstärkende Diskurse die Lernfähigkeit anderer Systeme aufrechterhalten und steigern sowie die Durchlässigkeit verschiedener Sprachspiele füreinander ermöglichen (Lernfähigkeit durch Recht).249

Während Teubner und Willke auf einen Rückzug der Gesetzgebung auf die Ermöglichung kooperativer Verhandlungsstrukturen und das Setzen prozeduraler Kontextbedingungen für gesellschaftliche Selbststeuerungsmechanismen setzen, und während Ritter die rechtsstaatliche Formalisierung kooperativen Staatshandelns über prozedurale Regeln für nötig hält, ist das Konzept der prozeduralen Steuerung bei Ladeur schon auf der Ebene des Verwaltungshandelns angesiedelt. Angesichts der zunehmenden Heterogenität und der situativen Ausdifferenzierung gesellschaftlichen und administrativen Handelns hält Ladeur selbst die Festlegung abstrakt-prozeduraler Regeln für überholt. Prozeduralisierning meint bei Ladeur die radikale Flexibilisierung des Rechts und dessen situative Ausgestaltung durch die Verwaltung. Empirisch wird diese These durch die wachsende Unbestimmtheit des Rechts und die Ausrichtung des Verwaltungshandelns am Rechtsobergrundsatz der Verhältnismäßigkeit auch belegt. ${ }^{250}$ Prozedurale Rationalität wird nicht durch Rechtsregeln gewährleistet, sondern auf der Ebene der Verwaltungsrechtsdogmatik als Orientierung an Lernfähigkeit verankert.251 Dieses Mißtrauen gegenüber der Allgemeinheit von Gesetzen liegt darin begründet, daß Ladeur als Anhänger einer Philosophie der Postmoderne deren Postulat vom Ende des Projekts der Aufklärung und damit vom Ende der Vernunftallgemeinheit übernimmt. ${ }^{252}$ Die Übertragung des postmodernen Interesses am Konkreten, Besonderen, Situativen, Pluralen und Widersprüchlichen auf das Recht färbt dabei unweigerlich auf Ladeurs Rechtstheorie ab: die Vielzahl von Veröffentlichungen stellt sich als rekursive Verknüpfung von situativ-flexiblen Wirklichkeitsentwürfen, als Herstellung von pluralen Optionsräumen von Rechts-Beschreibungen in der Zeit dar, wobei sich jede Selbstfestlegung - als bloß ereignishafte Ausgangslage des weiteren Prozessierens von Widersprüchlichkeit dienend - im unendlichen Tanz der sich selbst perturbierenden Kommunikationen verflüchtigt. In der Ablehnung der auch dem aufklärerischen Konzept von Theorie eigenen Verallgemeinerungen stellt sich Ladeurs postmoderne Rechtstheorie insofern konsquent als "Anti-Theorie" dar, was deren zusammenfassende Darstellung allerdings nicht unerheblich erschwert. 253

248 Ders., Selbstorganisation sozialer Systeme und Prozeduralisierung des Rechts, in: D.Grimm (Hrsg.), Wachsende Staatsaufgaben, 1990, S. $187 \mathrm{ff}$., $205 \mathrm{ff}$.

249 Ders., Lernfähigkeit des Rechts und Lernfähigkeit durch Recht, in: A.Görlitz (Hrsg.), Postinterventionistisches Recht, 1990, S.141-148.

250 S.o. Kap. 1 V. 1. Zur Krise des Rechtsstaats.

251 K.H.Ladeur, Prozedurale Rationalität, S.269; vgl. dazu auch die Kritik bei I.Maus, Perspektiven reflexiven Rechts, S.390ff.

252 Vgl. K.-H.Ladeur, Postmoderne Rechtstheorie.

253 Kritisch schon J.Nocke, Autopoiesis - Rechtssoziologie in seltsamen Schleifen, S.389. 


\section{e) Rechtsprechung}

Was bedeutet Prozeduralisierung des Rechts nun für die Rechtsprechung? Zunächst soll versucht werden, die "assoziativ-aphoristischen" (Selbstbeschreibung ${ }^{254}$ ), "oft kryptischen" (Fremdbeschreibung ${ }^{255}$ ) Ideen von Wiethölter ${ }^{256}$ darzustellen. ${ }^{257}$ Zwischen hyperzyklisch und episodenverknüpfend zusammengestellten "Berichten und Fragen"258 läßt sich folgendes herauslesen: Rechtsprechung war schon immer, und ist angesichts der zunehmenden Unbestimmtheit des gesetzlichen Rechts um so mehr Recht-Fertigung im systemischen Sinne von Rechtsproduktion, bzw. im kommunikativen Sinne von Normbegründung in Anwendungsdiskursen. Systemtheorie und Diskurstheorie zielen im Kern auf geänderte, verbesserte Institutionalisierung von Verfahren vernünftiger Willens- und Entscheidungsbildung. Die Frage der Zulässigkeit richterlicher Rechtsfortbildung stellt sich in diesem Zusammenhang als Problem der Gewinnung von Maßstäben, der Bestimmung von Foren und der Ausgestaltung von Verfahren der Rechtsgewinnung dar. Die Aufgabe der Rechtsprechung ist dabei die Kontrolle über AutonomieKompetenz-Rechtswahmehmungen durch - fremdbestimmende, ihrerseits aber auch autonome - Rechtswahrnehmung, kurz: die Kontrolle von Autonomie. Anhand der Rechtsprechung des BVerfG zur richterlichen Rechtsfortbildung zeigt Wiethölter, daß es nicht um deren Zulässigkeit an sich, sondern um die Abstimmung und Vermittlung zwischen kollidierenden Kompetenzwahrnehmungen geht, wenn etwa dem Bundesarbeitsgericht eine Rechtsfortbildungskompetenz über Konkursrecht abgesprochen wird. 259

Es geht um Kontrollprinzipien für die Aufhebungen kontrollierbarer Kompetenzwahrnehmung durch kontrollierende Kompetenzwahrnehmung, dem Internationalen Privatrecht entsprechend also um eine Art Kollisionsrecht. Betroffen sind dabei nicht nur Kontrollen von Verfassungsgerichten über Fachgerichte, sondern auch Kontrollen von Gerichten über Parlamente, Behörden, Unternehmen, Verbände, Private, oder von Verbänden über Mitglieder, von Unternehmen über Gesellschafter, von Privaten über Private. Das Kontrollproblem besteht darin, daß beanspruchte Autonomie nicht schon Gewährleistung dezentralen und sektoralen Allgemeinwohls, sondern ihrerseits Partei ist, der man Aktivitäten nur um den Preis sachlich gerechtfertigter Maßstabsbildungen, offen gehaltener Foren und eingehaltener Faimeß-Verfahren, kurzum: relativer Unparteilichkeit und Verallgemeinerbarkeit freigeben kann. Die Rechtsprechung hat auf dieses Problem entweder formal (etwa: wenn korrekte Satzungsgrundlage, faires Verfahren, kein ordre-public-Versto $\beta$, dann autonome Maßnahme zu billigen), oder material (Abwägung betroffener Rechtsverletzungen mit der Folge, daß Gerichte materielle Kriterien etwa von "Gewerkschaftsfeindlichkeit" bilden müssen) reagiert.

254 R.Wiethölter, Rechtsstaatliche Demokratie und Streitkultur, KJ 1988, S.403.

255 G.Teubner, Recht als autopoietisches System, S.132.

256 Vgl. R.Wiethölter, Entwicklung, S.38ff;; ders., Materialisierungen und Prozeduralisierungen von Recht, in: G.Brüggemeier/C.Joerges (Hrsg.), Workshop zu Konzepten des post-interventionistischen Rechts, Bremen: ZERP Materialien 4, S. 25ff., wiederabgedruckt in G.Teubner (Hrsg.), Dilemmas of Law in the Welfare State, S.221ff.; ders., Proceduralisation of the Category of Law, in Joerges/Trubek (Ed.), Critical Legal Thought, Baden-Baden 1989, S.501ff.

257 Ein Versuch der Zusammenfassung findet sich auch bei Martin/Renk/Sudhof, Maßstäbe, Foren, Verfahren: Das Prozeduralisierungskonzept Rudolf Wiethölters, KJ 1989, S.244ff.

258 R.Wiethölter, Rechtsfortbildung, S.1ff.

259 R.Wiethölter, Rechtsfortbildung, S.5f. 
Einen Ausweg aus diesem alten Elend reiner Formalisierungen sowie dem neuen Elend reiner Materialisierungen sieht Wiethölter in einer Prozeduralisierung. Prozedurales Recht als Einrichtung und Ausübung von inhaltsrechtlich orientierter Verfahrensqualität zielt auf eine autonome Wahrnehmung von jeweiligen Eigeninteressen zugleich als Allgemeininteresse. Diese Formulierung erinnert stark an das Modell von Teubner und Willke, autonome Diskurse durch prozedurale Regeln auf die Reflexion von Allgemeinwohlinteressen auszurichten. Rechtsprechung hat dann die Aufgabe der externen Kontrolle nicht $\mathrm{zu}$ rechtfertigender interner Prozeduren durch Recht-Fertigung von Struktur-Verbesserungen und Funktions-Sicherungen. "Wenn im Maße verbesserter Innenwelt-Aktivitäten wegen der - auf (gerichtliche) Kontrollen hin - gebilligten Maßstäbe, Foren und Verfahren die jeweilige Autonomie im Recht frei ist und bleibt, dann ändert sich gesellschaftliches Lernen en gros und en détail nicht durch Befehl und Gehorsam, nicht durch Vergerichtlichung und Verrechtlichung, sondern systemisch, kommunikativ und ökonomisch." 260

Ansätze für eine solche Ausrichtung an Prozeduralisierung findet Wiethölter in einer Tendenz der Rechtsprechung, Auflagen an die Qualität der Begründung überprüfter Entscheidungen etwa des Gesetzgebers oder der Verwaltung zu stellen. Die Aufgabe der Rechtsprechung ist es, Autonomie als Selbst-Bestimmung ernst zu nehmen, und gleichwohl unerläßliche Externalisierung (Kontrolle) nicht als Fremd-Bestimmung, sondern als mögliche Hilfe in Lagen unmöglicher Selbsthilfe - nicht unähnlich Beratungs-Hilfen und Verträglichkeitsstiftungen außerhalb von Recht - zu verstehen. ${ }^{261}$

In Anlehnung an Wiethölters Ideen sieht Teubner die Aufgabe von Rechtsprechung und Rechtsdogmatik in der Entwicklung eines intersystemischen Kollisionsrechts. ${ }^{262}$ Die von vielen Autoren als Deformation formal-rationalen Rechts interpretierte zunehmende Unbestimmtheit des Rechts sowie dessen Öffnung gegenüber politischen, wirtschaftlichen und sozialen Interessen (Materialisierung) ${ }^{263}$ versteht Teubner als zwingende Reaktion des Rechts auf die Ausdifferenzierung der Gesellschaft in autopoietische Subsysteme. Die gestiegene Komplexität seiner innergesellschaftlichen Umwelt kann das Recht nicht mehr in Form allgemeiner Gesetze und widerspruchsfreier Dogmatik abbilden. Bei Beibehaltung seiner operativen Geschlossenheit über den Rechtscode reagiert das Rechtssystem deshalb mit einer inneren Differenzierung und situativen Anpassung seiner Programme, was zu hoher Unbestimmtheit führt. An die Stelle einer durch Dogmatik garantierten Einheit des Rechts tritt eine Vielheit von funktionalen Rechtsterritorien, die miteinander in Konflikt treten.

Auf diese Konflikte will Teubner in Anlehnung an das Internationale Privatrecht, das als Kollisionsrecht die Konflikte zwischen unterschiedlichen nationalen Rechtsordnungen betrifft, mit der Entwicklung eines intersystemischen Kollisionsrechts reagieren, das auf Konflikte zwischen unterschiedlichen Teilsystemrationalitäten zugeschnitten ist. Teubner unterscheidet dabei drei mögliche Arten von Konflikten: erstens Konflikte zwischen gesellschaftlichen Teilsystemen, zweitens Konflikte zwischen staatlichem Recht

260 R.Wiethölter, Rechtsfortbildung, S.22.

261 R.Wiethölter, Rechtsfortbildung, S.27f.

262 G.Teubner, Recht als autopoietisches System, Kap. 6, S.123ff.

263 S.o. Kap. 1 V. 1, zur Krise des Rechtsstaats. 
und pluralen gesellschaftlichen Quasi-Rechtsordnungen und drittens Konflikte zwischen Teilrechtsordnungen innerhalb des staatlichen Rechts. ${ }^{264}$

Bezüglich des ersten Konfliktfeldes stellt sich zunächst die Frage, ob eine Verrechtlichung des Konflikts überhaupt wünschenswert ist oder ob das Recht Kollisionsnormen entwickeln kann, die durch Verrechtlichung der Verrechtlichung entgegenwirken. Sodann ist fraglich, ob das Recht sich mit formalen Verweisungen auf die Rationaliät eines der konfligierenden Systeme begnügt, oder aus dem Konflikt eigenständige Sachnormen durch Kompatibilisierung unterschiedlicher Rationalitäten entwickeln muß, eventuell sogar über eine Kompatibilisierung hinaus gesamtgesellschaftliche Interessen einbringen kann. Teubner hält solche Aktivitäten des Rechts für möglich, verweist aber gleichzeitig auf die Ausweichstrategie einer sekundären Verrechtlichung von konfliktlösenden Intersystembeziehungen, die statt an konkreten Ergebnissen an den organisatorischen und verfahrensmäßigen Prämissen solcher Prozesse ansetzt. Bezüglich des zweiten Konfliktfeldes hat Teubner an der modernen Praxis der gerichtlichen Inhaltskontrolle gesellschaftlichen Rechts durch Erarbeitung eigenständiger Sachnormen (Beispiel: Inhaltskontrolle von AGB anhand der Generalklausel des $\S 9$ AGBG) nichts auszusetzen, möchte die dabei vorgenommene Interessenabwägung jedoch um eine systemische Sichtweise ergänzen. Zudem sollen die Kontrollen darauf ausgerichtet sein, daß systemexterne Interessen durch Verfahren und Organisation internalisiert werden. Bezüglich des dritten Konfliktfeldes favorisiert Teubner die bloße Kompatibilisierung autonomer Teilrechtsordnungen zusammen mit dem reflexiven Einbau funktionaler Grundprinzipien der anderen Teilrechtsordnungen. ${ }^{265}$

Das Einfallstor, über das Rechtsprechung und Rechtsdogmatik solche Kollisionsregeln im Wege der Rechtsfortbildung produzieren können, findet Teubner ebenso wie Wiethölter gerade in der Unbestimmtheit des Rechts: Im Öffentlichen Recht ist es der Rechtsobergrundsatz der Verhältnismäßigkeit, im Zivilrecht sind es die Generalklauseln, die der Rechtsprechung eine situativ-flexible Bestimmung des Verhältnisses von Autonomie und Kontrolle am konkreten Fall ermöglichen. Dabei unterscheidet Teubner für jeden Fall ausgeübter Autonomie (konkret am Beispiel des Vertrags) drei Ebenen: Interaktions-, Institutions- und gesamtgesellschaftliche Ebene.

\footnotetext{
"Es muß für jede der drei Ebenen entschieden werden, ob eine Verweisung auf selbstregulatorische soziale Mechanismen in Frage steht (Standards), oder ob ein Versagen solcher Steuerungsmechanismen eine kompensatorische rechtliche Formulierung von Verhaltensanforderungen (Direktiven) notwendig macht. Die richterliche Diagnose darüber, ob und inwieweit auf der jeweiligen Ebene Selbststeuerung funktioniert, entscheidet dann über die Therapie..."266
}

Interaktionsversagen führt dann zur richterlichen Definition objektiver Vertragszwecke und Verhaltenspflichten, auf der Institutionsebene führt Marktversagen zur Ersetzung der bloßen Übernahme von Verkehrssitten und Handelsbräuchen durch Richterrecht und auf der gesamtgesellschaftlichen Ebene führt Politikversagen zur richterlichen Entscheidung, wie public policy im Einzelfall extra oder contra legem zu definieren ist. Die Kriterien für den richterlichen Aktivismus (Direktiven) soll der Richter dabei gewinnen, indem er eine funktionierende Selbststeuerung des versagenden Systems simuliert, also

264 G.Teubner, Recht als autopoietisches System, S.133ff.

265 Die Ausführungen werden hier - wie auch sonst - teilweise im Originalton wiedergegeben, um deutlich zu machen, wo die argumentativen Schwachzonen der Theorien liegen.

266 G.Teubner, Recht als autopoietisches System, S.144. 
etwa eine ergänzende Vertragsauslegung am mutmaßlichen Willen der Parteien orientiert 267. Die Paralelle zu Kants Idee vom demokratischen Verfahren als "Probierstein"268 für die Rechtmäßigkeit eines (undemokratisch erlassenen) Gesetzes liegt auf der Hand.

\section{f) Einige Probleme}

Die Konzepte des reflexiven Rechts und der Prozeduralisierung sind in der Rechtstheorie auf großes Interesse gestoßen und haben eine Vielzahl von engagierten Kritiken herausgefordert. Soweit die Kritik sich gegen das Autopoiesekonzept richtet, soll an dieser Stelle - soweit sich die Kritik nicht inzwischen selbst erledigt hat ${ }^{269}$ - nicht darauf eingegangen werden, da auf die Vor- und Nachteile der autopoietischen Systemtheorie als Gesellschaftsmodell später zurückgekommen wird. ${ }^{270}$ Recht emotionale Kritik macht sich am "Steuerungspessimismus" von Teubner und Willke fest. ${ }^{271}$ Nach Abzug der nicht des Eingehens werten Polemik ${ }^{272}$ beruht diese Kritik auf einem Mißverständnis: Denn vor dem Hintergrund des konsentierten Bestehens einer Steuerungskrise des Rechts ${ }^{273}$ dient die Autopoiesetheorie Teubner lediglich zur genaueren begrifflichen Analyse der Steuerungsprobleme, um Auswege zu suchen. Teubner und Willke sind insoweit gerade an der Fortentwicklung von politischen Steuerungsmöglichkeiten interessiert. Unter dem Gesichtspunkt der weiteren Diskussion scheinen allerdings zwei Kritikpunkte von Interesse zu sein.

Ein genereller Einwand bezieht sich auf die Fähigkeit eines prozeduralisierten Rechts, Gerechtigkeit zu gewährleisten. Der Vorwurf lautet, ein von materiellen Standards abstrahierendes prozedurales Recht, das lediglich Rechte auf Verfahrensteilhabe einräume, bevorzuge die gut ausgebildeten, ökonomisch starken Ellenbogen-Egoisten, die sich in bloß prozedural geregelten Verfahren der Konfliktlösung auf Kosten der "besitzlosen Volksklassen" durchsetzen würden. ${ }^{274}$ Dem kann man nur entgegenhalten, daß Freiheit schon immer eine Theorie des Selbermachen-Müssens enthielt. ${ }^{275}$ Mit Habermas kann man auch sagen, daß Rechte nicht verzehrt sondern ausgeübt werden müssen. Die Alternative besteht nur in einem sozial-autoritären Paternalismus. Ein prozeduralisiertes Recht kann auf diese Bedenken allerdings reagieren, indem es gerade durch prozedurale Rechtsregeln die faktisch vorhandenen Ungleichheiten kompensiert und so für

267 Ders., a.a.O., S.144ff.

268 S.o. Kap. 1 II. 3. d).

269 So hat etwa R.Münch seine Fundamentalkritik (Die sprachlose Systemtheorie. Systemdifferenzierung, reflexives Recht, reflexive Selbststeuerung und Integration durch Indifferenz, ZfRSoz 1985, S.19ff.) insoweit aufgegeben, als er sein Konzept der "Risikopolitik" (Ffm 1996) als Synthesemodell unter weitgehender Übernahme systemtheoretischer Erkenntnisse formuliert.

270 S.u. II. 1. und III.

271 Vgl. etwa P.Nahamowitz, Autopoietische Rechtstheorie: mit dem baldigen Ableben ist zu rechnen, ZfRSoz 1990, S.137ff.; ders., Steuerung durch Recht und Steuerung des Rechts, ZfRSoz 1992, S.27lff.; M.Deckert, Steuerung durch Recht - oder: mehr Mut zur Normierung im Umwelt- und Technikrecht, ZRP 1995, S.63ff.

272 Vgl. dazu schon die deutlichen Worte von N.Luhmann, Steuerung durch Recht? Einige klarstellende Bemerkungen, ZfRSoz 1991, S.142ff.

273 S.o. Kap. 1 V. 3.

274 N.Dimmel, Das egoistische Recht und die besitzlosen Volksklassen. Versprechen und Wirkung prozeduralen Rechts, ZfRSoz 10 (1989), S.50-66.

275 S.o. Kap. 1 IV. 1. 
ein Gleichgewicht der Verhandlungschancen sorgt. Diese Strategie kann durch eine als Staatsbürgerqualifikationspolitik verstandene Sozialpolitik ergänzt werden. ${ }^{276}$

Der zweite Kritikpunkt bezieht sich auf die Vereinbarkeit des reflexiven Rechts mit den Prinzipien des demokratischen Rechtsstaats. ${ }^{277}$ Während in den klassischen Bereichen gesellschaflicher Selbststeuerung über Privatautonomie, Satzungsautonomie und Selbstverwaltungsrecht dem Demokratieprinzip durch Mitgliedschaftsrechte und eine "demokratische Verfassung" von Vereinen, Gesellschaften, Verbänden, Kammern und Körperschaften Rechnung getragen wird, entstehen Probleme, wo der subsystemische Diskurs etwa der Wirtschaft oder der Wissenschaft mit Autonomie i.S.v. Selbstgesetzgebungsrecht ausgestattet werden soll. Kann man den Wirtschaftsdiskurs in Grenzen noch durch Mitbestimmungsregeln demokratisieren, so stellt sich die Legitimationsfrage umso schärfer, wenn reine Expertengremien wie etwa die medizinischen Ethikkommissionen über die Zulässigkeit von Gentherapie entscheiden. ${ }^{278}$

Aus rechtsstaatlicher Sicht ist hingegen die insbesondere bei Ladeur, aber auch bei Teubner und Wiethölter festzustellende Tendenz bedenklich, die reflexive Sichtblende der Trennung zwischen Normieren des Normierens und nachfolgendem normiertem Normieren ${ }^{279}$ einzureißen, indem Normbegründung und Normanwendung in Verwaltung und Rechtsprechung verschmolzen werden. Zu Recht hat Maus darauf hingewiesen, daß ein Mindestma $\beta$ an Fairneß von Verfahren nur dann zu erwarten ist, wenn die Verfahrensregeln selbst in Unkenntnis zukünftiger in diesem Verfahren zu bearbeitender Konflikte festgelegt werden. Wenn Ladeur hingegen auf gesetzlich vorab festgelegte Verfahrensregeln zugunsten einer situativ-flexiblen Vergabe von Teilnahmerechten durch die Verwaltung verzichtet, wird der unter dem Stichwort der Krise des Rechtsstaats diskutierte Zusammenbruch rechtsstaatlicher Reflexivität nochmals potenziert: Beteiligungschancen an den Konsensaushandlungsprozessen werden erst nach Maßgabe des "öffentlichen Interesses" je nach staatlichem Informations- und Legitimationsbedarf vergeben, und die faktischen gesellschaftlichen Machtpositionen werden in den Verhandlungsposition blo $\beta$ reproduziert. ${ }^{280}$

Ähnlich problematisch ist auch Teubners Vorstellung von der über Generalklauseln vermittelten Simulation von gesellschaftlicher Selbststeuerung in den Köpfen der Richter. Zunächst fehlt jede Angabe dazu, nach welchen Kriterien und Maßstäben die "richterliche Diagnose" über "Selbststeuerungsversagen" zustandekommen soll. Es verwundert, daß gerade der Konstruktivist Teubner nicht weiter darüber nachdenkt, daß eine solche Diagnose immer eine streng rechtsinterne Konstruktion der Außenwelt ist, die mit tatsächlichem Steuerungsversagen nichts zu tun haben muß. Teubner, der das Recht sonst schon einmal gern als "normhungriges Monster" bezeichnet, das die Menschen und ihre Konflikte zwecks Fortsetzung seiner Autopoiese durch Normproduktion "versklavt"281, scheint hier blind gegenüber dem Problem zu sein, daß das Recht aus reinem Normenhunger jeden externen Konflikt intern als Versagen mißverstehen könnte. Das

276 S.o. Kap. 1 V. 2.

277 Vgl. dazu I.Maus, Perspektiven reflexiven Rechts, S.390ff.; E.-H.Ritter, Recht als Steuerungsmedium, S.101ff.

278 Siehe dazu ausführlich unten Kap. 3 IV.

279 S.o. 2. d).

280 I.Maus, Perspektiven reflexiven Rechts, S.402ff.

281 M.Hutter/G.Teubner, Der Gesellschaft fette Beute: Homo juridicus und homo oeconomicus als kommunikationserhaltende Fiktionen, Sociologia Internationalis 1993. 
Problem liegt hier paralell zu den Problemen, die im Rahmen von Alexys prozeduralen Prinzipien diskutiert wurden. 282

Was schließlich die Möglichkeit von Selbststeuerungssimulation im Kopf des Richters angeht, so müßten die Aussagen von Kant zur autokratischen Staatsform (Gesetzgebung und Gesetzesanwendung sind in einer Person vereinigt) etwa wie folgt abgewandelt werden: Mangels vorhandener Institutionalisierung von Selbststeuerungsmechanismen in einem Subsystem kann die richterliche Simulation von Selbststeuerung zwar als "Probierstein" der richterlichen Rechtsschöpfung dienen. Dieses Simulationsprinzip gilt allerdings nur subsidiär bis zur Errichtung tatsächlicher Selbststeuerung, da auch "Engelsweisheit" (höchste Reflexionsfähigkeit) eines Richters deren Funktion nicht ersetzen kann. Und: Selbststeuerungssimulation, bei der der Richter die Regeln, die er anwendet, gleichzeitig erst erfindet, als Steuenungsform ist "die gefährlichste fürs Volk (reguliertes System), in Betracht des Despotismus (Interventionismus), zu dem sie so sehr einladet"283. Es fragt sich, ob der Richter seine Energien nicht besser auf die Unterstützung tatsächlicher Selbststeuerungsfähigkeit verwendet.

\section{g) Festzuhaltendes: die Kollision gesellschaftlicher Diskurse}

Zusammenfassend kann festgehalten werden, daß sich die moderne Kommunikationsgesellschaft angemessen nur noch im Bild eines polyzentrischen, heterarchisch organisierten Netzwerks beschreiben läßt. Durch funktionale Spezialisierung haben sich innerhalb der Gesellschaft anhand von Codes verschiedene Spezialdiskurse ${ }^{284}$ ausdifferenziert, die als Subsysteme mit der Steigerung von Selbstreferenz an Autonomie gewinnen, streng systeminterne Wirklichkeiten produzieren und Teilrationalitäten ausbilden. In diesem heterarchischen Kommunikationsnetzwerk verliert der Staat aufgrund des Prinzips der potentiellen Führung seine herausgehobene Stellung als alleiniger Repräsentant des Ganzen, der vom Zentrum her die Gesellschaft im Hinblick auf das Allgemeinwohl steuert. Die gesellschaftliche Diskursvielfalt stellt sich für Gesellschaftssteuerung als Problem der dreifachen Autopoiese der beteiligten Systeme Politik, Recht und reguliertes System dar. Auf die Potenzierung und Multiplikation von gesellschaftlicher Autonomie kann/soll das Recht reflektieren, indem das Verhältnis von Autonomie und Kontrolle prozeduralisiert wird. Reflexives Recht zielt auf eine rechtliche Überformung von gesellschaftlichen Selbststeuerungsmechanismen durch prozedurale Regeln über Kompetenzen, Organisation und Verfahren. Rechtliche Kontrolle soll im Sinne einer Hilfe-zur-Selbsthilfe gesellschafliche Autonomieausübung supervidieren, indem die Maßstäbe, Foren und Verfahren überprüft und verbessert werden, anhand derer sich die Rechtsausübungen dezentraler Diskurse als nicht nur an Eigeninteresse orientiert, sondern auch auf das Allgemeinwohl bezogen und damit verallgemeinerungsfähig ausweisen. Auf der materiellen Ebene wird der Mechanismus von Befehl und Gehorsam durch Formen der Kooperation und der Selbstbindung ersetzt. Effektivität und Legitimität des Rechts können so gleichzeitig gesteigert werden.

\section{S.o. I. 1. d).}

283 S.o. Kap. 1 II. 3. d) mit Nachweisen.

284 Das Verständnis von Subsystemen als Spezialdiskurse setzt einen neutralen Begriff von Kommunikation voraus, der den Begriff "Diskurs" nicht wie bei Habermas von vornherein gegenüber kommunikativem und strategischem Handeln abgrenzt: vgl. G.Teubner, Die Episteme des Rechts, S.115ff.; dazu ausführlich unten II. 2. u. III. 1. 


\section{Probleme einer Theorie prozeduralen Rechts}

Nach dieser Vorstellungsrunde verschiedener Ansätze zur Prozeduralisierung des Rechts soll im folgenden versucht werden, eine Theorie prozeduralen Rechts zu entwerfen, die im Verlauf des dritten Kapitels konkretisiert wird. Der Begriff Theorie steht dabei für Abstraktion, Verallgemeinerung und begriffliche Schärfe. Ziel ist es, das Allgemeine aus dem Besonderen der Ansätze herauszuarbeiten und zu einer im Recht verwendbaren Definition prozeduralen Rechts zu verdichten. Dabei ergeben sich eine Reihe von Problemen. Die vorgestellten Ansätze zur Prozeduralisierung sind schwer zu vergleichen (a), die methodische Position, aus der die Theorie entworfen werden soll, muß festgelegt werden (b), und schließlich ist zu klären, was mit dem Gegenstand "Recht" dieser Theorie gemeint sein soll (c).

\section{a) Probleme der Vergleichbarkeit der Ansätze zur Prozeduralisierung}

Auf den ersten Blick scheinen die vorgestellten Ansätze zur Prozeduralisierung des Rechts nur schwer vergleichbar zu sein. In der juristischen Argumentationstheorie von Alexy beschäftigt sich das Recht ausschließlich mit sich selbst und seiner Beziehung zur Moral. Aus einer normativen Teilnehmerperspektive wird die Anwendung von Normen analysiert und auf ihre Verbesserungsfähigkeit untersucht. Als Hintergrundtheorien dienen verschiedene argumentations-, diskurs- und entscheidungstheoretische Ansätze (s.o.1.). Die Habermassche Diskurstheorie des Rechts bezieht demgegenüber die Politik mit ein, indem eine Theorie der diskursiven demokratischen Gesetzgebung begründet und deren Verhältnis zur richterlichen Argumentation diskutiert wird. Aus einer normativ-soziologischen Doppelperspektive wird insbesondere der legitimen Entstehung und Verarbeitung von Recht nachgegangen (s.o.2.). Die Theorie des reflexiven Rechts ist vor allem eine soziologische Recht-in-der-Gesellschaft-Theorie. Als Hintergrundtheorie dient die Systemtheorie. Wenn dies auch eher für eine anormative Beobachterperspektive spricht, so sind mit dem reflexiven Recht auch normative Ansprüche verbunden, weshalb Teubner von einem normativ-analytischen Doppelstatus spricht ${ }^{285}$ (s.o.3.). Je breiter der Gegenstandsbereich der Theorien ist, desto weniger konkret sind diese im Detail. Sind die Theorien deshalb wechselseitig inkompatibel? Müßßte erst eine gesellschaftstheoretische Großdebatte unter dem Motto "Theorie der Gesellschaft oder Sozialtechnologie"286 ausgefochten werden, um hier weiterzukommen? Ich meine nein!

Wie in Aufbau, Art der Darstellung und Überschriften der Vorstellungsrunde zum Ausdruck kommt, handelt es sich bereits um eine hochselektive, interpretative Aufbereitung der Ansätze: das Gemeinsame findet sich danach in der Beschreibung des Rechts als Diskurs, wenn auch der Begriff Diskurs unterschiedlich verstanden wird ${ }^{287}$. Während Habermas den Begriff Diskurs ursprünglich in Abgrenzung vom Begriff des kommunikativen oder strategischen Handelns als eine handlungsentlastete mündliche Diskussion in einer idealen Sprechsituation bestimmte (Leitbild: Universitätsseminar), verbindet der Diskurs der politischen Normbegründung später subjektlos und dezentriert

285 G.Teubner, Recht als autopoietisches System, S.86.

286 Vgl. J.Habermas/N.Luhmann, Theorie der Gesellschaft oder Sozialtechnologie - Was leistet die Systemforschung?, Ffm 1971.

287 Vgl. zum Diskursverständnis bei Habermas, Foucault und Luhmann: G.Teubner, Die Episteme des Rechts, 1990. 
die Zivilgesellschaft mit Recht und Politik (Leitbild: Vernetzung unterschiedlicher Arenen und Foren) und erhält damit einen systemtheoretischen Einschlag (s.u. II. 2.). Bei Alexy ist der Diskursbegriff hingegen von Anfang an realitätsnäher als diskursive Auseinandersetzung mit sämtlichen in der (rechts-) wissenschaftlichen Diskussion vorgetragenen Argumenten bestimmt (Leitbild: richterliche Urteilsbegründung). Demgegenüber ist der von Teubner im Anschluß an Luhmanns Begriff der Kommunikation verwendete Diskursbegriff weiter, da auf einen schon im Begriff enthaltenen Rationalitätsanspruch zu Gunsten der aus Sicht der Handelnden zufälligen Selbstreproduktion von Kommunikation verzichtet wird (Leitbild: Surfen im Internet).

Den verschiedenen Ansätzen ist gemeinsam, daß das Recht als System von Handlungen und Kommunikationen verstanden wird, daß sich durch ein Raum und Zeit, konkrete Personen und Institutionen übergreifendes Aneinander-Anknüpfen von Kommunikationen, die Anspruch auf Geltung im Recht erheben, als juristischer Diskurs konstituiert. Wie man es dabei mit dem Anspruch auf Richtigkeit hält, richtet sich nach der gewählten theoretischen Perspektive (b), ohne daß die Übereinstimmung in der Betrachtungsweise des Rechts als System von kommunikativen Prozeduren aufgehoben würde. An diese Übereinstimmung kann angeknüpft werden, ohne daß entschieden werden müßte, welche Theorie richtig oder falsch ist. Von allen dargestellten Ansätzen kann vielmehr das als "Festzuhaltendes" Gekennzeichnete mitgenommen werden, um daraus eine Theorie prozeduralen Rechts zu entwerfen. Dabei soll der Rationalitätsgehalt der Autopoiesetheorie (Reflexion) mit dem Rationalitätsgehalt der Diskurstheorie verbunden werden, wobei die empirischen, analytischen und normativen Gehalte der zu Grunde gelegten Ansätze in unterschiedlichem Ausmaß zur Geltung kommen (s.u. III.).

\section{b) Rechtstheorie: Beobachter versus Teilnehmer}

Man kann das Recht aus einer externen Perspektive beobachten oder aus der internen Perspektive eines Teilnehmers verstehen. ${ }^{288}$ Eine rein normative Betrachtung, verschließt sie sich gegen die sozialwissenschaftliche Entzauberung des Rechts, unterliegt dabei immer der Gefahr, den Kontakt mit der gesellschaftlichen Realität zu verlieren und deshalb in der "Ohnmacht des Sollens" zu verharren. ${ }^{289}$ Eine rein soziologische Beobachtung des Rechts hat N. Luhmann vorgelegt. ${ }^{290}$ Er unterscheidet Selbstbeschreibung (Rechtstheorie) und Fremdbeschreibung (Rechtssoziologie) des Rechtssystems ${ }^{291}$, wobei letztere normative Implikationen strikt vermeide und sich auf Fakten beschränke. ${ }^{292}$ Luhmann ist sich dabei bewußt, daß eine solche Beobachtung des Rechts, die Geltung als Symbol für Anschlußfähigkeit im Recht ${ }^{293}$, Gerechtigkeit als Kontingenzformel und juristische Argumentation als Herstellung ausreichender Redundanz be-

$288 \mathrm{Zu}$ dieser Unterscheidung ein Überblick bei B.Peters, Rationalität, S.33ff, wobei Peters zwischen Perspektiven (intern/extern) und Rollen (Teilnehmer/Beobachter) trennt und so zu vier Kombinationsmöglichkeiten kommt (S.36).

289 J.Habermas, FuG, Kap. 3, II.

290 So der programmatische Titel: Die soziologische Beobachtung des Rechts, Köln 1986; ders., Das Recht der Gesellschaft, Ffm 1993 (im folgenden abgekürzt $R d G$ ).

291 N.Luhmann, RdG, S.24, und 496ff.

292 Ders., RdG, S.31; gegen die Möglichkeit eines solchen Ansatzes R.Dworkin, Law's Empire, Cambridge Mass. 1986, S.49ff, der meint, daß es auf die Frage, was Recht ist, keine neutrale, rein deskriptive Antwort gibt.

293 N.Luhmann, Die Geltung des Rechts, Rechtstheorie 1991, S.273, 279f 
schreibt ${ }^{294}$, nur für einen externen Beobachter möglich ist, während ein Teilnehmer eben diese Begriffe normativ erfassen muß.295 Rechtstheorie als Selbstreflexion muß das Rechtssystem deshalb so beschreiben, daß die Suche nach einer richtigen Antwort sinnvoll bleibt. ${ }^{296}$ Während die Rechtssoziologie sich also vornehmlich an die Wissenschaft selbst und nicht an das Rechtssystem richtet ${ }^{297}$, kann und soll die Rechtstheorie hingegen die soziologischen Beobachtungen des Rechts nicht einfach unreflektiert übernehmen, sondern muß entsprechend ihrer Fragestellung selektiv entscheiden, ob und welche Fremdbeschreibungen des Rechts sie übernehmen kann und will.298

$\mathrm{Da}$ die Diskussion über ein prozedurales Rechtsparadigma schon vom Thema her nicht auf der Ebene einer Beobachtung des Rechts als "so gegeben" - und dann auch anders möglich (kontingent) - stehen bleiben kann, sondern einen Standpunkt im Streit um das richtige Recht einnimmt ${ }^{299}$, wird für diese Untersuchung eine Teilnehmerperspektive gewählt. Andererseits verweist die Rede von einem Rechtsparadigma als "Sozialmodell des Rechts"300 immer auf Recht-in-der-Gesellschaft. Soziologische Beobachtungen der Gesellschaft (also auch des Rechts der Gesellschaft) werden folglich immer dann und soweit übernommen, als sie der Erfassung des Themas dienlich sind. Daraus ergibt sich eine "Doppelperspektive, aus der sich das Rechtssystem gleichzeitig von innen in seinem normativen Gehalt rekonstruktiv ernstnehmen, wie von außen als Bestandteil der sozialen Realität beschreiben läßt", wie sie Habermas für seine Diskurstheorie des Rechts gewählt hat. ${ }^{301}$ Das Problem verschiebt sich dann auf die Frage, wieviel soziologische Beobachtung eine normative Betrachtung des Rechts braucht und/oder vertragen kann. ${ }^{302}$

\section{c) Recht: Norm, Handlung und Kommunikation}

Man kann das Recht als Normsystem betrachten und kann dann die logische Struktur der Normen untersuchen, diese etwa nach Regeln und Prinzipien einteilen ${ }^{303}$, oder deren Beziehung zueinander als Stufenbau qualifizieren ${ }^{304}$ usf. Dabei stellt sich das Problem, daß man aus der Kenntnis der Normen eines Rechtssystems nie auf dessen gesellschaft-

294 N.Luhmann, RdG, Kap. 5 und 8.

295 So für Gerechtigkeit N.Luhmann, RdG, S.219.

296 N.Luhmann, RdG, S.504.

297 N.Luhmann, RdG, S.31.

298 In Luhmanns Terminologie soll Theorie "als Form struktureller Kopplung des Wissenschaftssystems mit den Reflektionstheorien der Funktionssysteme" eingesetzt werden, soziologische Beobachtung des Rechts ist ein Angebot an die Rechtstheorie ohne "Übernahme der Haftung für etwaige Mängel" (RdG, S.543f.); in diesem Sinne bezeichnet R.Dreier (Was ist und wozu Allgemeine Rechtstheorie?, Tübingen 1975, S.21) Rechtstheorie als "Grenzpostendiziplin", die die Aufgabe hat, nachbarwissenschaftliche Informationen auf ihre Relevanz für die Rechtswissenschaft zu überprüfen.

299 In Luhmanns Diktion also um Anschlußfähigkeit im Recht bemüht ist.

300 F.Wieacker, Sozialmodell der klassischen Privatrechtsgesetzbücher, S.5.

301 J.Habermas, FuG, S.62, siehe auch S.21, 79, 94; jeweils mit Bezug auf B.Peters, Rationalität, S.15ff und 33-43, der diese Doppelperspektive ausfuihrlich ausgearbeitet hat.

302 Um dies nochmals festzuhalten: Eine Entscheidung zwischen Systemtheorie und Diskurstheorie findet nicht statt! Beide Theorien sehen nur das, was sie sehen, bzw. sehen nicht, was sie nicht sehen. Ich sehe, was beide sehen, und nehme mit, was ich für meine Theorie brauche - selbstverständlich ohne zu sehen, was ich nicht sehe.

303 R.Alexy, Rechtsregeln und Rechtsprinzipien, S.13ff; J.Sieckmann, Regelmodelle und Prinzipienmodelle des Rechtssystems, 1990.

304 H.Kelsen, Reine Rechtslehre. 
liche Praxis schließen kann (law in the books vs. law in action ${ }^{305}$ ). Man kann dann zwar "secondary rules" über die Erkennung und Anwendung der "primary rules" untersuchen; da eine Regel aber nie ihre eigene Anwendung mitregeln kann ${ }^{306}$, bleibt letztlich nur der Verweis auf eine institutionelle Praxis ${ }^{307}$. Will man also neben den Normen selbst auch deren Anwendung und Interpretation berücksichtigen, so muß man das Recht als Handlungs- und Kommunikationssystem erfassen. Ein Schritt in diese Richtung ist die Beschreibung des Rechts in einem Regel/Prinzipien/Prozedur-Modell, in das die juristische Argumentation mit einbezogen wird. ${ }^{308}$ Diese Umstellung auf Handlung und Kommunikation kann noch einmal radikalisiert werden, indem das Recht im Rahmen einer allgemeinen Kommunikationstheorie der Gesellschaft beschrieben wird. Hierzu liegen zwei allgemeine Entwürfe vor ${ }^{309}$, die im folgenden diskutiert werden sollen, weil eine Darstellung des Rechts als Kommunikationssystem in der Gesellschaft die Möglichkeit eröffnet, das Recht in seiner Beziehung zur Gesellschaft, zu Politik, Wirtschaft und anderen gesellschaftlichen Teilbereichen zu erfassen. Genau diese Beziehungen stehen aber im Zentrum einer Theorie prozeduralen Rechts.

\section{Recht als Kommunikations- und Handlungssystem}

Im folgenden wird das Recht als Kommunikations- und Handlungssystem zunächst in der Gesellschaftstheorie von Niklas Luhmann (1.) und sodann in der Gesellschaftstheorie von Jürgen Habermas (2.) dargestellt. ${ }^{310}$

\section{Recht als Kommunikations- und Handlungssystem in der Systemtheorie}

\section{a) Mensch und Gesellschaft}

Die Systemtheorie unterscheidet psychische Systeme (Bewußtsein) von sozialen Systemen (Kommunikation). ${ }^{311}$ Beide Systemarten prozessieren Sinn ${ }^{312}$ und sind deshalb be-

305 Z.B. A.Podgorecki, Dreistufen-Hypothese über die Wirksamkeit des Rechts, in: E.Hirsch/ M.Rehbinder (Hrsg.), Studien und Materialien zur Rechtssoziologie, Köln 1967, S.271-283.

306 So schon Kant, Gemeinspruch, WW VI, S.127: "für die Urteilskraft nicht immer wiederum Regeln gegeben werden können, wonach sie sich in der Subsumtion zu richten habe (weil das ins Unendliche gehen würde)"; vgl. auch J.Esser, Vorverständnis und Methodenwahl in der Rechtsfindung, 1972; W.Hassemer, Juristische Hermeneutik, ARSP 1986, S.195ff. mit Verweis auf Gadamer.

307 In diesem Sinne schon H.L.A. Hart, The Concept of Law, der die "letzte" rule of recognition nur vom "external point of view" als richterliche Praxis für erfassbar hält (S.107).

308 R.Alexy, Rechtssystem, S.405, 416ff; ders., Begriff und Geltung des Rechts, S.46f.

309 Einmal die Diskurstheorie: J.Habermas, Theorie des kommunikativen Handelns, 2 Bde., Ffm 1981; ders., Faktizität und Geltung. Zur Diskurstheorie des Rechts und des demokratischen Rechtsstaats, Ffm 1992; und zum anderen die Systemtheorie: N.Luhmann, Soziale Systeme, Ffm 1984; ders., Das Recht der Gesellschaft, Ffm 1993; und G. Teubner, Recht als autopoietisches System, Ffm 1989.

310 Die getrennte Darstellung von Habermas' Rechts- und Gesellschaftstheorie rechtfertigt sich dadurch, daß oben unter I. 2. ("Prozedurale Rationalität und politischer Diskurs: Volkssouveränität als Verfahren") der Beitrag von Habermas und anderen Autoren zur Prozeduralisienungsdebatte dargestellt wurde, während hier die Gesellschaftstheorie von Habermas dargestellt wird. Niklas Luhmann wird hingegen nur hier diskutiert, weil er zur Prozeduralisierungsdebatte keinen eigenständigen Beitrag geliefert hat.

311 N.Luhmann, Soziale Systeme, Kap. 2 und 6.

312 Zum Sinn-Begriff N.Luhmann, Soziale Systeme, Kap. 2 ; sowie schon ders., Sinn als Grundbegriff der Soziologie, in: J.Habermas/N.Luhmann, Theorie der Gesellschaft oder Sozialtechnologie, Ffm 1971, S.25-100; neuerdings auch ders., Die Gesellschaft der Gesellschaft, 2 Bde., Ffm 1997, S.44ff.: 
sonders eng miteinander verkoppelt: "Die jeweils eine Systemart ist notwendige Umwelt der jeweils anderen. Personen können nicht ohne soziale Systeme entstehen und bestehen, und das gleiche gilt umgekehrt"..313 Obwohl beide Systeme sich gegenseitig Komplexität zur Verfügung stellen (Interpenetration) und sich so gegenseitig konstituieren, fallen sie nicht zusammen, da die Grenzen des Denkens nicht mit den Grenzen der Kommunikation identisch sind und umgekehrt. 314

\section{b) Gesellschaft als Kommunikationssystem}

Die basale Operation, die soziale Systeme von ihrer Umwelt unterscheidet, ist Kommunikation, wobei Kommunikation als Einheit von Mitteilung, Information und Verstehen definiert wird. ${ }^{315}$ Die Gesellschaft wird als das alle Kommunkationen umfassende soziale System verstanden, in dessen Umwelt es keine Kommunikationen, sondern nur Ereignisse anderer Art gibt (z.B. Bewußtsein, Leben, Dinge). ${ }^{316}$ Da die Gesellschaft alle Kommunikationen, aber auch nur Kommunikationen als ihre Operationen umfasst, ist die Gesellschaft ein operativ geschlossenes und in diesem Sinne autopoietisches System. "Kein Mensch kann kommunizieren (im Sinne von Kommunikation vollenden), ohne dadurch Gesellschaft zu konstituieren, aber das Gesellschaftssystem selbst ist (eben deshalb!) nicht kommunikationsfähig: Es kann keinen Adressaten außerhalb seiner selbst finden", Gesellschaft kann daher "nicht mit der Umwelt, aber sie kann und muß zwangsläufig über die Umwelt kommunizieren" und ist insofern zwar ein operativ geschlossenes, aber informationell offenes System. ${ }^{317}$ Operative Geschlossenheit (Autopoiesis) bedeutet demnach, daß ein System zur Herstellung eigener Operationen auf das Netzwerk eigener Operationen angewiesen ist. Kommunikation wird also im Vor- und Rückgriff auf andere Kommunikationen erzeugt und die Gesellschaft reproduziert sich in diesem Sinne selbst, wobei Produktion niemals die Kontrolle über sämtliche Ursachen des Produkts voraussetzt. ${ }^{318}$ Das System ist nicht nur informationell gegenüber seiner Umwelt offen, indem es über diese kommuniziert, sondern auch strukturel1 ${ }^{319}$ an seine Umwelt gekoppelt: Das Gesellschaftssystem ist an seine Umwelt (also an jede Form der Nicht-Kommunikation, für die eine operative Kopplung über Kommunikation eben ausscheidet) über Bewußtsein gekoppelt. Nur über Bewußtsein, welches seinerseits selektiv über die Sinnesorgane (z.B. Augen) an seine Umwelt gekoppelt ist, kann die

Die hier vorliegende Zusammenfassung der Rechts- und Gesellschaftstheorie von N.Luhmann wurde vor Erscheinen des ein Jahr vor seinem Tod fertiggestellten Abschlußwerkes „Die Gesellschaft der Gesellschaft" erstellt. Eine Überarbeitung hat sich erübrigt, da sich wesentliche inhaltliche Differenzen zu dem von Luhmann als „Einleitung“ (vgl. im Vorwort, a.a.O., Bd. 1, S.11ff.) zur Gesellschaftstheorie bezeichneten Werk ,Soziale Systeme“ nicht ergeben.

313 N.Luhmann, Soziale Systeme, S.92; und ausführlich in Kap. 6 zur Interpenetration.

314 N.Luhmann, Soziale Systeme, Kap. 6, S.290, 295.

315 N.Luhmann, Soziale Systeme, Kap. 4, S.19lff.

316 N.Luhmann, RdG, Kap. 2, III, S.54ff.; ders., Gesellschaft, Bd. 1, S.78ff.

317 N.Luhmann, Die Einheit des Rechtssystems, Rechtstheorie 1983, S.129, 137.

318 N.Luhmann, RdG, S.44 mit FN 14; ders., Gesellschaft, Bd. 1, S.92ff.

319 Unter Systemstrukturen versteht Luhmann eine spezifische Form von Sinn, nämlich generalisierte Erwartungen von Erwartungen kognitiver (Wissen) oder normativer Art (Normen, Regeln, Texte); vgl. N.Luhmann, Soziale Systeme, Kap. 8; ders., RdG, S.41, 126ff.; ders., Gesellschaft, Bd. 1, S.359ff. 
Gesellschaft Umweltreize aufnehmen; und dies wiederum nur, wenn diese sprachlich kommuniziert werden können. 320

\section{c) Recht als Kommunikationssystem}

Das Recht wird nun als ein Subsystem des Gesellschaftssystems verstanden, welches sich neben anderen Subsystemen wie Politik, Wirtschaft, Bildung, Gesundheit etc. innerhalb der Gesellschaft anhand einer spezifischen Funktion, die es für die Gesellschaft erfüllt, ausdifferenziert hat. ${ }^{321}$ Das Recht erfüllt für die Gesellschaft die Funktion der Stabilisierung normativer Erwartungen, indem es diese in zeitlicher, sachlicher und sozialer Hinsicht generalisiert. Recht ermöglicht also Erwartungssicherheit. ${ }^{322}$ Daneben erbringt das Recht für seine innergesellschaftliche Umwelt, vor allem für andere Funktionssysteme der Gesellschaft, Leistungen, insbesondere die der Verhaltenssteuerung und der Konfliktlösung ${ }^{323}$. Die Orientierung an der Funktion reicht für eine Bestimmung des Rechts allerdings nicht aus. Als Teilsystem der Gesellschaft besteht das Rechtssystem aus Kommunikationen, jede Rechtsoperation vollzieht damit immer auch Gesellschaft ${ }^{324}$. Rechtskommunikationen unterscheiden sich von Kommunikationen anderer Art durch ihren Bezug auf den binären Code Recht/Unrecht. Jede gesellschaftliche Kommunikation kann sich dem Rechtssystem also selbst zuordnen, indem sie sich am Rechtscode orientiert. Das ist immer dann der Fall, wenn eine Kommunikation etwas als Recht (oder Unrecht) behauptet, also einen Anspruch auf rechtliche Geltung erhebt. ${ }^{325}$ Anhand dieses Codes vollzieht sich die operative Schließung des Rechts zu einem autopoietischen System. "Es gibt keinen Input von rechtlicher Kommunikation in das Rechtssystem, weil es überhaupt keine rechtliche Kommunikation außerhalb des Rechtssystems gibt"326. Autopoiese des Rechts bedeutet demnach, daß kein rechtlich relevantes Ereignis seine Normativität aus der Umwelt beziehen kann, sondern Geltung immer nur von Rechtskommunikation auf Rechtskommunikation übertragen werden kann, indem diese aneinander anknüpfen und sich so gegenseitig produzieren. ${ }^{327}$ Der rekursive Verweis von Rechtsoperationen auf Rechtsoperationen wird dabei über Strukturen (Normen, Regeln, Texte) vermittelt. Diese Strukturen finden ihre (beobachtbare) Realität aber wiederum nur in den Rechtskommunikationen, in denen sie kondensiert und konfirmiert (z.B. erinnert oder vergessen, angewandt und bestätigt, interpretiert und uminterpretiert) werden. ${ }^{328}$ Struktur und Operation, Rechtsnorm und Urteil stehen in einem zirkulären Verweisungszusammenhang und produzieren sich in diesem Sinne ge-

$320 \mathrm{Zu}$ strukturellen Kopplungen allgemein N.Luhmann, RdG, Kap. 10; zur Kopplung zwischen Bewußtsein und Gesellschaft ders., Die Wissenschaft der Gesellschaft, Ffm 1990, S.11ff.

321 Hierzu und zum folgenden N.Luhmann, RdG, Kap. 2, insbes. S.55ff.; sowie G.Teubner, Recht als autopoietisches System, Ffm 1989, Kap. 3.

322 N.Luhmann, Rechtssoziologie, Kap. II, insbes. S.94ff.; ders., RdG, Kap. 3, S.131.

323 N.Luhmann, RdG, S.156ff.

324 N.Luhmann, RdG, Kap. 12, S.550-554.

325 N.Luhmann, RdG, Kap. 2, insbes. S.66-75 und Kap. 3; ders., Die Codierung des Rechtssystems, Rechtstheorie 1986, S.171ff., $178 \mathrm{f}$.

326 N.Luhmann, RdG, S.69.

327 N.Luhmann, RdG, S.98ff; ders., Die Geltung des Rechts, Rechtstheorie 1991, S.273-286.

328 N.Luhmann, RdG, S.45-50, 63; zur "Logik des Kondensierens und Konfirmierens" auch S.127; und ders., Soziale Systeme, Kap. 8 II. 
genseitig ${ }^{329}$. Autopoiesis bedeutet nicht monadische Abschließung des Rechts gegenüber der Gesellschaft, sondern ist bloße Voraussetzung dafür, daß es überhaupt ein ausdifferenziertes Rechtssystem gibt. Denn nur anhand des Codes Recht/Unrecht kann das Rechtssystem sich selbst im Unterschied zu seiner innergesellschaftlichen Umwelt (nichtrechtliche Kommunikation) identifizieren. Der Begriff der Autopoiese zielt daher nicht auf eine Alternative zwischen offenem und geschlossenem Rechtssystem, sondern nur zwischen operativ geschlossenem Rechtssystem oder gar keinem Rechtssystem, wobei operative Geschlossenheit informationelle Offenheit und strukturelle Kopplung erst ermöglicht und kausale Beziehungen zwischen System und Umwelt nicht ausschließt. ${ }^{330}$

\section{d) Kommunikation und Handlung}

Auf der operativen Ebene der Kommunikationen läßt sich das Rechtssystem relativ einleuchtend als geschlossen beschreiben, weil eben per definitionem jede Kommunikation, die sich auf den Rechtscode bezieht, zum Rechtssystem gehört. Auch die Rede von autopoietischer Selbstreproduktion ist auf der Ebene der Kommunikation nachvollziehbar, ist damit doch nicht mehr gemeint, als daß Kommunikationen auf vergangene Kommunikationen Bezug nehmen, an diese also anknüpfen, und in ihrem Kommunikationswert auf weitere Kommunikationen verweisen, also auf Weiterverwendung angelegt sind, Ja/Nein-Stellungnahmen herausfordern usw. ${ }^{331}$ Problematisch ist hingegen, daß Kommunikationen in ihrer Einheit aus Mitteilungshandeln, Information und Verstehen nicht direkt beobachtet, sondern nur erschlossen werden können. ${ }^{332} \mathrm{Ob}$ egos Mitteilungshandlung verstanden wurde, kann häufig nur am Anschlußverhalten von alter abgelesen werden. ${ }^{333}$ Man kann Kommunikation reflexiv nur handhaben (z.B. bestreiten, zurückfragen, widersprechen), wenn sich feststellen läßt, wer gehandelt hat. ${ }^{334}$ Mit Einführung von Schrift und Buchdruck differenzieren sich Mitteilung und Information deutlicher aus und Mitteilung und Verstehen fallen zeitlich immer weiter auseinander. Ein Text muß gelesen, das positive Gesetz muß angewandt (interpretiert) werden, damit Kommunikation als Einheit von Mitteilung, Information und Verstehen zustandekommmt. Weil Handlungen einfacher $z \mathfrak{u}$ erkennen und $z u$ behandeln sind als Kommunikationen und weil die Reduktion auf Handlung das zeitliche Asymmetrisieren sozialer Beziehungen erleichtert, konstituieren sich soziale Systeme auf der Ebene der Selbstbeschreibung als Handlungssysteme ${ }^{335}$. Kommunikationen werden, obwohl sie die Zeit übergreifen, auf den Zeitpunkt, in dem der Mitteilende handelt, bezogen. Das Kommunikationssystem Gesellschaft konstituiert sich folglich als ein System, in dem Aktoren Handlungen zugeschrieben werden.

329 G.Teubner, Recht als autopoietisches System, S.54ff., 56; N.Luhmann, RdG, S.45.

330 N.Luhmann, RdG, Kap. 2 IV; ders., Steuerung durch Recht?, S.142ff.; für ein voraussetzungsvolleres Konzept von Autopoiese als gesteigerte Autonomie i.S.d. gegenseitigen Produktion sämtlicher Systemkomponenten über einen Hyperzyklus siehe G.Teubner, Recht als autopoietisches System, Kap. 3, insbes. S.44 und 56.(s.o. I. 3. b).

331 N.Luhmann, Soziale Systeme, Kap. 4; eine Definition von Produktion auf S.233.

332 N.Luhmann, Soziale Systeme, S.226.

333 N.Luhmann, Soziale Systeme, S.198f.

334 N.Luhmann, Soziale Systeme, S.241.

335 N.Luhmann, Soziale Systeme, S.232f. 


\section{e) Recht als Handlungssystem}

Aus ähnlichen Gründen beschreibt sich auch das Recht selbst als Handlungssystem. Kommunikationen, die sich am Code Recht/Unrecht orientieren, können von jederman zu jeder Zeit und an jedem Ort vorgenommen werden. Die Grenzen des Rechts als Menge aller Rechtskommunikationen verlaufen damit quer zu allen Institutionen und Organisationen. Das Rechtssystem reduziert diese Komplexität, indem es seine tatsächliche Einheit (alle Rechtskommunikationen) verkürzt als Handlungssystem beschreibt (Identität). ${ }^{336}$ Das Rechtssystem in einem engeren Sinne besteht daher aus Rechtsakten, wobei Rechtsakt jede Handlung ist, die Rechtsfolgen auslöst und damit die Rechtslage ändert. ${ }^{337}$ Rechtsakte sind Verfügungen, die Geltung in dem Sinne transportieren, als daß sie das, was gilt, inhaltlich festlegen, sei es in abstrakt-generellen Regeln, sei es im individuell-konkreten Einzelakt. Entscheidend ist, daß die Geltungslage als der Zustand des Rechts, von dem dieses bei seinen folgenden Operationen ausgehen muß, geändert wird. $\mathrm{Zu}$ den Rechtsakten zählen daher neben dem Gesetz auch Urteil, Vertrag, Satzung, Verwaltungsakt, Testament etc. ${ }^{338}$ Innerhalb des Rechtssystems als Menge aller am Rechtscode orientierter Kommunikationen bildet sich so ein engerer Bereich rechtlich verbindlichen Entscheidens zur Feststellung und Änderung des Rechts heraus. Dieses organisierte Entscheidungssystem des Rechts (Rechtssystem i.e.S.) beruht auf der Reflexität des Normierens (Normieren des Normierens), also auf Kompetenz-, Organisations- und Verfahrensnormen ${ }^{339}$, deren Beachtung dazu führt, daß eine Entscheidung selbst normierende Kraft hat, also ein Rechtsakt ist. ${ }^{340}$

\section{f) Recht und Gesellschaft: strukturelle Kopplungen}

Sobald ein organisiertes Entscheidungssystem im Recht institutionalisiert ist, kann nur noch in diesem festgelegt werden, was in einem offiziellen Sinne Recht ist (normative Geschlossenheit). Nicht nur Fakten können das Recht nicht ändern; vielmehr hat auch nicht jede Rechtskommunikation diese Wirkung, sondern nur noch solche, die als Rechtsakte anerkannt sind. ${ }^{341}$ Dieses Rechtssystem i.e.S. differenziert sich nun im Laufe der Zeit in Zentrum und Peripherie. ${ }^{342}$ Zunächst ist für die Ausdifferenzierung eines organisierten Entscheidungssystems des Rechts aber nur die Einrichtung von Gerichten notwendig. Unabhängige Richter sind aufgrund des Justizverweigerungsverbotes verpflichtet, jeden Fall (auch sog. hard cases) zu entscheiden. Im Entscheidungsprozeß werden so von Fall zu Fall Normen kondensiert und konfirmiert, an die die Gerichte über den Präjudizienverweis selbst gebunden werden können. Aus Gründen der Gerech-

336 N.Luhmann, RdG, S. 74f.

337 N.Luhmann, Die Einheit des Rechtssystems, S.129, $135 f$.

338 N.Luhmann, Die Geltung des Rechts, S.273, 282f; ders., RdG, S.107; G.Teubner, Recht als autopoietisches System, S.55, 113.

339 "Secondary rules" i.S.v. H.L.A. Hart (The Concept of Law, S.79), der diese in "rule of recognition", "rules of change" und "rules of adjudication" unterteilt (S.91ff.), wobei die "rules of change" auch Privatpersonen zur Änderung der "primary rules" ermächtigen und deshalb auch bei Hart Verträge, Testamente etc. als Rechtsetzung erfasst werden (S.93f.).

340 N.Luhmann, RdG, S.145ff.,147: "Das Rechtssystem ... ist auf der Basis der Reflexität seiner Operationen ausdifferenziert."; i.d.S. bezeichnet auch H.L.A.Hart die Einführung von "secondary rules" als "step from the pre-legal into the legal world" (Concept of Law, S.91).

341 N.Luhmann, RdG, S.86ff, $143 \mathrm{ff}$.

342 N.Luhmann, RdG, Kap. 7. 
tigkeit, der Rechtssicherheit und später auch der Legitimiation werden dann aber innerhalb des Rechtssystems die Funktionen der Gesetzgebung und der Rechtsprechung ausdifferenziert. ${ }^{343}$ Der Richter soll "ohne Ansehen der Person" gleiche Fälle gleich entscheiden. Die streitentscheidenden Regeln sollen daher als allgemeine Gesetze im Voraus festgelegt werden und dann im Einzelfall gleichermaßen auf Freund und Feind (arm und reich etc.) angewandt werden. Die Festlegung der Regeln im Vorhinein ermöglicht zudem die Orientierungsfunktion des Rechts (Rechtssicherheit als Vorhersehbarkeit richterlichen Entscheidens). Gesetzgebung und Rechtsprechung bleiben aber zwei Varianten einer einheitlichen Aufgabe, der iurisdictio, für die z.B. im Territorialstaat der Fürst als oberster Gerichtsherr und Gesetzgeber in einer Person verantwortlich war ${ }^{344}$. Das Recht etabliert sich nun nach Luhmann als autopoietisches System im Sinne eines normativ geschlossenen Systems, sobald ein organisiertes Entscheidungssystem im Recht eingeführt wird. ${ }^{345}$ Immer dann, wenn überhaupt verbindlich über Recht und Unrecht entschieden wird, gilt als Recht nur noch, was vom organisierten Entscheidungssystem als Recht anerkannt wird, ob diese Funktion nun von einem unabhängigen Gericht oder von einem Fürsten als oberstem Gerichtsherrn wahrgenommen wird. ${ }^{346}$ Diese Tatsache bleibt allerdings verdeckt, solange Rechtsprechung als bloße Anwendung und Gesetzgebung lediglich als Niederschrift extern vorgegebenen Natur- oder Vernunftrechts verstanden wird. ${ }^{347}$ Mit dem Verfall der Überzeugungskraft des Naturrechts wird dann die Tatsache der Positivität des Rechts offenbar. Damit stellt sich die Frage nach der Legitimation des Rechts neu. Legitimation kann jetzt nur noch über Konsens vermittelt werden. Da die Gerichte selbst keinen Konsens beschaffen können, werden die Konsensanforderungen in eine Peripherie des Rechtssystems abgeschoben, in der das Recht über prozedurale Regeln seiner Umwelt die Möglichkeit gibt, in Rechtsakten Rechtsinhalte festzulegen. Dies geschieht vornehmlich über Gesetz und Vertrag. ${ }^{348}$ Das Recht legitimiert sich dann dadurch, daß die Rechtsinhalte in Form demokratisch beschlossener Gesetze oder in Form des Vertrages als selbstgesetzt erscheinen.

Diese Art von Konsensimport kann nun aber nicht in Form einer operativen Kopplung des Rechts an die Politik oder an die Wirtschaft in dem Sinne stattfinden, daß eine politische oder wirtschaftliche Kommunikation ohne weiteres die Rechtslage ändern könnte. Dadurch würde die normative Geschlossenheit des Rechts aufgehoben und es wäre unmöglich, zwischen Recht und Unrecht zu unterscheiden. Vielmehr bietet das Recht seiner gesellschaftlichen Umwelt die Möglichkeit, selbst verbindliche Rechtsakte in Form von Verträgen oder Gesetzgebung vorzunehmen, wobei das Recht präzise definiert, unter welchen Voraussetzungen eine solche Handlung rechtsverbindlich ist. Im Gegensatz zur operativen Kopplung nennt Luhmann diese Verbindung des Rechts mit seiner Umwelt strukturelle Kopplung. ${ }^{349}$ Die Idee struktureller Kopplung ist, daß Einflüsse der Umwelt auf das System beschränkt und dadurch gleichzeitig erleichtert werden. "Gehirne sind mit ihren Augen und Ohren nur in einer sehr schmalen physikalischen Bandbreite an ihre Umwelt gekoppelt...; aber gerade deshalb machen sie den Or-

343 N.Luhmann, RdG, Kap. 7 II und Kap. 5.

344 N.Luhmann, RdG, S.300.

345 N.Luhmann, RdG, S.62: Luhmann nennt hier als ungefähres Datum das 11./12. Jahrhundert.

346 N.Luhmann, RdG, Kap. 2 VI, insbes. S.78f., 85, 88f., sowie S.147ff. und $299 \mathrm{ff}$.

347 N.Luhmann, RdG, Kap. 11 III.

348 N.Luhmann, RdG, Kap. 7 V.

349 N.Luhmann, RdG, Kap. 9 und 10. 
ganismus in unwahrscheinlich hohem Maße umweltsensibel. ${ }^{350}$ Ebenso steht es mit dem Rechtssystem: solange es ohne Einschränkung den Pressionen seiner Umwelt ausgesetzt ist, bleibt es korrupt. ${ }^{351}$ Solange Wirtschaft, Recht und Politik nicht ausdifferenziert sind, bleibt das Recht wehrlos gegenüber jeder Form politischen Terrors, politischer Korruption und privater Pressionsmacht. ${ }^{352}$ Erst wenn diese drei Bereiche sich anhand ihrer Funktion und ihres spezifischen Codes als operativ geschlossene Subsysteme ausdifferenzieren, können diese ihre wechselseitigen Beziehungen selektiv über strukturelle Kopplungen organisieren und so Gewalt, Macht und Korruption als Möglichkeiten der Verknüpfung ausschließen. Recht und Politik koppeln sich dann über das Institut der Verfassung. Wechselseitige Beeinflussung von Recht und Politik kann nur noch in den von der Verfassung - als in beiden Systemen wirksamer Struktur - vorgesehenen Kanälen stattfinden. ${ }^{353}$ Recht und Wirtschaft koppeln sich über Eigentum und Vertrag. ${ }^{354}$ Dazu differenzieren sich die Funktionssysteme in Zentrum und Peripherie. Im Zentrum des Rechtssystems stehen die Gerichte, in dessen Peripherie finden über Gesetzgebung, Vertrag, Rechtsdogmatik und Rechtstheorie die strukturellen Kopplungen zu anderen gesellschaftlichen Subsystemen statt. ${ }^{355}$ Im Zentrum des Wirtschaftssystems finden sich die Banken, in dessen Peripherie Produktion, Handel und Konsum. ${ }^{356}$ Zentrum des politischen Systems ist die Staatsorganisation, deren Grenze zur Peripherie (Parteien, Lobbys, Wahlen, Opposition, Bürgerbewegungen etc.) durch Amtsträgerschaft gekennzeichnet wird. Im Zentrum stehen daher Regierung und politische Verwaltung. ${ }^{357}$

Was heißt nun strukturelle Kopplung, wenn in den Grenzbereichen der Peripherie die Systeme zu verschmelzen scheinen? In der "Gesetzgebung als Ort der Transformation von Politik in Recht" 358 sind politische und rechtliche Kommunikationen so eng miteinander verwoben, daß trotz Luhmanns Bestehen auf der Unterscheidbarkeit von politischen und Rechtsfragen häufig unklar bleibt, ob eine Kommunikation mehr im politischen System oder mehr im Rechtssystem abläuft. ${ }^{359}$ Der Status der Gesetzgebung in der Systemtheorie ist daher lange unklar geblieben. Konnte man bei Luhmann und Teubner zunächst nur lesen, daß "das Rechtssystem sich durch Gesetzgebung und richterliche Entscheidung reproduziert" 360 , oder gar: "In Gesetzgebungsakten erfindet sich das Recht" (und nicht etwa die Politik) "seine gesellschaftliche Umwelt"361, so wurde die Gesetzgebung vom Öffentlichrechtler und Politologen Helmut Willke für das politi-

350 N.Luhmann, RdG, S.441.

351 N.Luhmann, RdG, S.445.

352 N.Luhmann, RdG, S.470f.

353 N.Luhmann, RdG, Kap. 9 und 10 IV.

354 N.Luhmann, RdG, Kap. 10 III.

355 N.Luhmann, RdG, Kap. 7 V.

356 N.Luhmann, RdG, S. 334f.; ders., Die Wirtschaft der Gesellschaft, Ffm 1988.

357 N.Luhmann, RdG, S.335-337, und Kap. 9.

358 N.Luhmann, RdG, S.429.

359 N.Luhmann, RdG, S.433, 441; Die Zuordnung der Gesetzgebung zum Rechtssystem ist deshalb immer wieder kritisiert worden: J.Nocke, Autopoiesis - Rechtssoziologie in seltsamen Schleifen, S.364ff. bei FN 106; P.Nahamowitz, Autopoietische Rechtstheoric: mit dem baldigen Ableben ist zu rechnen, ZfRSoz 1990, S.137-155; ders., Steuerung durch Recht und Steuerung des Rechts, ZfRSoz 1992, S.271-293; dazu N.Luhmann, Steuerung durch Recht? Einige klarstellende Bemerkungen, ZfRSoz 1991, S.142-146.

360 N.Luhmann, Die Codierung des Rechtssystems, S.192.

361 G.Teubner, Recht als autopoietisches System, S.97. 
sche System reklamiert. ${ }^{362}$ Einen Ausweg scheint der von Teubner ${ }^{363}$ eingeführte Begriff der Interferenz zu bieten. Interferenz bezeichnet die Kopplung verschiedener Systeme über ein kommunikatives Ereignis, ist insofern also eine operative Kopplung. Interferenz als punktuelle Verknüpfung von Systemen soll deshalb möglich sein, weil alle sozialen Systeme aus denselben Elementen, nämlich aus Kommunikationen bestehen. Jede spezialisierte Rechtskommunikation ist immer zugleich auch allgemeingesellschaftliche Kommunikation. Darüber hinaus kann eine Rechtskommunikation aber auch uno actu mit Kommunikationen anderer Teilsysteme zusammenfallen. So fallen im Vertrag Rechtshandlung, Lebenswelthandlung (im Sinne allgemeingesellschaftlicher Kommunikation) und Wirtschaftshandlung zusammen. ${ }^{364}$ In diesem Sinne fallen auch im Gesetzgebungsakt politische und rechtliche Kommunikation zusammen und gleiches gilt für eine Vielzahl von Rechtsakten, in denen das Recht anderen Systemen unter gewissen Bedingungen erlaubt, in seiner Peripherie die Rechtslage ändernde Handlungen vorzunehmen. Diese momenthafte Kopplung von Operationen, in der z.B. eine wirtschaftliche Zahlung eine Rechtsverbindlichkeit erfüllt oder der Erlaß eines Gesetzes politischen Konsens symbolisiert, liegt allerdings nicht auf einer Ebene mit der autopoietischen Verkoppelung von Operationen innerhalb eines Systems. In der Gesetzgebung treffen sich rechtliche und politische Autopoiese nur momenthaft, um anhand eines zeitlichen Ereignisses parallel je verschiedenen Sinn zu prozessieren. Nach diesem Zusammentreffen trennen sich beide Kommunikationszusammenhänge wieder, und das gemeinsame Ereignis erhält in jedem System einen eigenen Sinn, indem es in den geschichtlichen Ablauf der jeweiligen Autopoiesis eingeordnet wird, erinnert oder vergessen, interpretiert und rekonstruiert wird. ${ }^{365}$ Für die Politik stellt der Gesetzgebungsakt den Abschluß einer politischen Diskussion dar. Das Gesetz kann von der Regierung als politischer Erfolg verkauft oder von der Opposition kritisiert werden und fügt sich so in den Code Regierung/Opposition ein. Die politische Diskussion muß mit dem Gesetzgebungsakt auch nicht beendet sein, sondern kann in Parteien und Bürgerbewegungen weitergeführt werden, in Wahlen als Argument der Opposition verwandt werden und bei einem Regierungswechsel unter Umständen zu einer erneuten Gesetzesänderung führen. Für den Rechtsdiskurs hingegen ist diese politische Diskussion nicht relevant. Die Rechtslage ist verbindlich geändert und das Gesetz entwickelt im Rechtssystem seine eigene Geschichte, wird angewandt und interpretiert etc. ${ }^{366}$ Wenn dabei auf die Motive des Gesetzgebers zurückgegriffen wird, so werden diese unter rechtsinternen Gesichtspunkten gefiltert. "Nicht alle Motive des Gesetzgebers sind rechtlich verwertbar. Nie liest man in einem Gerichtsurteil, daß das Gesetz sich einem parteipolitischen Schach-

362 H.Willke, Ironie, S.32f.

363 G.Teubner, Recht als autopoietisches System, S.106-111.

364 G.Teubner, Recht als autopoietisches System, S.113; Teubner diskutiert dies allerdings nur für die Institutionen des Vertrags und des subjektiven Rechts, nicht aber für die Gesetzgebung. Das Verhältnis Politik/Recht fasst er insofern inkonsequent unter dem Begriff der Eigendynamik: ders., Napoleons verlorener Code, FS für Maihofer, 1988, S.587-601.

365 Diesen schwierigen Sachverhalt kann man sich auch anhand der Unterscheidung von Handlung und Kommunikation (s.o.) verdeutlichen: Ein und dieselbe Handlung, der Gesetzgebungsakt, wird in unterschiedlichen Kommunikationskreisläufen (Recht/Politik) auf unterschiedliche Weise zur Selbstbeschreibung benutzt.

366 Siehe dazu N.Luhmann, RdG, Kap. 9 und 10 V, S.434ff. 
zug verdankt". ${ }^{367}$ Interferenz steht daher nicht im Gegensatz zur Autopoiese. Ermöglicht wird Interferenz über strukturelle Kopplungen, indem nämlich in beiden gekoppelten Systemen ähnliche Strukturen verwandt werden. Wirtschaft setzt ebenso wie das Recht Eigentum und Vertrag voraus, wobei beide Institutionen in den Systemen unterschiedliche Bedeutungen haben. ${ }^{368}$ Ebenso nimmt die den Rechtsstaat konstituierende Verfassung in Politik und Recht einen je verschiedenen Sinn an. Für das Recht ist wesentlich, daß die Politik zunächst den Frieden sichert (Gewaltmonopol) und die Durchsetzung des Rechts garantiert. Darüber hinaus erhält das Recht aus einer demokratischen Gesetzgebung seine Legitimation. Für die Politik stellt der Rechtsstaat gleichzeitig Möglichkeit und Grenzen der Benutzung des Rechts für Zwecke der politischen Steuerung dar. Je nach Systemreferenz meint die Rechtsstaatsformel also Verschiedenes. ${ }^{369}$ Die Trennung der Systeme Politik und Recht sieht Luhmann als Bedingung der Steigerung wechselseitiger Abhängigkeit, in der sich Demokratisierung der Politik und Positivierung des Rechts gegenseitig ermöglichen und stimulieren. ${ }^{370}$

Wir halten fest, daß die Systeme Recht, Wirtschaft und Politik sich einerseits zu operativ geschlossenen Systemen ausdifferenziert haben und andererseits über Formen von struktureller Kopplung verbunden sind. Dadurch sind Abhängigkeit und Unabhängigkeit der Systeme gleichzeitig in einer Weise gesteigert worden, die den Systemen und der Gesellschaft insgesamt die Ausbildung eines höheren Komplexitätsniveaus ermöglichen. Diesen Vorgang kann man auf Luhmanns knappe Formel der Steigerung von Komplexität durch (aufgrund von) Reduktion von Komplexität bringen. ${ }^{371}$

\section{Recht als Kommunikations- und Handlungssystem in der Diskurstheorie}

Im Gegensatz zur Systemtheorie beschränkt Habermas die Diskurstheorie des Rechts nicht auf die soziologische Beobachtung von Fakten, sondern entwickelt eine Doppelperspektive, unter der er Faktizität und Geltung des Rechts miteinander vereint (s.o.). Die Einbeziehung normativer Aspekte hat eine teilweise unüberwindbare Differenz der Grundbegriffe wie Kommunikation, Handlung, Norm, System etc. zur Folge. Die gleichzeitige Übernahme systemtheoretischer Beschreibungen führt dann allerdings oft zu begrifflichen Unklarheiten in Habermas' Theorie. Das Rechtskonzept von Habermas wird nur auf dem Hintergrund seiner Theorie des kommunikativen Handelns verständlich, weshalb im folgenden auch einige Grundbegriffe der Diskurstheorie dargestellt werden.

\section{a) Handlung, Kommunikation und kommunikative Vernunft}

Wer wie Habermas normative Aspekte in die Rechtstheorie einbeziehen will, muß zunächst zeigen, daß normative Fragen rational entscheidbar sind. Die überkommenen Theorien der praktischen Vernunft befinden sich in dem Trilemma, daß sich normative Gehalte weder aus der Geschichte, noch aus der Konstitution des Menschen (Natur),

367 N.Luhmann, RdG, S.89.

368 N.Luhmann, RdG, Kap 10 III.

369 N.Luhmann, RdG, S.426.

370 N.Luhmann, RdG, S.438f.

$371 \mathrm{Zu}$ diesem Grundmuster siehe N.Luhmann, Rechtssoziologie, S.6ff und passim; mit Bezug auf das Rechtssystem benutzt Luhmann auch die Formel "Offenheit aufgrund von (operativer) Geschlossenheit", ders., RdG, S.76, 83ff. 
noch aus der Tradition (Überlieferung) überzeugend ableiten lassen. ${ }^{372}$ Die Diskurstheorie verlegt das Vernunftkriterium nun in das Medium der Umgangssprache. Kommunikative Vernunft realisiert sich als Intersubjektivität in der durch Sprache ermöglichten Vernetzung von Interaktionen, wird also nicht länger einem einzelnen Aktor zugeschrieben. ${ }^{373}$ Während sich Theorien der praktischen Vernunft auf Normen des Handelns (Inhalte) beziehen, hat die Diskurstheorie kontrafaktische Grundlagen faktischer Verständigungsprozesse zum Thema. Kommunikative Vernunft beschränkt sich auch nicht auf praktische Fragen (Moral), sondern erstreckt sich auf Wahrheit, Richtigkeit und Wahrhaftigkeit. ${ }^{374}$

Das Kriterium der Richtigkeit bezieht sich auf normative (praktische) Fragen. Auf die Frage, wie solche Fragen rational entscheidbar sind, hat Habermas in der auf individuelle Willensbildung (Moral) zugeschnittenen ${ }^{375}$ Diskursethik durch die Angabe des Universalisierungsgrundsatzes (U):

"Jede gültige Norm muß der Bedingung genügen, daß die Folgen und Nebenwirkungen, die sich aus ihrer allgemeinen Befolgung für die Befriedigung der Interessen jedes Einzelnen voraussichtlich ergeben, von allen Betroffenen zwanglos akzeptiert werden können ${ }^{\text {376 }}$

geantwortet. Diesen Grundsatz (U) hat Habermas aus den allgemeinen pragmatischen Voraussetzungen von Argumentationen abgeleitet. ${ }^{377}$ Dazu unterscheidet er zwischen Kommunikation als einer Subjekt-Subjekt-Beziehung und Nicht-Kommunikation als einer Subjekt-Objekt-Beziehung. ${ }^{378}$ In den Bereich der Nicht-Kommunikation fällt das instrumentelle Handeln, was den Kontakt mit Dingen meint. Zur Nicht-Kommunikation zählt Habermas auch das strategische Handeln. Hier wirkt ein Mensch auf einen anderen durch Androhung von Sanktionen, durch Gratifikationen oder durch Manipulation (z.B. Lügen) ein, um ein bestimmtes Ziel zu erreichen (Zweckrationalität). Dem strategisch Handelnden begegnen die anderen Interaktionsteilnehmer nur als Objekte, als soziale Tatsachen. ${ }^{379}$

Zum Bereich der Kommunikation gehört hingegen das kommunikative Handeln. Hier möchte ein Subjekt ein anderes Subjekt zu einer Handlung rational motivieren. ${ }^{380} \mathrm{Kom}$ munikatives Handeln vollzieht sich durch die gegenseitige Vornahme von Sprechakten.

372 Siehe hierzu und zum folgenden J.Habermas, Faktizität und Geltung (FuG), Kap. I, S.17, 24ff.

373 Zum Unterschied zwischen Intersubjektivität und Autopoiesis vgl. G.Teubner, Die Episteme des Rechts, S.115, $118 \mathrm{ff}$.

374 J.Habermas, FuG, S.17ff.

$375 \mathrm{Zu}$ dieser Einschränkung J.Habermas, FuG, S.21 und zum Verhältnis von Recht und Moral S.135ff, $187 \mathrm{ff}$.

376 So angegeben in: J.Habermas, Moralität und Sittlichkeit - was macht eine Lebensform rational?, in: H.Schnädelbach (Hrsg.), Rationalität, Ffm 1984, S.218ff., 219.

377 So z.B. in: J.Habermas, Vorbereitende Bemerkungen za einer Theorie der kommunikativen Vernunft, in: ders./Luhmann, Theorie der Gesellschaft, S.101ff.; ders., Was heißt Universalpragmatik, in: K.-O.Apel u.a. (Hrsg.), Sprachpragmatik und Philosophie, Ffm 1976, S.174ff; ders., Diskursethik - Notizen zu einem Begründungsprogramm, in: ders., Moralbewußtsein und kommunikatives Handeln, Ffm 1983, S.53ff.

378 Hierzu und zum folgenden J.Habermas, Diskursethik, S.63ff.

379 J.Habermas, Diskursethik, S.68; ders., FuG, S.43 mit FN 18; hier liegt der entscheidende Unterschied zu Luhmanns Kommunikationsbegriff (s.o.), da strategisches Handeln Kommunikation i.w.S. als Einheit von Mitteilung, Information und Verstehen einschließt: vgl. N.Luhmann, Soziale Systeme, Kap. 4 VII und IX.

380 J.Habermas, Diskursethik, S.68. 
Im Anschluß an die Sprechakttheorie ${ }^{381}$ unterteilt Habermas die Sprechakte in einen performatorischen Ausdruck (illokutionärer Akt) und einen präpositionalen Ausdruck (lokutionärer Akt). ${ }^{382}$ Durch den performatorischen Ausdruck wird der pragmatische Sinn festgelegt, den der präpositionale Satz haben soll und ohne den dieser nicht verstanden werden kann:

$\begin{array}{lll}\text { Beispiel: } & \text { performatorischer Ausdruck } & \text { präpositionaler Satz } \\ & \begin{array}{l}\text { Ich behaupte } \\ \text { Ich befehle }\end{array} & \text { A geht nach B } \\ \text { Ich verspreche } & \end{array}$

Bei gleichbleibendem präpositionalem Satz kann der pragmatische Sinn variieren. Mit dem performatorischen Ausdruck vollzieht der Sprecher eine bestimmte Handlung (einen Befehl geben, ein Versprechen machen, eine Behauptung aufstellen etc.), weshalb Habermas von kommunikativem Handeln spricht. Diese Handlung kann jedoch nur vollzogen werden, wenn der im performatorischen Ausdruck indizierte Verwendungssinn vom Hörer aufgefasst und akzeptiert werden kann. ${ }^{383}$

Habermas teilt die Sprechakte nun nach ihrem pragmativen Sinn in drei Klassen ein. In konstativen Sprechakten (z.B. Behauptungen) erhebt der Sprecher einen Wahrheitsanspruch, in regulativen Sprechakten (z.B. Befehle) einen Anspruch auf Richtigkeit und in repräsentativen Sprechakten (Intentionen, Einstellungen) einen Anspruch auf Wahrhaftigkeit. ${ }^{384}$ Das bedeutet z.B., daß eine Behauptung (konstativer Sprechakt) nur dann vollzogen (der Sprechakt gelingen) kann, wenn der Hörer den präpositionalen Satz (A geht nach B) und dessen pragmativen Sinn (der Sprecher behauptet) richtig auffasst (d.h., der Sprecher muß sich verständlich machen) und den im performatorischen Ausdruck enthaltenen Geltungsanspruch (hier: die Behauptung ist wahr) akzeptiert. Bezieht sich ein Sprecher auf eine Norm (regulativer Sprechakt), muß der Hörer die Norm als richtig akzeptieren können, bringt ein Sprecher eine Intention zum Ausdruck (repräsentativer Sprechakt), muß der Hörer die Aufrichtigkeit des Sprechers akzeptieren können. Damit liegen vier Voraussetzungen für eine Verständigung in kommunikativem Handeln vor:

$\begin{array}{lll}\text { 1. } & \text { Verständlichkeit } & \text { (bzgl. propositionalem und pragmatischem Sinn) } \\ \text { 2. Wahrheit } & \text { (bzgl. konstativer Aussagen) } \\ \text { 3. } & \text { Richtigkeit } & \text { (bzgl. Normen, Handlungen) } \\ \text { 4. } & \text { Wahrhaftigkeit } & \text { (bzgl. Intentionen, Einstellungen) }\end{array}$

Für eine ungestörte Kommunikation müssen diese vier Bedingungen erfüllt sein, d.h., der Sprecher erhebt den Anspruch, diese Bedingungen zu erfüllen, und der Hörer muß diese Ansprüche gelten lassen (akzeptieren). Im kommunikativen Handeln werden diese Geltungsansprüche nach Habermas nun naiv anerkannt. Er nennt dies den handlungsbegleitenden Konsens. Dieser Konsens ermöglicht das Gelingen der Sprechakte und ermöglicht so Kommunikation i.S.v. Verständigung.

Wird einer dieser Geltungsansprüche in Frage gestellt, so ist der Konsens gestört. Diese Störung hat zur Folge, daß der fragliche Geltungsanspruch zum Thema gemacht wird. Wird die Verständlichkeit einer Äußerung angezweifelt, so findet eine Einigung

381 Z.B. J.R.Searle, Sprechakte; vgl. auch R.Alexy, Argumentation, S.78ff. m.w.N.

382 J.Habermas, Vorbereitende Bemerkungen, S.102f.

383 J.Habermas, Vorbereitende Bemerkungen, S.116.

384 J.Habermas, Vorbereitende Bemerkungen, S.111. 
über die Sprache statt, die verwendet werden soll. ${ }^{385}$ Der Anspruch auf Wahrhaftigkeit wird nicht kommunikativ, sondern vom Sprecher in der Konsequenz seines Verhaltens eingelöst. Wird aber der Anspruch auf Wahrheit oder Richtigkeit einer Aussage in Zweifel gezogen, so treten die Sprecher/Hörer in den Diskurs ein. Der Diskurs gehört nicht mehr in den Bereich der Handlung, sondern ist handlungsentlastet und erfahrungsfrei in dem Sinne, daß in den Diskurs zwar Erfahrungen einfließen, aber keine Erfahrungen gewonnen werden, sondern rein argumentativ vorgegangen wird. ${ }^{386} \mathrm{Im}$ Diskurs werden die Geltungsansprüche mit dem Ziel argumentativ überprüft, den gestörten Konsens wiederherzustellen. Dies geschieht durch Erklärungen und Rechtfertigungen, wobei eine Konklusion zwar aus bestimmten Daten in Verbindung mit einer Schlußregel abgeleitet werden kann, im entscheidenden Moment aber induktiv vorgegangen wird. ${ }^{387}$ In einer Wahrheitsargumentation (theoretischer Diskurs) wird z.B. ein physikalisches Gesetz aus der experimentellen Erfahrungsbasis abgeleitet, wobei die konsenserzielende Kraft der Induktion darin liegt, daß eine bestimmte Erfahrung jederzeit wiederholbar und für jeden Diskursteilnehmer nachvollziehbar ist. In Richtigkeitsargumentationen (praktische Diskurse) findet die Induktion durch den Hinweis auf Folgen und Nebenwirkungen der Normbefolgung für die Erfüllung bestimmter Bedürfnisse statt. ${ }^{388}$ Das Brückenprinzip, welches der Induktion die konsenserzielende Kraft verleiht, findet Habermas in dem Universalisierungsgrundsatz. ${ }^{389}$ Dieser Grundsatz gewährleistet nämlich, daß im Diskurs alles herausfällt, was im Kreise der potentiell Betroffenen als Ausdruck eines partikularen Interesses gelten muß - und nicht als eine Partikularität von der Art, wie sie jedem der Beteiligten zugestanden werden könnte. 390 Kann ein Sprecher den von ihm im kommunikativen Handeln erhobenen Geltungsanspruch diskursiv begründen, so hat er sein Begründungsversprechen eingelöst, der Konsens ist wiederhergestellt. Ist er dazu nicht in der Lage, so wird der von ihm erhobene Geltungsanspruch abgelöst und durch einen neuen Konsens ersetzt.

Habermas findet also sowohl das Wahrheitskriterium, als auch das Richtigkeitskriterium im Konsens der Diskursteilnehmer. Um wahre Konsense von bloß faktischen Konsensen unterscheiden zu können, führt er die ideale Sprechsituation ein. Ideal nennt er eine Sprechsituation, in der Kommunikationen weder durch äußere Einwirkungen noch durch Zwänge behindert werden, die sich aus der Kommunikation selbst ergeben. Dies ist dann der Fall, wenn alle Diskursteilnehmer die gleiche Chance haben, Sprechakte aller Art zu wählen und auszuführen. ${ }^{391}$ Damit ist der Universalisierungsgrundsatz in seinen Komponenten der Berücksichtigung der Interessen aller potentiell Betroffenen und des zwanglosen Konsenses zusammengestellt.

Mit dem Konzept der kommunikativen Vernunft wird nun einerseits die rationale Entscheidbarkeit von Wahrheits-, Richtigkeits- und Gerechtigkeitsfragen behauptet. Andererseits ist das Kriterium der Gültigkeit diesbezüglicher Aussagen auf eine weiche

385 J.Habermas, Vorbereitende Bemerkungen, S.139.

$386 \mathrm{Vgl}$. dazu R.Alexy, Argumentation, S.138ff. m.w.N..

387 J.Habermas, Wahrheitstheorien, in: Wirklichkeit und Reflexion, FS f. W.Shulz, hrsg. v. H.Fahrenbach, Pfullingen 1973, S.211ff., 266.

388 J.Habermas, Wahrheitstheorien, S.263f.

389 J.Habermas, Wahrheitstheorien, S.267.

390 J.Habermas, Moralität und Sittlichkeit, S. 221.

391 J.Habermas, Vorbereitende Bemerkungen, S. 136ff. 
Form der "Geltung, die sich für uns erweist", umgestellt. ${ }^{392}$ In die Begriffe der Wahrheit und der Richtigkeit sind gleich mehrfach Spannungen zwischen Faktizität und Geltung eingelassen. ${ }^{393}$ Die Diskursteilnehmer müssen sich gegenseitig Zurechnungsfähigkeit unterstellen, Diskurse müssen handlungsentlastet, d.h. frei von Zeit- und Entscheidungsdruck, stattfinden. Diskurse verweisen nicht nur auf ihre aktuellen Teilnehmer, sondern auf den Konsens einer unbegrenzten Kommunikationsgemeinschaft. Schließlich ist die ideale Sprechsituation eine Idealisierung, die nur annäherungsweise erfüllt werden kann. ${ }^{394}$ Damit wird aber der "wahre" Konsens als "final opinion" selbst zu einer Fiktion. Die Begriffe der Wahrheit und Richtigkeit werden kommunikativ verflüssigt zu einem nie erreichten Ziel eines offenen, aber zielgerichteten Interpretations- und Lernprozesses der unbegrenzten Kommunikationsgemeinschaft. Diesen Befund wendet Habermas nun allerdings wieder, indem er den Wahrheit und Richtigkeit gewährleistenden Kommunikationsvoraussetzungen trotz ihrer Idealität den Status von kontrafaktischen Unterstellungen zuweist, die "alle Beteiligten faktisch jedesmal dann machen müssen, wenn sie überhaupt die Wahrheit einer Aussage behaupten oder bestreiten, und für die

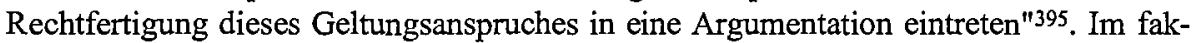
tischen Vollzug von Sprechakten erhalten die idealen Kommunikationsbedingungen somit ihre kontrafaktische Wirklichkeit.

\section{b) Recht, Lebenswelt und System}

Zentralbegriff der Diskurstheorie ist die Lebenswelt. Die Lebenswelt besteht aus einem dezentral verzweigten Netz von umgangssprachlichen (nicht-kodierten) Kommunikationen ${ }^{396}$. In den Grenzen der multifunktionalen Umgangssprache ist die Lebenswelt in die Komponenten Kultur, Gesellschaft und Persönlichkeit ausdifferenziert. Obwohl auch strategische Handlungen (z.B. Lügen, Täuschen) in ihr vorkommen, konstituiert und reproduziert sich die Lebenswelt nur in einem Strom kommunikativen Handelns, in welchem sich kulturelle Reproduktion, soziale Integration und persönliche Sozialisation wechselseitig voraussetzen und produzieren. 397 Strategisches Handeln ist damit kein Mechanismus zur Erzeugung einer Ordnung, sondern findet seinen Platz nur in einer über kommunikatives Handeln schon konstituierten Lebenswelt. 398

\section{(1) Kultur: Recht und Moral als Wissenssysteme}

In der Kulturkomponente der Lebenswelt wird kulturelles Wissen u.a. in Form von Handlungsnormen bevorratet. Unter Handlungsnormen versteht Habermas zeitlich, so-

392 J.Habermas, FuG, S. 29.

$393 \mathrm{Zu}$ den notwendigen Idealisierungen ausführlich J.Habermas, FuG, S.33ff.

394 J.Habermas, Universalpragmatik, S.251ff.

395 J.Habermas, FuG, S.31, vgl. auch ders., Vorbereitende Bemerkungen, S.117ff, 120; ders., Universalpragmatik, S.251ff.

396 Vgl. hierzu und zum folgenden J.Habermas, Handlungen, Sprechakte, sprachlich vermittelte Interaktionen und Lebenswelt, in: ders., Nachmetaphysisches Denken, Ffm 1988, S.95ff.

397 J.Habermas, FuG, S.107f.

398 J.Habermas, FuG, S.43 FN 18: so ist ein Betrug nur möglich, wenn der Getäuschte den vom Täuschenden erhobenen Anspruch auf Wahrhaftigkeit über den handlungsbegleitenden Konsens naiv anerkennt. Ein Kreditbetrug scheitert hingegen, wenn z.B. Banken ihrerseits in strategischer Einstellung ausreichende Sicherheiten verlangen. 
zial und sachlich generalisierte Verhaltenserwartungen. ${ }^{399}$ Mit dem Verfall des Naturrechts haben sich nun rechtliche und moralische Regeln gleichzeitig aus traditionaler Sittlichkeit ausdifferenziert und treten als zwei verschiedene, aber einander ergänzende Sorten von Handlungsnormen nebeneinander. ${ }^{400}$ Modernes, gesatztes Recht und postkonventionelle, prinzipiengeleitete Moral bilden zwei unterschiedliche, aber miteinander verschränkte Wissenssysteme.401 Verschränkt sind Recht und Moral, weil beide Handlungsnormen zum Gegenstand haben. So wie "wahr" als Prädikat in theoretischen Diskursen gültigen assertorischen Sätzen zugeordnet wird, wird "gerecht" als Prädikat in praktischen Diskursen gültigen Handlungsnormen zugeordnet. 402 Auf postkonventionellem Begründungsniveau gilt daher das "sparsame Diskursprinzip"

D: Gültig sind genau die Handlungsnormen, denen alle möglicherweise Betroffenen als Teilnehmer an rationalen Diskursen zustimmen könnten. ${ }^{403}$

Recht und Moral unterscheiden sich hingegen im Hinblick auf ihre Institutionalisierung. Während das Recht in der Gesellschaftskomponente der Lebenswelt als Handlungssystem institutionalisiert ist und deshalb mit dem Anspruch auf Verbindlichkeit auftritt (s.u.), ist die Moral als reines Wissenssystem nicht an die konkrete Lebensform einer bestimmten Gesellschaft gebunden, sondern abstrahiert in ihrem Bezug auf eine unbegrenzte Kommunikationsgemeinschaft (Menschheit) von allen Hintergrundgewißheiten, indem sie (ethische) Fragen des "Guten" von (moralischen) Fragen des "Gerechten" trennt. ${ }^{404}$ Die Moral betrachtet grundsätzlich alles im scharfen, aber engen Kegel des Universalisierungsprinzips (U), das als Spezifizierung des allgemeinen Diskursprinzips ${ }^{405}$ gültige moralische Normen als "richtig" ausweist. 406

Rechtsnormen erheben zwar den Anspruch, nicht gegen Moralnormen zu verstoßen. $\mathrm{Da}$ das Recht als Handlungssystem aber immer in einer konkreten Gesellschaft institutionalisiert ist, können Rechtsnormen nicht nur mit moralischen, sondern auch mit pragmatischen (Frage: Was ist zweckmäßig?) und ethisch-politischen (Frage: Was ist gut für uns?) Gründen gerechtfertigt werden und gegebenenfalls das Ergebnis eines fairen Kompromisses darstellen. ${ }^{407}$ In ethisch-politischen Diskursen bildet die Lebensform "je unseres" politischen Gemeinwesens das Bezugssystem, in pragmatischen Diskursen gegebene Ziele und akzeptierte Werte.

Rechtsnormen legitimieren sich daher am Demokratieprinzip (D'), welches seinerseits als Spezifizierung des allgemeinen Diskursprinzips genau den Rechtsnormen Gel-

399 J.Habermas, FuG, S.138; diese Formulierung kommt von N.Luhmann (Rechtssoziologie, Kap. II, S.94, 99), ist in Bezug auf moralische Normen aber ungenau, da soziale Generalisierung i.S.v. Luhmann (a.a.O., S.64ff.) auf reflexive Institutionalisierung und damit auf ein Handlungssystem hinausläuft. Die Moral ist nach Habermas (FuG, S.106) aber gerade kein Handlungssystem. Zur Abgrenzung von Luhmanns Normbegriff siehe J.Habermas, FuG, S.70f.

400 J.Habermas, FuG, S.135.

401 J.Habermas, FuG, S.106f.

402 J.Habermas, FuG, S. 190.

403 J.Habermas, FuG, S.138.

404 J.Habermas, Moralität und Sittlichkeit - Was macht eine Lebensform rational?, S.220f.

405 J.Habermas, FuG, S.139, 145.

406 J.Habermas, FuG, S.193.

407 J.Habermas, FuG, S.193, $197 \mathrm{ff}$. 
tung zuspricht, die in einem ihrerseits rechtlich verfaßten diskursiven Rechtsetzungsprozeß die Zustimmung aller Rechtsgenossen finden können. ${ }^{408}$

Dieser diskursive Rechtssetzungsprozess umfasst pragmatische, ethisch-politische, moralische und juristische (i.S.e. juristischen Kohärenzprüfung von Gesetzen) Diskurse sowie verfahrensregulierende Verhandlungen ${ }^{409}$, weshalb Rechtsnormen im Gegensatz zu moralischen Normen nicht nur gerecht, sondern "legitim" i.S.v. zweckmäßig, gut für uns, fair und kohärent sind. .10411

\section{(2) Gesellschaft: Recht als Handlungssystem}

In der Gesellschaftskomponente der Lebenswelt sind verschiedene Handlungssysteme anhand von Kodes und Funktionen ausdifferenziert. Das Recht erfüllt die Funktion der Stabilisierung von Verhaltenserwartungen und konstituiert sich über einen binären Rechtskode (recht/unrecht). ${ }^{412}$ Zum Recht als Handlungssystem im weiteren Sinne gehören alle Kommunikationen, die an Recht orientiert sind. Zum Rechtssystem im engeren Sinne gehören hingegen nur solche Interaktionen, die neues Recht produzieren und als Recht reproduzieren (Rechtsakte). Das Rechtssystem i.e.S. wird über sekundäre Regeln institutionalisiert, die Kompetenzen der Setzung (Begründung), Anwendung und Implementierung von Recht konstituieren und übertragen. ${ }^{413}$ Als Teil der Gesellschaftskomponente der Lebenswelt ist das Recht eine reflexiv gewordene legitime Ordnung. Gleichzeitig ist es als Wissenssystem (Kultur) und als rechtssozialisatorisch erworbene Kompetenz der Interpretation und Beachtung von Rechtsregeln (Persönlichkeitsstruktur) in den beiden anderen Komponenten der Lebenswelt präsent. Alle drei Komponenten haben gleichursprünglich Teil an der Produktion von Rechtshandlungen. Der Rechtskode behält insofern Anschluß an das lebensweltliche Medium der Umgangssprache. ${ }^{414}$

Von den derart ausdifferenzierten Handlungssystemen unterscheidet Habermas nun Funktionssysteme wie die geldgesteuerte Ökonomie und die machtgesteuerte Verwaltung. Deren Spezialkodes Geld und Macht vereinseitigen unter funktionalen Gesichtspunkten die Aspekte von Kosten und Nutzen sowie Befehl und Gehorsam und reproduzieren sich daher ausschließlich über strategische Interaktionen. Der lebensweltliche Kreislauf kommunikativen Handelns wird dort, wo er auf die für umgangssprachliche

408 J.Habermas, FuG, S.141.

$409 \mathrm{Zu}$ diesem Prozeßmodell der vernünftigen politischen Willensbildung ders., FuG, S.207.

410 J.Habermas, FuG, S.194.

411 Die Begrifflichkeiten sind bei Habermas zum Teil widersprüchlich, zum Teil verwirrend. Zusammenfassend wird man folgende Begriffe einander zuordnen können: (1.) Theoretische Fragen, theoretische Diskurse, Wahrheit. (2.) Praktische (normative) Fragen, praktische Diskurse, Gerechtigkeit, Diskursprinzip D. Als Unterfälle von (2.) ergeben sich: (a) moralische Fragen, Richtigkeit, Universalisierungsprinzip (U) und (b) Rechtsfragen, Legitimität, Demokratieprinzip D'. Demgemäß sind alle Handlungsnormen gerecht, moralische Normen zusätzlich richtig und Rechtsnormen zusätzlich legitim. Vgl. zur Begrifflichkeit nochmals J.Habermas, Die Einbeziehung des Anderen, Ffm 1996, S.59f.

412 J.Habermas, FuG, S.179; als weitere Handlungssysteme nennt Habermas Erziehungs- und Wissenschaftssystem, Schule und Familie (FuG, S.428f.).

413 J.Habermas, FuG, S.108, 239: die Paralellen zu Luhmann sind offensichtlich; inkonsequenterweise rechnet Habermas zum Rechtssystem i.e.S. jedoch nur die staatlichen Funktionen der Gesetzgebung, Justiz und Verwaltung (S.239), während die privatautonome Erzeugung von Rechtsakten als durch reflexives Recht konstituierter Kernbereich des Rechts i.w.S. verstanden wird (S.240).

414 J.Habermas, FuG, S.108. 
Botschaften tauben Medien Geld und adminstrative Macht stößt, unterbrochen. Anhand der Spezialkodes sind die Funktionssysteme aus der reicher strukturierten Umgangssprache nicht nur ausdifferenziert, sondern ausgegliedert. ${ }^{415}$

Die Leistung des Rechtskodes erklärt Habermas nun auf doppelte Weise. Einer aus konkreter Sittlichkeit ausdifferenzierten postkonventionellen Moral, die über das Universalisierungsprinzip die normative Kraft des Faktischen der Hintergrundgewissheiten einer konkreten Lebensform außer Kraft setzt, bleibt nur noch die schwache Motivationskraft rationaler Einsichten. Handlungswirksamkeit erreicht sie nur über die Verankerung moralischer Grundsätze im Persönlichkeitssystem. Die moralisch urteilende Person ist aber mit der eigenständigen Aneignung, Anwendung und Umsetzung moralischen Wissens überlastet. ${ }^{416}$ Die mit dem Verfall traditionaler Sittlichkeit einsetzende Pluralisierung von Lebensformen und Individualisierung von Lebensgeschichten führt zudem zu einer Entschränkung von Kommunikation, welche das im kommunikativen Handeln angelegte Dissensrisiko enorm erhöht. Darüber hinaus werden in modernen Wirtschaftsgesellschaften eine wachsende Menge sozialstrukturell unentbehrlicher strategischer Kommunikationen freigesetzt. Mit wachsender Komplexität (Ausdifferenzierung, Pluralisierung und Entzauberung) tritt in modernen Gesellschaften daher eine Verstetigung von Dissens ein, der die Integrationskapazität verständigungsorientierten Handelns hoffnungslos überfordert. ${ }^{417}$ Ist die Moral schon innerhalb der Lebenswelt mit der Aufgabe der gesellschaftlichen Integration überfordert, so liegt ein zweites Problem in der Ausgliederung der Funktionssysteme. Diese sind anhand ihres Spezialkodes gegenüber lebensweltlichen Botschaften verschlossen, so daß kommunikatives Handeln als Mechanismus der sozialen Integration hier von vorneherein ausscheidet. 418

Das Recht antwortet auf diese doppelte Problemlage nun, indem es die Faktizität der Rechtsdurchsetzung mit der Legitimität eines diskursiven Verfahrens der Rechtssetzung verbindet. Es stellt den Rechtsadressaten dadurch frei, gegenüber einer Rechtsnorm eine objektivierende (strategische) oder eine performative (kommunikative) Einstellung einzunehmen. ${ }^{419}$ Weil Recht in seiner Faktizität auch für die Spezialkodes Macht und Geld verständlich ist, kann es moralische Botschaften aus der Lebenswelt in eine für die Funktionssysteme verständliche Form bringen und so als Transformator im gesellschaftsweiten Kommunikationskreislauf zwischen Lebenswelt und System dienen. ${ }^{420}$ Auf das im entschränkten kommunikativen Handeln angelegte Dissensproblem antwortet das Recht hingegen durch eine Kombination von Entschränkung und Eingrenzung von Kommunikation, nämlich durch Positivierung. Einerseits wird in positiven Gesetzen verbindlich festgelegt, was Recht ist, um so Rechtssicherheit zu gewährleisten. Andererseits ist das geltende Recht in den dafür vorgesehenen Verfahren jederzeit änderbar. Das Dauerrisiko des Widerspruchs wird so diskursiv auf Dauer gestellt und in die Produktivkraft einer präsumptiv vernünftigen politischen Meinungs- und Willensbildung umgewandelt. 421

415 J.Habermas, FuG, S.77f., 100f., 150.

416 J.Habermas, FuG, S.146ff.

417 J.Habermas, FuG, S.37, 42, 44 mit FN 18a, S.55ff.

418 J.Habermas, FuG, S.108, 150.

419 J.Habermas, FuG, S.47ff.

420 J.Habermas, FuG, S.108, 150, 429.

421 J.Habermas, FuG, S.56f. 
Sowohl Faktizität als auch Geltung bezieht das Recht aus einer Verbindung, die es mit politischer Macht eingeht. Seine faktische Durchsetzungskraft erhält das Recht in einem Proze $\beta$, in dem sich staatliches Recht und politische Macht gleichursprünglich konstituieren. Auf einer ersten Stufe verschmelzen sakrales Recht und soziale Macht in der Position eines königlichen Richters oder Richterkönigs. Auf einer zweiten Stufe dient Recht der Konstituierung eines binären Machtkodes (Befehl/Gehorsam), durch den sich politische Herrschaft in Formen des positiven Rechts zur legalen Herrschaft entwickelt. Umgekehrt dient Macht, soweit sie richterlichen Entscheidungen Nachachtung verschafft, zur Konstituierung eines binären Rechtskodes. ${ }^{422}$

Seine Legitimität kann das Recht hingegen nicht ebenfalls diesem Bündnis mit letztlich auf physischer Gewalt beruhender - administrativer Macht entnehmen. Die Legitimität des Rechts beruht statt dessen auf einem Bündnis mit einer rechtsetzenden kommunikativen Macht, die der Meinung, auf die sich viele öffentlich geeinigt haben, entspringt. Das Recht ist insofern ein Medium, über das sich kommunikative Macht in administrative umsetzt. ${ }^{423}$

\section{c) Diskurse, Rechtsverfahren und Legitimität}

Habermas führt eine Vielzahl von unterschiedlichen Diskursen ein, die die Annahme nahelegen könnten, daß er die These der Möglichkeit einzig richtiger Antworten auf praktische (normative) Fragen und damit den Anspruch auf Begründung universell geltender Normen aufgegeben hat. ${ }^{424}$ Die Unterscheidung zwischen moralischen, ethisch-politischen, pragmatischen und juristischen Diskursen, sowie die Unterteilung in Begründungs- und Anwendungsdiskurse ${ }^{425}$ bedeutet jedoch keine Auflösung in sich widersprechende Teilrationalitäten, sondern spezifiziert lediglich das allgemeine Diskursprinzip (D) in sachlicher, zeitlicher und sozialer Hinsicht. Sachlich dient die Aufteilung praktischer Fragen in solche der Zweckmäßigkeit, des Guten und des Gerechten der Unterscheidung von Recht und Moral (s.o.), sowie der Begründung der vom Demokratieprinzip schon vorausgesetzten ${ }^{426}$ These, daß demokratische Rechtssetzung auch da, wo sie über moralische Fragen hinausgreift, als rationaler Prozeß verstanden werden kann.427 Zeitlich dient die Unterscheidung von Normbegründung und Normanwendung der Unterscheidung und Abgrenzung von Gesetzgebung und Rechtsprechung. ${ }^{428}$ Sozial, d.h. im Hinblick auf die Institutionalisierung von Rechtsdiskursen, dient die Unterscheidung

422 J.Habermas, FuG, S.176-179, mit Verweis auf K. Eder, Die Entstehung staatlich organisierter Gesellschaften, Ffm 1976; zu den Parallelen bei Luhmann (Funktion/Leistung) s.o.

423 J.Habermas, FuG, S.182ff.

424 Tendenziell in diese Richtung hat G.Teubner Habermas' Rechtstheorie diskutiert: De collisione discursuum. Communicative rationalities in law, morality and politics, Paper for the conference "Jürgen Habermas. On his recent contributions to legal theory", Cardozo Law School, New York, Sept. 1992; ebenso ders., Frankfurter Rundschau v. 11.11,1992 S. B 7; kritisch dazu R. Dreier, Bemerkungen zu "Faktizität und Geltung", Typoskript, Göttingen 1993, S.16f.; vgl. dazu auch die Replik von J.Habermas, Die Einbeziehung des Anderen, S.309ff., 370-377.

425 J.Habermas, FuG, S.196ff., 265ff.; ders., Vom pragmatischen, ethischen und moralischen Gebrauch der praktischen Vernunft, in: ders., Erläuterungen zur Diskursethik, Ffm 1991, S.100-118; zur Unterscheidung von Begründungs- und Anwendungsdiskursen siehe auch K.Günther, Der Sinn für Angemessenheit, Ffm 1988.

426 J.Habermas, FuG, S.140.

427 J.Habermas, FuG, S.161, 170, 196ff.

428 J.Habermas, FuG, Kap. V, S.280f., 285ff., Kap. VI, S.318. 
zwischen moralischen, ethischen und pragmatischen Diskursen der funktionalen Differenzierung von Gesetzgebung, Justiz und Verwaltung, indem Gewaltenteilung als Verteilung von Zugriffsmöglichkeiten auf verschiedene Sorten von Gründen verstanden wird. ${ }^{429}$ Die vielfältigen Diskursarten explizieren auf dieser Ebene also nur die einheitliche regulative Idee des Diskursprinzips (D).

Die Legitimität des Rechts bemißt sich nun an der Vernünftigkeit des demokratischen Verfahrens politischer Gesetzgebung. Rechtsanwendungsdiskurse betreffen demgegenüber die Angemessenheit der Anwendung einer Norm auf einen konkreten Fall. Richterliche Urteile sind deshalb immer relativ vernünftig im Bezug auf die Vernünftigkeit der Gesetze. ${ }^{430}$ Während die Spezifizierung des Diskursprinzips (D) durch die unterschiedlichen Diskurstypen erklärt, wie eine vernünftige politische Willensbildung überhaupt möglich ist, sagt das Demokratieprinzip, wie diese institutionalisiert werden kann. ${ }^{431}$ Das Demokratieprinzip verdankt sich einer Verschränkung von Diskursprinzip und Rechtsform. Menschenrechte ${ }^{432}$ und Volkssouveränität ergeben sich dabei gleichursprünglich aus der (privaten und öffentlichen) Autonomie der Bürger, die sich als Rechtsgenossen zusammenschließen, um ihr Zusammenleben mit Mitteln des positiven Rechts legitim zu regeln. ${ }^{433}$ Volkssouveränität verkörpert sich allerdings nicht in einer identifizierbaren Versammlung autonomer Bürger oder ihrer Repräsentanten, sondern zieht sich in die gleichsam subjektlosen Kommunikationskreisläufe von vernünftig strukturierten Beratungen in Foren und Körperschaften zurück. ${ }^{434}$ Die Einheit der vollständig prozeduralisierten Vernunft der politischen Willensbildung findet sich in der wechselseitigen Ergänzung von einer in der Zivilgesellschaft verankerten, nicht-institutionalisierten politischen Öffentlichkeit (Peripherie) einerseits, und einem über demokratische Verfahren institutionalisierten Kern deliberativer Politik (Zentrum) andererseits ${ }^{435}$. Das diskurstheoretische Ideal einer "einzig richtigen" Entscheidung kann allerdings nur auf dieser hochabstrakten Ebene festgehalten werden, auf der sich die in einer Vielzahl von Foren und Gremien dezentrierte, subjektlose kommunikative Vernunft in einer Gesamtschau zu einem offenen, aber doch am regulativen Ideal einer "final opinion" orientierten, und deshalb zielgerichteten Lernprozeß verbindet.

Andererseits zerfällt diese Einheit der Vernunft schon durch die Einbeziehung von ethisch-politischen Fragen in den Rechtssetzungsprozeß. Denn dadurch wird legitimen Rechtsnormen ein Bezug zu konkreten Lebensformen (staatlich organisierten Gesellschaften) eingeschrieben, der es zuläßt, daß inhaltlich gegensätzliche Normen in zwei demokratischen Staaten gleichzeitig als legitim gelten. ${ }^{436}$ Das Gesetzgebungsverfahren besteht zwar neben ethischen auch aus moralischen Diskursen, und Rechtsnormen erhe-

429 J.Habermas, FuG, S.235f.

430 J.Habermas, FuG, S.284ff.

431 J.Habermas, FuG, S.142.

432 Die Menschenrechte rekonstruiert Habermas als ein System von Rechten, die Bürger einander zuerkennen müssen, wenn sie ihr Zusammenleben mit den Mitteln des positiven Rechts regeln wollen. Das System der Rechte etabliert den Rechtskode. Es gibt kein legitimes Recht ohne diese Rechte. J.Habermas, FuG, S.151ff., 155, 159.

433 J.Habermas, FuG, S.154ff.

434 J.Habermas, FuG, S.170, 228, 362, 365.

435 J.Habermas, FuG, S.224 und Kap. VII und VIII, S.429ff,; vgl. ausführlich oben I. 2. b).

436 Darauf weist zu Recht G.Teubner (De collisione discursuum) mit dem Zitat von B. Pascal hin; "A funny justice that ends at a river! Truth on this side of the Pyrenees, error on that". 
ben deshalb den Anspruch, mit Moralnormen übereinzustimmen, also nicht gegen sie zu verstoßen. ${ }^{437}$ Unklar bleibt dabei aber, was die Konsequenz eines Widerspruches zwischen moralischen Geboten und dem in einem Gesetz zum Ausdruck kommenden ethisch-politischen Selbstverständnis der Rechtsgemeinschaft ist. Habermas formuliert hier so weich, als ob ein Widerspruch gar nicht vorkommen könne. ${ }^{438}$ Im Endeffekt hat jedenfalls das im demokratischen Prozeß entstandene Gesetz immer die Vermutung der Vernünftigkeit auf seiner Seite. ${ }^{439} \mathrm{Da}$ ein allgemeiner moralischer Diskurs nicht institutionalisiert ist, ist ein solcher Widerspruch zunächst auch gar nicht verbindlich feststellbar. $\mathrm{Zu}$ einem solchen Widerspruch kann es demnach nur im Rahmen der verfassungsgerichtlichen Kontrolle der Gesetzgebung kommen, wobei Habermas diese in ihrer Kontrollmacht mit dem prozeduralistischen Rechtsparadigma eher beschränken will. 440

Dieser Befund leitet über zu einem Bereich, in welchem sich das Problem von Teilrationalitäten erst in seiner ganzen Schärfe zeigt. Damit der weitverzweigte, in subjektlose Öffentlichkeiten eingelassene Diskurs der politischen Willensbildung zu verbindlichen Ergebnissen führen kann, muß dieser Diskurs nämlich in einem organisatorisch-professionellen Kernbereich institutionalisiert werden. Dieser Kernbereich bildet sich um die drei staatlichen Gewalten und wird von Habermas, je nach Perspektive, als Rechtssystem im engeren Sinne oder als Zentrum des politischen Systems bezeichnet. ${ }^{441}$ In diesem Kernbereich werden die verschiedenen Diskurstypen nun in Rechtsverfahren eingebettet. Rechtsverfahren stellen allerdings keine direkte Institutionalisierung des Diskursprinzips dar, weil sich die Binnenstruktur von Argumentationsprozeßen rechtlicher Regelung entzieht. Die Einbettung von Diskursen läßt nun zwar deren innere Logik unangetastet, unterwirft die Diskurse aber bestimmten zeitlichen, sozialen und sachlichen Beschränkungen. ${ }^{442}$ Insbesondere die Mehrheitsregel verleiht Rechtsentscheidungen (Gesetz und Urteil) den Status eines bloß interimistisch festgehaltenen Ergebnisses einer fortlaufenden Diskussion. Insgesamt tritt die dem Rechtskode entlehnte soziale Verbindlichkeit eines verfahrensgerecht erzielten Resultates (Geltung) an die Stelle einer durch die Form der Argumentation gesicherten Verfahrensrationalität (Gültigkeit). ${ }^{443}$ Zudem verleiht die Tatsache, daß die Ergebnisse von in Rechtsverfahren eingebetteten ethischen und moralischen Diskursen als Recht Geltung erlangen, diesen Diskursen ge-

437 J.Habermas, FuG, S.193f.

438 J.Habermas, FuG, S.193f.

439 J.Habermas, FuG, S.51 und öfter.

440 J.Habermas, FuG, Kap. VI., S.320: "Allein die Verfahrensbedingungen der demokratischen Genese von Gesetzen sichert die Legitimität des gesatzten Rechts...das Verfassungsgericht soll eben jenes System der Rechte hüten, welches die private und öffentliche Autonomie der Staatsbürger ermöglicht...Deshalb muß das Verfassungsgericht die Inhalte strittiger Normen vor allem im Zusammenhang mit den Kommunikationsvoraussetzungen und Verfahrensbedingungen des demokratischen Gesetzgebers überprüfen." Insofem dürfte Habermas Position nicht als "nichtpositivistische Theorie mit positivistischen Implikationen" (so R.Dreier, Bemerkungen, S.10) sondem als "demokratischer Positivismus" (so z.B. I.Maus, Volkssouveränität, S.137ff.) am besten erfasst sein.

441 J.Habermas, FuG, S.239 einerseits und S.430 andererseits.

442 Diese Beschränkungen arbeitet Habermas insbesondere für das Gerichtsverfahren heraus: J.Habermas, FuG, S.288-291; in Rechtsverfahren eingebettete Diskurse sind damit nicht mehr handlungsentlastet. Da Handlungsentlastung und Erfahrungsfreiheit aber Definitionsmerkmale des Diskurses sind (s.o.), ist fraglich, ob mit der Einbettung nicht der Begriff des Diskurses aufgelöst wird. Jedenfalls verändert er seinen Sinn.

443 J.Habermas, FuG, S.219f; Habermas' Antwort auf die Frage, wie Legitimität kraft Legalität möglich ist, besteht also darin, daß demokratische Legalität eine Vermutung der Legitimität für sich hat. 
genüber analogen Alltagsdiskursen einen spezifisch eingeschränkten Sinn. Denn die Berücksichtigung politisch-ethischer, pragmatischer und moralischer Aspekte darf die Rechtsform nicht zerstören; sie darf Recht nicht in Politik oder Moral aufgehen lassen. Um die "Differenz der Sprachen" aufrechtzuerhalten, bedürfen ethisch-politische und moralische Gehalte einer Übersetzung in den Rechtskode. Alle Beschlüsse unterliegen daher unter juristischem Aspekt einer Kohärenzprüfung. ${ }^{444}$

Ist damit auf die begrenzte Vernunft ${ }^{445}$ von in Rechtsverfahren eingebetteten Diskursen verwiesen, so entstehen echte Konflikte zwischen "Teilrationalitäten" dadurch, daß innerhalb des organisierten Zentrums von Recht und Politik eine Vielzahl von Rechtsverfahren institutionalisiert ist, wodurch im Hinblick auf die einzig richtige Entscheidung Kompetenzprobleme entstehen. Solche Kompetenzprobleme zeigen sich am deutlichsten bei der verfassungsrichterlichen Normenkontrolle, durchziehen aber das gesamte organisierte Entscheidungssystem. Dieses Kompetenzproblem löst Habermas, indem er den demokratischen Gesetzgebungsprozeß grundsätzlich vor allen anderen Rechtsverfahren auszeichnet und über die Gewaltenteilung Rechtsprechung und Verwaltung in der Verfügung über verschiedene Sorten von Gründen einschränkt. ${ }^{446}$ Das Problem bricht allerdings dort wieder auf, wo die Verwaltung und damit auch die Rechtsprechung durch unbestimmte Gesetze nicht hinreichend programmiert werden und deshalb rechtsetzende Funktionen wahrnehmen. ${ }^{447}$ Darauf kommen wir später zurück. An dieser Stelle kommt es nur darauf an, daß ein Widerspruch zwischen Teilrationalitäten dadurch entsteht, daß ein und dasselbe Diskursprinzip (D) an verschiedenen Stellen und in unterschiedlicher Art in Rechtsverfahren institutionalisiert wird. ${ }^{448}$

\section{Recht, Rationalität und Gesellschaft}

Im folgenden werden aus den bisherigen Darstellungen Schlußfolgerungen anhand der drei Begriffe Gesellschaft, Rationalität und Recht gezogen. Dabei werden diese Begriffe so ausgearbeitet, daß Prozedurales Recht als ein Konzept erscheint, das eine Antwort auf ein spezifisches Rationalitätsproblem anbietet, welches als gesellschaftliches Problem der Systemrationalität durch die Institutionalisierung prozeduraler Rationalität entsteht. Mit anderen Worten: Prozedurales Recht in seinen drei Komponenten (Norm, Diskurs, Paradigma) reagiert auf ein Abstimmungsproblem, das entsteht, weil der vom Diskursprinzip (D) geleitete Diskurs der gesamtgesellschaftlichen Integration nicht institutionalisiert ist, sondern dezentriert und subjektlos zum einen in der Zivilgesellschaft zirkuliert, zum anderen an ganz unterschiedlichen Stellen, und unter je verschiedenen zeitlichen, sachlichen und sozialen Beschränkungen in rechtlich organisierte Verfahren

444 J.Habermas, FuG, S. 189 und 207 mit FN 33, sowie S.250ff., 253.

445 Im Sinne der Entfernung vom Diskursideal, nicht hingegen i.S.v. begrenzter Rationalität, denn die Einbettung in Rechtsverfahren ist unter dem Gesichtspunkt der Garantie von fristgerechten, unzweideutigen und bindenden Entscheidungen selbst diskursiv begründbar: J.Habermas, FuG, S.220.

446 S.o. I. 2. c)

447 J.Habermas, FuG, S.235ff. mit FN 62, sowie S.516-537; s.o. I. 2. d)

448 Das gilt in besonderem Maße im Verhältnis Parlament und Verfassungsgericht, aber auch zwischen Parlament und verordnungsgebender Verwaltung, zwischen Gesetzgeber und einfachem Richter, zwischen Vertragspartnern und vertragsauslegendem Richter, im föderalen Staat auch zwischen Landtag und Bundestag und neuerdings bei unklarer Kompetenzabgrenzung über das Subsidiaritätsprinzip zwischen EU und Mitgliedsstaat. 
eingebettet ist. Dieses Abstimmungsproblem kann auch als Problem der strukturellen Kopplung verstanden werden.

\section{Gesellschaft}

Im Anschluß an Luhmann wird Gesellschaft als die Gesamtheit aller Kommunikationen verstanden, wobei Kommunikation kommunikatives und strategisches Handeln einschließt. Kommunikation in diesem weiten Sinne ${ }^{449}$ hört erst da auf, wo physische Gewalt angewendet wird. Denn Gewalt ist Negation der Kommunikation. Der Einsatz von physischer Gewalt kann zwar, insbesondere für miterlebende Dritte, auch einen symbolischen und damit kommunikativen Gehalt haben ${ }^{450}$, ein konkreter "Interaktionspartner" wird durch physischen Zwang aber weder rational noch durch den Einsatz strategischer Mittel motiviert; auf dessen Verstehen oder Annehmen kommt es vielmehr gar nicht an. Im Bereich der Kommunikation erscheint eine Unterscheidung zwischen rationaler Motivation durch "gute Gründe" und strategischer Motivation durch Sanktionen oder Gratifikationen zwar prinzipiell sinnvoll; die Unterscheidung von kommunikativem und strategischem Handeln ist aber aus verschiedenen Gründen ungeeignet für eine strikte Trennung der Gesellschaft in (gute) Lebenswelt und (böse) Funktionssysteme. Denn die Übergänge zwischen strategischem und kommunikativem Handeln sind, gerade auch aus der Aktorperspektive, fließend. So können wir uns schon in der Lebenswelt selbst nie sicher sein, ob wir dem Anspruch auf Wahrhaftigkeit gerecht werden, oder uns selbst und andere täuschen ${ }^{451}$. Rechtskommunikationen definiert Habermas selbst als Mischung von kommunikativem und strategischem Handeln. ${ }^{452}$ Aber auch wirtschaftliche Kommunikationen sind nicht immer und ausschließlich nur strategisch über das

449 Unausgesprochen verwendet auch Habermas einen solchen weiten Kommunikationsbegriff, wenn er sagt: "Zum Recht gehören alle Kommunikationen, die an Recht orientiert sind" (FuG, S.108). Denn Kommunikationen, die an Recht orientiert sind, verweisen implizit oder explizit immer auf staatliche Durchsetzbarkeit, motivieren also durch Verweis auf politische Macht und sind daher strategische Interaktionen.

450 In diesem Sinne hat N.Luhmann darauf hingewiesen, daß physische Gewalt in archaischen Gesellschaften zum Beweis des Rechts diente, indem ihre Anwendung symbolisch das Festhalten an einer verletzten Erwartung darstellte. Mit der Einrichtung des staatlichen Gewaltmonopols und der Ausdifferenzierung eines organisierten Rechtssystems verliert Gewalt ihre Symbolqualität und gibt sie an die Entscheidung ab. Der Beweis des Rechts liegt jetzt in der abstrakten Entscheidung über Recht und Unrecht (Urteil).Die öffentliche Ausübung physischer Gewalt wirkt in der Kommunikationsgesellschaft dagegen delegitimierend (N.Luhmann, Rechtssoziologie, S.106ff., 113,115).

451 Diese Ambivalenz von Aufrichtigkeit, Selbst- und Fremdtäuschung ist z.B. von E.Goffman (Wir alle spielen Theater (1959), deutsche Neuausgabe München 1983, insbes. S.65ff.) in vielen Variationen ausgearbeitet worden.

452 J.Habermas, FuG, S.45-60. Faktisch überwiegt aber wohl strategische Motivation: Wenn der Vermieter $\mathrm{V}$ unangemeldet vor der Tür steht, um die Wohnung des Mieters $M$ zu besichtigen, kann $M$ antworten: "Sie haben kein Recht, die Wohnung unangemeldet zu betreten". Darin mag auch ein Verweis auf den moralischen Gehalt der Rechtslage liegen. Implizit liegt aber immer schon der Verweis auf staatliche Durchsetzbarkeit im Raum. Den uneinsichtigen V wird $M$ daher auf die Rechtsfolgen verweisen ("Ich zeige Sie an wegen Hausfriedensbruch"). Dem zögernden V wird M die Rechtslage erläutern (Ein Gesetz, ein Urteil oder ein Handbuch des Mietrechts zitieren). Behauptet $V$ nun, das Gesetz sei unrichtig, kann $M$ ihn auf den politischen Weg verweisen. All dies sind strategische Interaktionen, sie motivieren $V$ nicht rational i.S.v. kommunikativem Handeln. Bittet $V$ den $M$ nun etwa unter Verweis auf seinen langen Anfahrtsweg, ihn doch einzulassen, so ist der Bereich der rechtlichen Kommunikation verlassen. Auf diese moralische Kommunikation kann $M$ sich einlassen oder eben nicht. 
Medium Geld motiviert. ${ }^{453}$ Geld kann zudem selbst ein "guter Grund" zur Annahme eines Kommunikationsangebots sein, denn einerseits behält Geld über seinen Tauschwert immer einen Bezug zu kommutativer Gerechtigkeit ${ }^{454}$, andererseits kann wirtschaftliche Wertschöpfung auch der Verwirklichung moralischer Gebote dienen. ${ }^{455}$ Das Wirtschaftssystem ist also keineswegs als gegenüber kommunikativem Handeln "taubblindes" Funktionssystem aus der Lebenswelt ausgeglieder ${ }^{456}$, sondern grundsätzlich ebenso gegenüber moralischen Gehalten offen wie das Rechtssystem. Handelten Konsumenten und Produzenten lediglich erfolgsorientiert, so wäre nicht zu erklären, warum z.B. das gemeinwohlorientierte Merkmal der Umweltfreundlichkeit eines Produktes zu einem entscheidenden Verkaufsargument der vergangenen Jahre avanciert ist und so den gesamten wirtschaftlichen Kommunikationskreislauf457 beeinflußt hat. Gemeinwohlorientierung fügt sich so in die wirtschaftliche Autopoiese ein, ja wird für einzelne Unternehmen sogar zur Überlebensfrage, wenn dem "Umweltschwein" die Pleite droht. Ebenfalls unerklärlich bleibt für Habermas auch die Tatsache, daß nicht nur einzelne Unternehmer, sondern auch organisierte Unternehmerverbände immer wieder öffentlich beklagen, daß eine umweltfreundliche und sozialverträgliche Ausrichtung der Unternehmenspolitik durch politisch-rechtliche Rahmenbedingungen (und nicht etwa durch den Marktmechanismus selbst) nicht nur nicht begünstigt, sondern effektiv behindert wird. 458 Ist die Wirtschaft damit grundsätzlich gegenüber "lebensweltlicher" Kommunikation offen, so gilt für das Wirtschaftssystem ebenso wie für das Rechtssystem, daß die Differenz der Sprachen ${ }^{459}$ aufrechterhalten bleiben muß. Moralische Gehalte bedürfen daher jeweils einer Übersetzung in den Rechts- oder Wirtschaftskode, die diesen eine kodespezifische Bedeutung verleiht. Gleiches gilt auch für die machtgesteuerte Verwaltung. Daß die moderne politische Verwaltung in ihrer Vielfalt nicht gleich einer Ar-

453 A schließt einen mündlichen Vertrag mit B über den Verkauf seines Hauses, Obwohl C ihm kurze Zeit später mehr Geld bietet, und obwohl A wegen $\S 313$ BGB rechtlich nicht zum Verkauf an B verpflichtet ist, verkauft er an B, weil er sich moralisch an die Einigung "per Handschlag" gebunden fühlt (eine "Ehrensache"). Der homo oeconomicus (rational actor) ist weder realer psychischer Sachverhalt noch rein analytische Konstruktion, sondern kommunikationserhaltende Realfiktion: M.Hutter/G.Teubner, The Fat Plunder of Society, Homo juridicus and homo oeconomicus as Communicative Fictions, Typoskript, EHI May 1994.

454 Zum aristotelischen Begriff der kommutativen (synallagmatischen) Gerechtigkeit vgl. R.Dreier, Gerechtigkeit, S.8ff., $14 \mathrm{f}$.

455 Unmittelbar, wenn Sparsamkeit, Fleiß und Arbeit, wie etwa insbesondere bei den Calvinisten, selbst zu moralischen Tugenden erklärt werden; mittelbar, wenn moralisch gebotene Leistungen (Sozialstaat, Entwicklungshilfe etc.) erst "erwirtschaftet" werden müssen.

456 So aber J.Habermas, FuG, S.78, 108, 150 und öfter.

457 Also nicht nur Zahlungen i.S.v. einzelnen Kaufentscheidungen, sondern Forschung und Entwicklung, Werbung, Investitionsstrategien, auch Unternehmenskultur etc..

458 Indem nämlich der Faktor Arbeit durch Sozial- und Steuerpolitik künstlich verteuert wird, während Ressourcenverschwendung häufig begünstigt wird, wodurch wirtschaftliche Investitionen künstlich in arbeitsplatzvernichtende Rationalisierungsmaßnahmen anstatt in Umweltschutzmaßnahmen gelenkt werden. Das Marktprinzip der Gewinnmaximierung ist grundsätzlich gegenüber beiden Investitionsarten neutral, läßt also bei unter dem Gesichtspunkt der Gewinnmaximierung gleichwertigen Investitionsmöglichkeiten Raum für eine moralische Wahl, der erst durch (nicht-intendierte) politische Steuerung eingeschränkt wird. S.o. Kap. 1 V. 3.

459 So J.Habermas für die Trennung von Recht und Moral, s.o. 
mee auf das Schema Befehl/Gehorsam reduziert werden kann, bedarf keiner Erläuterung. 460

Bei der Unterteilung in ausgegliederte Funktionssysteme und blo $\beta$ ausdifferenzierte Handlungssysteme geht es Habermas darum, die Möglichkeit von vernunftorientierter, intentionaler Gesellschaftsintegration gegenüber nichtintentionaler, systemischer Vergesellschaftung zu behaupten.. ${ }^{461}$ Damit ist das Spannungsverhältnis von Autonomie und Entfremdung angesprochen. M.E. läßt sich diese Spannung aber nicht durch die Gegenüberstellung von autonommieermöglichender Lebenswelt und entfremdender Funktionssysteme auflösen. Vielmehr ist die Ambivalenz zwischen Freiheitsermöglichung und Entfremdung grundsätzlich in jeder gesellschaftlichen Systembildung angelegt. Das gilt schon für das lebensweltliche Medium der Umgangssprache, worauf u.a. die Frauenbewegung immer wieder hingewiesen hat. ${ }^{462}$ Einerseits setzen Ich-Identität und Persönlichkeitsbildung gesellschaftliche Kommunikation voraus ${ }^{463}$, andererseits tritt den Individuen die Macht der Verhältnisse in Form der in die Umgangssprache eingelassenen kulturellen Überlieferungen entgegen (Sprache schafft Wirklichkeit). ${ }^{464}$ Gleiches gilt für Recht und Politik. Politische Macht in Form des staatlichen Gewaltmonopols ermöglicht das Entstehen der Kommunikationsgesellschaft ebenso, wie sie - in ihrer Tendenz zur Verselbständigung - die kommunikative Freiheit gefährdet. Recht befreit die Individuen aus ursprünglichen sozialen Abhängigkeiten, indem es jedermann die gleichen rechtlichen Freiheiten einräumt (Autorisierung), ebenso, wie eine fortschreitende Verrechtlichung diese Freiheit gefährdet (paternalistische Betreuung). Wirtschaft ermöglicht Freiheit in Form von Tauschfreiheit und wirtschaftlicher (eben nicht rechtlicher) Unabhängigkeit ebenso, wie sie zur Entfremdung führt. Systeme sind deshalb von Haus aus zweischneidige Schwerter.

Diese Zweischneidigkeit erfasst Habermas nicht, wenn er das Rechtssystem zu dem zentralen Instrument der intentionalen gesellschaftlichen Integration idealisiert, welches allein in der Lage sei, lebensweltliche Botschaften an die Funktionssysteme mitzuteilen. ${ }^{465}$ Die früher von Habermas ausgearbeitete These der "Kolonialisierung der Lebens-

460 Neben der traditionellen Eingriffsverwaltung haben sich die Leistungsverwaltung und im Bereich des technischen Sicherheitsrechts die Präventionsverwaltung etabliert. Verwiesen sei auch auf den Begriff des "integrativen Verwaltungshandelns". Ein guter Überblick bei D.Fürst, Die Neubelebung der Staatsdikussion: Veränderte Anforderungen an Regierung und Verwaltung in westlichen Industriegesellschaften, Jahrbuch zur Staats- und Verwaltungswissenschaft 1987, S.261-284, sowie E.H.Ritter, Staatliche Steuerungspraxis, S.321ff.; H.Hill, Integratives Verwaltungshandeln - Neue Formen von Kommunikation und Bürgermitwirkung, DVwBl 1993, S.973ff.

461 Vgl. die Diskussion von Luhmann und Teubner bei J.Habermas, FuG, S.68-78.

462 Ein guter Überblick bei C.Smart, The Woman of Legal Discourse, Social and Legal Studies 1992, S.29-44; Zur Macht und Gewalt der Sprache siehe auch N.Luhmann, RdG, S.126f mit Nachweisen in FN 10, sowie die Debatte um "political correctness".

463 Dies ist insbesondere von G.H.Mead (Geist, Identität und Gesellschaft (1934), 7.Aufl. Ffm 1988), sowie von L.S.Wygotski (Denken und Sprechen, Ffm 1980) und J.Piaget ausgearbeitet worden.

464 P.L.Berger/T.Luckmann, Die gesellschaftliche Konstruktion der Wirklichkeit, Ffm 1969; ein Überblick über Theorien des sozialen Konstruktivismus bei J.Baecker et al., Sozialer Konstruktivismus eine neue Perspektive in der Psychologie, in: S.J.Schmidt (Hrsg.), Kognition und Gesellschaft, Ffm 1992, S.116ff., wo ausgeführt wird, wie sehr das individuelle Denken und Sprechen an aus "kommunalen Mythen" gespeiste Sprachskripte, Denk- und Verhaltensdrehbücher gebunden ist (a.a.O. S.122ff.).

465 Fast scheint es so, als ob Habermas immer den jeweiligen Gegenstand seiner Untersuchung idealisiert. Bestand der Witz der Diskurstheorie nämlich zunächst in der Forderung, daß moralische Ur- 
welt" durch Recht passt nicht zu diesem Idealbild des Rechts und wird deshalb in "Faktizität und Geltung" nicht fortgeführt. ${ }^{466}$

Demgegenüber wird hier ein zunächst neutraler Systembegriff bevorzugt, innerhalb dessen dann das Problem der Ambivalenz von Freiheitermöglichung und Entfremdung diskutiert werden kann. Ein solcher neutraler Systembegriff ist aber Luhmanns Begriff des autopoietischen Systems. Wie oben dargestellt bedeutet Autopoiese dabei nicht, daß ein System sich gegenüber moralischen Gehalten abschließt und deshalb intentionale, vernünftige gesellschaftliche Integration unmöglich wird. ${ }^{467}$ Autopoiese ist vielmehr logische Voraussetzung dafür, daß es überhaupt Systeme gibt, weil der Begriff des Systems als Innenseite einer Form immer den Begriff der Umwelt als Außenseite der Form mit einbezieht und es ein System deshalb nur geben kann, wenn dieses sich selbst von seiner Umwelt unterscheiden kann. Im Falle von Kommunikationssystemen, die sich von anderen Kommunikationen unterscheiden müssen, geschieht dies anhand eines Kodes, der - und insofern besteht ja Einigkeit - bewirkt, daß moralische Gehalte nur über einen Akt der Transformation in das Recht eingeführt werden können.

Das Autopoiesekonzept schließt weiterhin nicht aus, daß es so etwas wie lebensweltliche Kommunikation gibt. Die Gesellschaft besteht zunächst aus allen Kommunikationen. Da zwischen Kommunikation und Nicht-Kommunikation unterschieden werden kann, bedarf die Gesellschaft selbst zur Abgrenzung von ihrer Umwelt keines Codes. Für Luhmann gibt es zwar keine nicht-systemische Kommunikation, weil für ihn schon jede Interaktion ein System ist. ${ }^{468}$ Daraus folgt allerdings nicht, daß es keine Kommunikation außerhalb der großen Subsysteme Politik, Recht, Wirtschaft, Gesundheit etc. geben könnte. Daß Kommunikationen sich den Codes der Subsysteme selbst zuordnen ${ }^{469}$, schließt die Möglichkeit ein, daß sie sich keinem dieser Codes zuordnen. Insofern gibt es nicht-codierte, allgemeingesellschaftliche Kommunikationen, die man auch als le-

teile in faktisch stattfindenden Diskursen zwischen den Betroffenen gefunden werden sollten, womit der Moral eine aktuell kritische Wirksamkeit in Konkurrenz zu Politik und Recht (gleichsam als Gegenpolitik) zugeordnet wurde, so soll die Moral sich nunmehr wieder traditionell (und damit wirkungslos) auf individuelle Willensbildung beschränken (FuG, S.21).

466 Zur Kolonialisierung der Lebenswelt siehe J.Habermas, Theorie des kommunikativen Handelns, Bd. 2, S.530-547; Das Problem wird nunmehr als Problem der sozialstaatlichen Materialisierung des Rechts diskutiert, die These selbst wird aber mit der ihr zugrundeliegenden Unterscheidung zwischen Recht als Institution und Recht als Medium fallengelassen: ders., FuG, S.501ff. mit FN 47.

467 So versteht aber Habermas den Begriff der Autopoiese, was u.a. darauf zurückzuführen ist, daß er nicht Luhmanns sondern Teubners Autopoiesebegriff diskutiert (FuG, S.68ff). Das führt insofern in die Irre, als Teubner a) Autopoiese als gradualisiertes Konzept fasst, nach dem sich das Recht in mehreren Schritten immer weiter gegenüber seiner Umwelt abschließt (G.Teubner, Recht als autopoietisches System, S.38), b) Informationelle Offenheit radikal konstruktivistisch als Erstellung eines streng systemrelativen, inneren Modells der Außenwelt versteht und so die Geschlossenheit verdoppelt (a.a.O., S.88), c) als Zivilrechtler das Konzept der Interferenz nur auf den Vertrag bezieht, wohingegen die Rolle der Gesetzgebung völlig im Dunkeln bleibt, so daß der Eindruck entsteht, Autopoiese bedeute die Abkopplung des Rechts von demokratischer Politik und deshalb Selbstlegitimation, und d) als Steuerungstheoretiker eine Darstellung wählt, die zunächst zur Verdeutlichung des Steuerungsproblems die Geschlossenheit des Rechts übertreibend auf die Spitze treibt, um dann im zweiten Teil reflexives Recht als Lösung anzubieten. (s.o. I. 3.; ausfïhrlich unten III. 3.).

468 So sind für Luhmann auch Diskurse, soweit sie faktisch an einem bestimmten Ort und zu einer bestimmten Zeit stattfinden, Diskussion-Systeme: N.Luhmann, Systemtheoretische Argumentationen. Eine Entgegnung auf Jürgen Habermas, in: Habermas/Luhmann, Theorie der Gesellschaft oder Sozialtechnologie, S.291ff., dort II. Diskussion als System, S.316ff.

469 N.Luhmann, RdG, S.69. 
bensweltliche Kommunikationen bezeichnen kann. ${ }^{470}$ Am Moralcode ${ }^{471}$ orientierte moralische Kommunikationen können, da die Moral nicht als Handlungssystem institutionalisiert ist, nicht unmittelbar wirksam werden. Soweit sie sich auf Recht beziehen, also eine Rechtsänderung herbeiführen wollen, gehören sie als Rechtskommunikationen zum Rechtssystem im weiteren Sinne. Um im Recht wirksam zu werden, bedürfen sie allerdings der Umsetzung durch Rechtsakt (Gesetz, Urteil), weshalb sie z.B. in Parteien und sozialen Bewegungen als politische Forderungen auftreten, die sich an die politischen Entscheidungszentren richten. ${ }^{472}$

Die Gesellschaft ist als Kommunikationsgesellschaft zentrumslos. Innerhalb der Gesellschaft bilden sich anhand von bestimmten Funktionen Subsysteme, die aufgrund ihres jeweiligen Codes ausdifferenziert sind. Die so konstituierten Kommunikationskreisläufe reproduzieren sich im oben beschriebenen, weichen Sinne selber und bilden so Spezialsprachen aus, die zwar Anschlu 3 an die Umgangssprache halten, vom "Laien" in ihrem spezifischen Sinn allerdings nicht ohne weiteres verstanden werden können. Innerhalb dieser Kommunikationskreisläufe bildet sich ein Handlungskern (z.B. Rechtsakte, Zahlungen), der sich wiederum in Zentrum und Peripherie gliedert. In diesem Sinne ist die Gesellschaft eine polyzentrische Gesellschaft ${ }^{473}$, wobei den staatlichen Systemen Recht und Politik nur insofern eine Sonderstellung zukommt, als deren Funktionen der Stabilisierung von Verhaltenserwartungen und des kollektiv verbindlichen Entscheidens einen besonderen Bezug zur Aufgabe der gesamtgesellschaftlichen Integration aufweisen. ${ }^{474}$

\section{Rationalität}

Rationalität interessiert hier zunächst in Zusammenhang mit gesellschaftlichen Entscheidungen, also als Prädikat. ${ }^{475} \mathrm{Im}$ Recht steht dabei die Entscheidung von normativen Fragen im Vordergrund, weshalb für solche Fragen auch das Prädikat gerecht verwendet werden kann (s.o.). Rationalität oder Gerechtigkeit ist dabei an Begründung gebunden. Rational ist die Entscheidung, für die gute Gründe angegeben werden können. Gute Gründe sind dabei immer substantielle Gründe, die aus der Erfahrung stammen. ${ }^{476}$ Damit stellt sich die Frage, wie gute Gründe identifiziert werden können. Alle materialen Gerechtigkeitstheorien, die solche guten Gründe anhand eines externen, objektiven Kriteriums identifizieren wollen, sind letztendlich gescheitert. 477 Die Idee prozeduraler

470 So z.B. G.Teubner, Recht als autopoitisches System, S.106ff, 109.

471 Nach obigen Ausführungen zu Habermas' Unterscheidungen hieße der Moralcode (richtig/unrichtig). Wer Habermas' Unterscheidung zwischen ethischen Fragen des Guten und normativen (moralisch und rechtlichen) Fragen des Gerechten nicht mitvollzieht, könnte den Moralcode auch (gut/böse) bezeichnen.

472 Hier sehe ich volle Übereinstimmung zwischen Habermas und Luhman. Zu Luhmanns Verständnis der Moral siehe ders., The Code of the Moral, Cardozo Law Review 1993, S.995-1009; zum Verhältnis von Recht und Moral ders., RdG, S.78ff., 94f., 99f., 137, 148f.

$473 \mathrm{Zu}$ diesem Begriff vgl. H.Willke, Ironie, S.57 und öfter.

474 Auch Habermas meint, daß man sich den Staat realistischerweise nur als ein System unter anderen vorstellen kann (FuG, S.489), und unterscheidet Politik von Recht, wobei weder Politik in Recht noch Recht in Politik aufgehen dürfe (FuG, S.173ff., 189). Der Begriff staatlich kann allerdings nicht mehr i.S.v. Zentrum der Gesellschaft verstanden werden. Denn staatlich sind auch das Erziehungs- und Bildungssystem, das Gesundheitssystem in seinem Zentrum (Krankenhäuser, insbes. Universitätskliniken), die Wissenschaft und bei einer Staatsquote von zuletzt wieder über $50 \%$ teilweise auch das Wirtschaftssystem. 
Rationalitätstheorien ist daher, daß man nur den Grund als gut identifizieren kann, der sich in einem freien Argumentationsprozeß als überzeugend erweist. Damit wird Rationalität an den Konsens aller möglicherweise Betroffenen angebunden. Rationalitätskriterium ist damit ein Verfahren, das in idealer Weise in Form des Diskursprinzips (D) erklärt werden kann. Dieses Verfahrenskriterium ist allerdings, wie oft kritisiert wird ${ }^{478}$, inhaltsleer. Aus dem Verfahren selbst können keine Inhalte abgeleitet werden. Diese entstammen vielmehr der Erfahrung. Der Witz der diskurstheoretischen Forderung nach Beteiligung aller Betroffenen liegt nun aber darin, daß dadurch gleichzeitig dem Rationalitätsgebot, nach dem Entscheidungen unter Berücksichtigung aller relevanten Informationen, also unter Bedingungen optimaler Information, getroffen werden sollen ${ }^{479}$, Rechnung getragen wird. Sind nämlich alle Betroffenen beteiligt, so gehen auch alle verfügbaren Informationen (Erfahrungen, Bedürfnisse etc.) in den Diskurs ein. Ein Mehr an Rationalität ist in dieser Welt nicht erreichbar.

Die Probleme des abstrakten Diskursprinzips haben wir bereits diskutiert. Neben den schon an sich unvermeidlichen Idealisierungen stellt sich vor allem das Problem der Institutionalisierung. Argumentationen (Diskurse) selbst sind in ihren Details einer Institutionalisierung nicht zugänglich, sondern können in der Realität nur als dezentrierte, offene Argumentationsprozesse in der Zeit verstanden werden. Da die Gesellschaft aber nicht unbegrenzt Zeit hat, müssen Diskurse in Verfahren eingebettet werden, die zumindest zu einem vorläufig verbindlichen Ergebnis führen. Damit werden die Diskurse zeitlichen, sachlichen und sozialen Beschränkungen unterworfen, die zu einem "second best"-Problem führen: Wenn die Verfahrensbedingungen, welche die "beste" Lösung garantieren würden, nicht realisierbar sind, bedeutet das nicht, daß die zweitbeste Lösung durch Verfahren gegeben ist, die dem besten Verfahren möglichst nahe kommen. ${ }^{480}$ Ein freies Prozessierèn von Argumenten ist in real stattfindenden Diskursen (Diskussionen ${ }^{481}$ ) z.B. nur bis zu einer bestimmten Teilnehmerzahl möglich (ca. neun?), während eine Diskussion unter mehreren Beteiligten der Formalisierung durch Tagesordnung, Rednerliste etc. bedarf. Das führt z.B. dazu, daß nicht jeder Teilnehmer frei Sprechakte wählen darf, sondern nur noch bestimmte Sprecher repräsentativ für bestimmte Gruppen (z.B. Fraktionen im Bundestag) das Wort ergreifen. Diskussionsfähig ist auch nicht ein Thema als solches, sondern nur schriftlich formulierte, abstimmungsfähige Anträge. Kleinere Diskussionsgruppen leiden hingegen unter einem Mangel an Repräsentativität, ihr direkt einfließender Erfahrungsschatz beschränkt sich auf den ihrer Mitglieder, während andere Perspektiven nur durch eine fiktive Rollenübernahme (advokatorisch) einbezogen werden. Solche Elitendiskurse bieten keine Gewähr für eine

475 Vgl. hierzu und zum folgenden B.Peters, Rationalität, Recht und Gesellschaft, Ffm 1991, Kap. VI, S.167ff.

476 Vgl. B.Peters, Rationalität, S.259; A. Kaufmann, Prozedurale Theorien, S.19.

477 Siehe R.Dreier, Gerechtigkeit, S.20ff;; A.Kaufmann, Prozedurale Theorien, S.7f; ausführlich auch anhand neuerer Theorien ausgearbeitet bei J.S.Fishkin, The dialogue of justice: towards a self-reflective society, London 1992, Kap. 1 und 2; s.o. Kap. 1.

478 Siehe nur A.Kaufmann, Prozedurale Theorien, S.18-20; B.Peters, Rationalität, S.247-271.

$479 \mathrm{Vgl}$. zu diesem Gebot N.Rescher, Rationality. A Philosophical Inquiry into the Nature and the Rationale of Reason, Oxford 1988, ch. 2.

480 B.Peters, Rationalität, S.249 m.w.N.

$481 \mathrm{Zu}$ den folgenden Einschränkungen einer "Diskussion als System" vgl. N.Luhmann, Systemtheoretische Argumentationen. Eine Entgegnung auf Jürgen Habermas, S.29lff., 316-342. 
universale Perspektivenverschränkung und neigen insofern za paternalistischer Bevormundung. Alle gesellschaftlich institutionalisierten Entscheidungsverfahren stehen daher grundsätzlich unter dem Vorbehalt der "beschränkten Rationalität"482. Dieser Aspekt der gleichzeitigen Begründung und Beschränkung von Rationalität durch Verfahren wird auch vom sog. radikalen Konstruktivismus betont. ${ }^{483}$ Danach sind Wirklichkeitskonstruktionen strikt systemrelative Vorgänge, die entscheidend von den dem Konstruktionsprozeß zugrundeliegenden Strukturen abhängig sind, woraus u.a. folgt, daß verschiedene Probleme in je unterschiedlich strukturierten Verfahren am besten entschieden werden können. Daraus ergibt sich die funktionale Differenzierung der Gesellschaft insofern, als die entstehenden Subsysteme sich anhand ihrer Funktion auf ein je spezifisches gesellschaftliches Problem spezialisieren und zur Lösung dieses Problems spezifische Verfahren herausbilden. In diesem Sinne bilden die Subsysteme Teilrationalitäten aus.

Die Ausgangsfrage nach der Institutionalisierung von Rationalität stellt sich dann als Frage der Systemrationalität im Sinne einer gesamtgesellschaftlich sinvollen Aufgabenverteilung und entsprechender Institutionalisierung. Rationalität bedeutet dann, daß die spezifischen Rationalitätsleistungen unterschiedlicher Systeme, sowie die Rationalitätskapazität einzelner in diesen Systemen ausdifferenzierter Entscheidungsverfahren rekonstruiert werden, um dann zu einer vernünftigen Aufgabenverteilung zu kommen. Habermas' prozeduralistisches Rechtsparadigma kann in genau diesem Sinne verstanden werden, wobei er sich auf die Rekonstruktion der Rationalität von Rechtsprechung und Gesetzgebung, einschließlich des dieser zugrundeliegenden politischen Willensbildungsprozesses, konzentriert, also eine Theorie der Aufgabenteilung zwischen Politik und Recht entwirft. Während Habermas diese Abgrenzung allerdings aus der quasi übergeordneten Perspektive des Diskursprinzips vornimmt, ist für Luhmann eine solche Abgrenzung nur intern von den Systemen selbst zu leisten, da er eine extra-systemische Kommunikation von einem Meta-Standort ausschließt. ${ }^{484}$ Luhmann definiert allerdings Rationalität in einem sehr ähnlichen Sinne als gesteigerte Form von Reflexion. ${ }^{485}$ Reflexion versteht Luhmann als Selbstbeschreibung, mit der ein System sich selbst im Unter-

482 Dieses Prinzip der "bounded rationality" wurde von H.A.Simon (Rationality as Process and as Product of Thought, in: The American Economic Review 68 (1978), S.1-16) für die ökonomische Theorie herausgearbeitet. In diesem Zusammenhang führt er einen Begriff von prozeduraler Rationalität ein, nach dem die Rationalität einer Entscheidung durch den Entscheidungsprozess zugleich gewährleistet und beschränkt wird. Im Gegensatz zur idealen Rationalität des spieltheoretischen rational actor ist eine Handlung schon dann prozedural rational, wenn sie unter gegebenen Bedingungen auf "appropriate deliberation" beruht. Ähnlich N.Rescher, Rationality, Ch. 2.4 und $11.4-11.5$, der als"The Predicament of Reason" herausarbeitet, daß einerseits "the rationality of a problem-solution is information-sensitive" und andererseits "in the real world our information is always incomplete"(S.25) und "practicable rationality" im Gegensatz zu "ideal rationality"(S.28) als "procedural process"(S.189) begreift, "which is directed to resolutions that are optimal as best we can manage to tell".

483 Siehe dazu die Beiträge in S.J.Schmidt (Hrsg.), Der Diskurs des radikalen Konstruktivismus, Ffm 1987. Vgl. auch R.Rorty, Contingency, Irony and Solidarity, Oxford 1988, ch. 1.

484 Auch seine eigenen Ausführungen bezeichnet Luhmann als strikt wissenschaftssystem-relative Beobachtungen der Außenwelt, die von dieser über strukturelle Kopplungen (Theorie) als Selbstbeschreibungen übernommen werden können, oder nicht, dazu aber in jedem Falle eines Aktes der Transformation bedürfen: Luhmann, Die Wissenschaft der Gesellschaft; sowie oben I. 4. b) Beobachter vs. Teilnehmer.

485 N.Luhmann, Soziale Systeme, S.638ff. 
schied zu seiner Umwelt bezeichnet und dadurch seine Identität bestimmt ("Ich sagt"), sowie seine Grenzen zu seiner Umwelt festlegt. Solche Selbstbeschreibung findet auf unterster Stufe bei jeder Systemoperation als sog. mitlaufende Selbstreferenz statt. Auf einer höheren Stufe kann das System sozusagen "bewußt" auf sich selbst reflektieren, indem es eine Theorie von sich selbst anfertigt. Rationalität ist dann die höchste Stufe der Reflexion, auf der ein System sich bewußt als ein System-in-einer-Umwelt-von-anderen-Systemen wahrnimmt, und im Hinblick darauf seine Grenzen bestimmt. ${ }^{486}$ Systeme können sich nach Luhmann zwar nur selbst beschränken, dies können sie aber aufgrund einer Reflexion auf ihre eigenen und auf fremde Fähigkeiten tun. In diesem Sinne können z.B. judicial self-restraint, political question doctrine und eine rechtsintern erstellte Theorie des demokratischen Rechtsstaats verstanden werden, die der Bestimmung des Verhältnisses von Recht und Politik dienen. Damit verweist Luhmanns Begriff der Rationalität auf den Bereich struktureller Kopplungen. Mit dem so beschriebenen Rationalitätsbegriff ist ein Problem formuliert, an dem wir das Konzept prozeduralen Rechts festmachen können.

\section{Recht}

Recht wird als ein (autopoietisches) Kommunikationssystem ${ }^{487}$ verstanden. Als System ist das Recht einerseits Garant von Freiheit und intentionaler gesellschaftlicher Integration, insofern es "natürliche" Freiheit, die letztendlich auf der Macht des Stärkeren beruht, in rechtliche Freiheit transformiert. Gleichzeitig ist Recht als System aber auch ein nichtintentionaler, systemischer Mechanismus, der zur Kolonialisierung und Verrechtlichung autonomer gesellschaftlicher Bereiche und zur paternalistischen Bevormundung von Individuen neigt. Auf dieser Ebene kann man das Recht als "normhungriges Monster" beschreiben, das die Menschen und ihre Konflikte über die Realfiktion des "homo juridicus" als Träger subjektiver Rechte ausbeutet und versklavt, indem es etwa subjektive Klagerechte nur deshalb zur Verfügung stellt, um den Menschen ihre Konflikte zu enteignen und ihnen rechtsintern produzierte Standards aufzuzwingen. 488

Autopoiese wird in dem oben dargestellten Sinne als Voraussetzung der Ausdifferenzierung eines Kommunikationssystems (Recht) innerhalb des Kommunikationssystems Gesellschaft verstanden, welche durch operative Schließung anhand eines Codes erfolgt. Diese Schließung erfolgt, sobald überhaupt an einem Ort verbindlich über Recht entschieden wird. ${ }^{489}$ Im Zentrum des Rechts stehen daher die Gerichte. Idealtypisch

486 N.Luhmann, Soziale Systeme, S.601, $617 \mathrm{ff} ., 640$.

487 Die Betonung liegt auf Kommunikationssystem, während der Zusatz "autopoietisch" von nachrangiger Bedeutung ist, weil damit i.S.v. Luhmann und im Gegensatz zu Teubner Nichts über die Steuerbarkeit oder Beeinflußbarkeit des Rechts durch die Politik oder durch die sonstige Umwelt des Rechts gesagt ist (s.o. 1. Gesellschaft).

488 So auf die Spitze getrieben bei M.Hutter/G.Teubner, Der Gesellschaft fette Beute: Homo juridicus und homo oeconomicus als kommunikationserhaltende Fiktionen.

489 N.Luhmann hatte hier grob auf das 11./12. Jahrhundert datiert. Er betont aber, daß das Recht im strengen Sinne keinen Anfang hat. Denn immer wenn verbindlich über Recht entschieden wird, wird so getan, als habe das, was durch Entscheidung als geltendes Recht festgestellt wird, schon immer gegolten (als Gottes-, Natur- oder Gewohnheitsrecht), vgl. N.Luhmann, RdG, S.57 und öfter. In diesem Sinne ist jedes Rechtssystem auf positivem, d.h. willkürlich gesatztem Recht gegründet. Davon zu unterscheiden ist der traditionelle Begriff der Positivierung des Rechts i.S.v. schriftlicher Fixierung allgemeiner Gesetze. 
(nicht unbedingt historisch) kann man sich die Entwicklung daher folgendermaßen vorstellen. Zunächst entscheidet ein Gericht in Form eines königlichen Richters oder eines Richterkönigs über Recht und Unrecht, wobei Normen im täglichen Entscheiden kondensiert und konfirmiert werden. In diesem autopoietischen Prozeß legitimiert sich das Recht selbst, auch wenn es auf angeblich unabhängig geltendes, höheres Recht verweist. Die Positivierung des Rechts und die damit verbundene Ausdifferenzierung von Gesetzgebung und Rechtsanwendung fügt dem solange nichts hinzu, als diese Funktionen von derselben Person wahrgenommen werden. Das ändert sich erst, wenn Gesetzgebung als politischer Prozeß an die Politik und die Festsetzung von Vertragsinhalten an die Wirtschaft abgegeben werden. Damit wird die Positivität des Rechts, versteht man diese als Entscheidungsabhängigkeit des Rechts, einerseits offenbar. In diesem Sinne war das Recht aber auch vorher schon entscheidungsabhängig, was durch den Bezug auf Natur, Gott oder Gewohnheit lediglich verdeckt war. Andererseits kann mit Fallen des Schleiers des Naturrechts die Entscheidung von substantiellen Fragen nicht uneingeschränkt bei den Gerichten verbleiben. Die Entscheidung über Rechtsinhalte wird vielmehr an Wirtschaft und Politik abgegeben, wobei natürlich auch die Richter in ihren Urteilen weiterhin über inhaltliche Fragen entscheiden, nunmehr aber abgeleitet aus Gesetz und Vertrag in Form der Auslegung. Da das Recht als System seine Abgrenzungsfähigkeit aufrechterhalten muß, können Politik und Wirtschaft nicht als Politik und Wirtschaft über Rechtsinhalte entscheiden. Politische und wirtschaftliche Entscheidungen werden deshalb als zum Rechtssystem gehörende Rechtsakte in Form von Vertrag und Gesetz rekonstruiert. Legitimation wird dadurch hergestellt, daß die Gesellschaft im Recht handeln kann. Diese Verbindung kann als strukturelle Kopplung des Rechts mit der Gesellschaft und ihren Teilen verstanden werden.

Dieses Konzept der Autopoiese weicht von Teubners Konzept ab. Teubner konstruiert den Begriff der Autopoiese nämlich als relativen, und damit steigerungsfähigen Begriff ${ }^{490}$. Das Recht schließt sich danach in einem dreistufig rekonstruierten Entwicklungsprozeß immer weiter von seiner Umwelt ab. Auf dem höchsten Niveau der autopoietischen Geschlossenheit sind alle Elemente des Rechts selbstproduziert und in einem Hyperzyklus rekursiv miteinander vernetzt, so daß sich Norm (Struktur) und Urteil (Operation), abgestützt durch Verfahren und Dogmatik, wechselseitig produzieren.491 Während wir die Aufgliederung des Rechts in Zentrum und Peripherie also als Öffnung des Rechts gegenüber der Gesellschaft verstehen, wobei diese Öffnung in Form der strukturellen Kopplung aus besagten Gründen nur innerhalb des Rechts über die Rekonstruktion von Umwelthandlungen als Rechtsakte geschehen kann, versteht Teubner den Prozeß der inneren Ausdifferenzierung des Rechts als Steigerung von Geschlossenheit. Diese operative Geschlossenheit des Rechts verdoppelt Teubner sodann nochmals, indem er die informationelle Offenheit des Rechts in Anlehnung an den radikalen Konstruktivismus in eine rein rechtsinterne Konstruktion der Außenwelt verwandelt, die in einer Rechtswirklichkeit mündet. Damit ist dann nicht nur normativer in- und output, sondern auch in- und output von Information ausgeschlossen. Rechtssystem und Umwelt produzieren füreinander nur Lärm. ${ }^{492}$ Somit ist dann wirklich ein monadisch in sich verkapseltes Rechtssystem beschrieben, was Habermas zu Recht ablehnt. Wie gezeigt,

490 G.Teubner, Recht als autopoietisches System, S.48ff. mit Abbildung auf S.50.

491 G.Teubner, Recht als autopoietisches System, S.56.

492 G.Teubner, Recht als autopoietisches System, S.88ff., $97 \mathrm{ff}$. 
muß dieser Befund aber nicht insgesamt zur Ablehnung des Autopoiesekonzepts führen. Zum einen muß zwischen operativer Geschlossenheit (Autopoiese) und informationellem Konstruktivismus unterschieden werden. Zum anderen zeigt uns die Erfahrung, daß sowohl einzelne Menschen, als auch ganze Systeme im Alltag ihre Konstruktionen relativ zufriedenstellend aufeinander abstimmen können. Zudem wird das Problem des order-from-noise, wie ja insbesondere Teubner herausarbeitet, durch vielfältige strukturelle Kopplungen (Interferenzen) relativiert. Teubner malt das etwas übertriebene Bild eines völlig in sich verkapselten Rechtssystems nicht zuletzt deshalb, weil er vornehmlich an Steuerungsproblemen des Rechts interessiert ist. Um diese zu verdeutlichen bietet sich eine entsprechende Darstellung auch an.

Stellt sich das Rechtssystem nun als ein zwar operativ geschlossenes, aber doch in vielfältiger Weise an seine Umwelt gebundenes System dar, so stellt sich die Frage nach der Rationalität des Rechts als eine dreifache. Erstens können wir nach der Rationalität des juristischen Diskurses i.e.S. als dem von Rechtsdogmatik begleiteten und im gerichtlichen Instanzenzug geordneten richterlichen Diskurs fragen. Dieser juristische Diskurs kann zum einen am Begriff der prozeduralen Rationalität als rationale juristische Argumentation erklärt werden. ${ }^{493}$ Gleichzeitig muß aber im Auge behalten werden, $\mathrm{da}$ dieser juristische Diskurs unter strengen zeitlichen, sachlichen und sozialen Beschränkungen stattfindet, so daß eine spezifisch "juridische Rationalität" 494 ausgebildet wird. Diese Beschränkungen können am Diskursprinzip selbst ${ }^{495}$, oder aber über den Systemcharakter des Rechts am Begriff des juristischen Konstruktivismus erläutert werden. ${ }^{496}$

Die Rationalität des juristischen Diskurses i.e.S. bleibt, soweit substantielle Entscheidungen über strukturelle Kopplungen etwa in Form von Vertrag und Gesetz importiert werden, immer von der Rationalität der diesen Entscheidungen zugrundeliegenden Verfahren und Diskursen abhängig. Zweitens sind deshalb diese Entscheidungen (Rechtsakte) in den Möglichkeiten und Grenzen ihrer Rationalität zu beleuchten. In diesem Sinne hat Habermas den Prozeß der politischen Willensbildung in seinen institutionalisierten und nicht-institutionalisierten Komponenten anhand der Begriffe von Zivilgesellschaft und deliberativer Politik als rationalen Diskurs rekonstruiert. Gleiches ist auch für die Willensbildung in der Verwaltung, auch unter Einbeziehung neuer Formen der Bürgerbeteiligung, sowie für die privatwirtschaftliche Willensbildung zu leisten, wobei die jeweiligen Beschränkungen sich wiederum aus Abweichungen vom Diskursprinzip und aus spezifisch systemischen Mechanismen ergeben können. ${ }^{497}$

493 Z.B. R.Alexy, Argumentation; siehe auch J.Habermas, FuG, Kap. V.

494 H.Schelsky, Die juridische Rationalität, in: ders, Die Soziologen und das Recht, Opladen 1980, S.34-76, schreibt diese Rationalität im Gegensatz zu herkömmlichen Rationalitätstheorien nicht dem Individuum oder der Intersubjektivität von Kommunikationsprozessen, sondern dem institutionellen, nach Regeln arbeitsteilig organisierten (Regierung und Opposition in der Gesetzgebung, Gerichte als Drittinstanz) juristischen Prozeß zu (a.a.O., S.35f.). Zur Rationalität von Institutionen vgl. auch B.Peters, Rationalität, Kap. VI 4, S.201ff m.w.N.

495 So J.Habermas, FuG, Kap. V. und VI.

496 N.Luhmann, RdG, S.184ff; G.Teubner, Recht als autopoietisches System, S.96ff.; zum Ganzen siehe auch die Übersicht bei B.Peters, Rationalität, Kap. VIII.

497 Für eine Rekonstruktion der Rationalität der Marktmechanismen steht nach wie vor A.Smith's "invisible hand" (ders., Der Wohlstand der Nationen (1776), München 1978, S.370f.); siehe auch F.A.Hayek, Mißbrauch und Verfall der Vernunft (1952), Ffm 1959, sowie ders., Law, Legislation and Liberty, 3 Bände, London 1973-1979; die Rationaliät der vertraglichen Einzelentscheidung 
Drittens stellt sich dann die Frage der Abstimmung zwischen diesen Rationalitäten. Rationalität in Form von Reflexion kann dabei auf der Ebene der Operation im Einzelfall stattfinden, implizit etwa wenn ein Richter sein Urteil auf die Gesetzesbindung stützt oder sich auf die Vertragsfreiheit beruft, oder schon expliziter wenn sich ein Verfassungsgericht unter Berufung auf Einschätzungsprärogativen und Beurteilungsspielräume des demokratischen Gesetzgebers in seiner materiellen Prüfung beschränkt (judicial self-restraint). Auf abstrakterer Ebene findet solche Reflexion auch als Bestimmung des Gesamtverhältnisses zweier Systeme etwa in der Theorie des demokratischen Rechtsstaats statt. Rationalität in diesem Sinne heißt dann, daß das Rechtssystem in seinen Operationen eine Selbst- und Fremdbeschreibung bezüglich der Rationalität von Entscheidungen mitführt und diese Beschreibungen bei der Bestimmung seiner Grenzen berücksichtigt.

\section{Dimensionen prozeduralen Rechts: ein Definitionsversuch}

\section{Normebene: Prozedurale Normen}

\section{a) Prozedurales Recht im weiteren Sinne}

Prozedurales Recht im weiteren Sinne ist alles Recht, das durch Kompetenz-, Organisations- und Verfahrensvorschriften die Anwendung und Entstehung primärer Normen regelt, umfasst also ebenfalls in einem weiteren Sinne alle sekundären Normen i.S.v. H.L.A. Hart. Wenn Reflexivität als Anwendung eines Prozesses auf sich selbst verstanden wird (Normierung der Normierung), dann ist prozedurales Recht in diesem Sinne reflexives Recht, weil es seine Anwendung und Erzeugung regelt. Primäre Normen regeln demgegenüber ein Rechtsverhältnis inhaltlich, substantiell. Diese Normen werden auch als materiell bezeichnet (etwa materielles Strafrecht $=$ StGB) und so vom Prozeßund Verfahrensrecht abgegrenzt. Prozedurales Recht begrenzt sich aber nicht auf Prozeßrecht (etwa Strafverfahrensrecht), sondern umfasst auch Kompetenz- und Organisationsvorschriften wie etwa das Gerichtsverfassungsgesetz. Es beschränkt sich darüber hinaus nicht auf Gerichtsverfahren, sondern erstreckt sich auf das Staatsorganisationsrecht, dort etwa insbesondere auf das Gesetzgebungsverfahren, aber auch das Verwaltungsverfahren. Insofern ist prozedurales Recht nicht identisch mit dem englischen Rechtsterm "procedural law", der in dem engeren Begriff Prozeßrecht im technischen Sinne (StPO, ZPO, VwGO) eine bessere Übersetzung findet. Im öffentlichen Recht wird die Unterscheidung zwischen primären und sekundären Normen, zwischen prozeduralem und substanziellem Recht auch an den Begriffen formeller und materieller Rechtsbeziehungsweise Verfassungsmäßigkeit festgemacht, wobei formelles Recht in diesem Zusammenhang Kompetenz (Zuständigkeit), Form und Verfahren meint. Wenn prozedurales Recht gleichsam die Verfassung des Rechts regelt, so ist es doch nicht identisch mit dem Verfassungsrecht, da es nicht nur Verfassungsnormen enthält und die Verfassung auch primäre Normen enthält, insbesondere im Grundrechtsteil. Die Abgrenzung zwischen prozeduralem und materiellem Recht ist dabei nicht immer eindeutig vorzunehmen, da eine Norm auch beide Aspekte enthalten kann: so wird Art. 20 I GG einer-

kann hingegen auch anhand des Diskursprinzips erklärt werden, insofern dessen Gebote (Konsens, Ausschluß von Drohung und Täuschung, Irrtum) z.B. im BGB AT zum Ausdruck kommen. Der zweiseitige Vertrag ist sogar der einzige Rechtsakt, für den es auf Konsens im Gegensatz zum Mehrheitsbeschluß wirklich ankommt. 
seits als Festlegung von Strukturprinzipien verstanden, andererseits wird aus dem Sozialstaatsprinzip auch ein substanzielles Recht auf Sozialhilfe abgeleitet und die Grundrechte haben neben dem materiellen auch einen prozeduralen Gehalt. Unter dem Oberbegriff prozedurales Recht können also Rechtsnormen zusammengefasst werden, die traditionell als Verfahrens- und Prozeßrecht, als Organisations- und Kompetenzrecht, teilweise als Verfassungsrecht, als formelles (nicht formales) Recht oder aber als sekundäre Normen bezeichnet werden. Kurzum regelt das prozedurale Recht das "Wie" im Gegensatz zum "Was".

\section{b) Prozedurale Normen und prozedurale Rationalität}

Die Einführung des Begriffs prozedurales Recht kann aber nicht damit begründet werden, daß dieser als Oberbegriff für die verschiedensten Rechtsnormen im oben beschriebenen Sinne dient. Als solcher Oberbegriff könnte auch der Begriff formelles Recht dienen. Mit der Einführung des Fremdwortes prozedural ist noch etwas anderes gemeint, prozedurales Recht ist ein Mehr gegenüber formellem Recht. Formelles Recht verweist auf den formalen Rechtsstaat im Sinne eines Systems rechtstechnischer Kunstgriffe (Forsthoff). Dem Wort formal haftet dabei ein etwas schaler Beigeschmack der Inhaltsleere an, er erinnert an Formalien, an juristische Kautelen, die zwar - warum auch immer - einzuhalten sind, aber von den eigentlichen Fragen nach dem Inhalt, nach der Substanz, ablenken, diese gar behindern. Dementsprechend werden Formalien im Recht abgehandelt. Mit lockerem Handstreich geht man häufig über sie hinweg, um sich den Fragen materieller Rechtmäßigkeit zuzuwenden.

Demgegenüber verweist das Adjektiv prozedural auf ein Mehr. Es ist nämlich in der (rechts-) philosophischen Diskussion um Gerechtigkeit, Richtigkeit und Wahrheit solchen Theorien beigeordnet, die als prozedurale Theorien die Bedingungen der Entscheidbarkeit von Gerechtigkeits- oder Wahrheitsfragen in ein Verfahren verlegen. Weil alle materiellen Theorien der Gerechtigkeit gescheitert sind, wird seit Kant versucht, Kriterien der Richtigkeit in den verfahrensmäßigen Bedingungen der Entscheidung solcher Fragen zu finden. Herausragende Beispiele solcher Theorien sind Rawls Theorie der Gerechtigkeit und Habermas Diskurstheorie, letztlich gründen sich aber alle neueren Theorien der Gerechtigkeit auf ein Verfahren und auf Konsens, sei es jeweils auch nur ein fiktives Verfahren. Mit dem Adjektiv prozedural verbindet sich also der Verweis auf Verfahren als Kriterium der Richtigkeit der Entscheidung materieller Fragen.

Überträgt man aus diesem Zusammenhang den Begriff prozedural auf das Recht, so wird klar, daß prozedurales Recht nicht mit formellem Recht identisch ist. Als prozedurales Recht im engeren Sinne sollen daher nur solche formellen Rechtsvorschriften über Kompetenz, Organisation, Form und Verfahren verstanden werden, die als Regeln über die Entscheidung materieller Fragen die Rationalität dieser Entscheidungen gewährleisten oder zumindest fördern. Unter diesem Gesichtspunkt stellen sich zwar viele formelle Vorschriften als prozedurales Recht dar, und insofern läge wieder Deckungsgleichheit vor. Für die Einführung des Begriffs prozedurales Recht spricht aber einerseits, daß nicht alle formellen Vorschriften prozedurale Rationalität gewährleisten. So kann etwa eine polizeirechtliche Kompetenzvorschrift allein der Notwendigkeit entspringen, die Zuständigkeit zwischen den Behörden A und B überhaupt festzulegen, ohne daß dabei auf prozedurale Rationalität verwiesen würde, weil etwa unter diesem Gesichtspunkt keine der beiden Behörden als besser zur Entscheidung geeignet erscheint 
(was generell für Vorschriften über die örtliche Zuständigkeit gilt). Darüber hinaus erscheint die Einführung des Begriffs prozedurales Recht aber vor allem deshalb sinnvoll, weil er im Gegensatz zum Begriff des formellen Rechts auf den normativen Gehalt sekundärer Normen verweist. Gerechtigkeit, Richtigkeit und Legitimität sind im prozeduralen Recht immer schon als prozedurale Rationalität mitgedacht.

Zusammenfassend bezeichnet prozedurales Recht auf der Normenebene alle Kompetenz-, Organisations- und Verfahrensvorschriften, die einen Bezug zur Richtigkeit (Rationalität, Gerechtigkeit, Legitimation) der durch sie ermöglichten Entscheidungen aufweisen.

\section{Normanwendung: Prozedurale Rationalität des juristischen Diskurses}

Geht es bei prozeduralem Recht um die Richtigkeit von Entscheidungen, so ist festzuhalten, daß Entscheidungen durch Verfahrensregeln weder vollständig determiniert werden können noch die diskursive Rationalität einer Entscheidung vollständig rechtlich institutionalisierbar ist. Jede Norm muß angewendet, interpretiert und fortgebildet werden, keine Norm kann ihre eigene Anwendung mitregeln. Das Ideal vom Richter als Subsumtionsautomaten, der bloß der Mund des Gesetzes ist, ist spätestens durch die juristische Hermeneutik gründlich widerlegt worden. Gesetze allein können die Rationalität einer Entscheidung nicht gewährleisten

Versteht man nun rechtlich geregelte Entscheidungen als rationale Diskurse, so kann die Rationalität der Entscheidungsverfahren nie ausschließlich durch Rechtsregeln garantiert werden. Rationale Diskurse sind nämlich nicht institutionalisierbar, sondern rationale Diskurse können nur in rechtliche Verfahren eingebettet werden. Die ideale Rationalität von Diskursen geht dabei insofern verloren, als Rechtsverfahren dem Diskurs einen Entscheidungsbezug vermitteln. Rechtsverfahren sind im Gegensatz zu idealen Diskursen nicht handlungsentlastet. Es können nicht alle beteiligt werden, nicht alle Bedürfnisse und Informationen können verarbeitet werden und das Konsenskriterium wird durch den Mehrheitsentscheid ersetzt.

Einerseits können also bestimmte Diskursregeln, wie etwa die Abwesenheit von Zwang, Macht oder Täuschung oder bestimmte Argumentations- und Beweislastregeln, nicht rechtlich garantiert werden (weshalb etwa die juristische Methodenlehre nicht gesetzlich geregelt ist), andererseits liegt gerade in der rechtlichen Institutionalisierung von Verfahren ein Widerspruch zu den Diskursregeln (Mehrheit statt Konsens etc.).

Um also die Rationalität rechtlichen Entscheidens so weit wie möglich zu gewährleisten, $\mathrm{mu} \beta \mathrm{zu}$ der durch prozedurale Normen institutionalisierten prozeduralen Rationalität auf der Normenebene eine rechtlich nicht institutionalisierbare Ebene der rationalen juristischen Argumentation hinzutreten. Deshalb muß die Normanwendung als ein Verfahren rationaler juristischer Argumentation verstanden werden, durch welches die durch die Gesetze offengelassene Rationalitätslücke insofern ausgefüllt wird, als sich die Rechtsanwendung am Ideal eines rational geführten juristischen Diskurses legitimiert.

Der juristische Diskurs verläuft dabei dezentriert und gleichsam "subjektlos" durch Raum und Zeit, er ist in eine Vielzahl von Arenen und Foren der juristischen Argumentation eingelassen, ohne auf konkrete Personen oder Institutionen angewiesen zu sein. Die kommunikative Vernunft des juristischen Diskurses verwirklicht sich durch ein unendliches Aneinanderanknüpfen von rechtspolitischer, rechtsdogmatischer und richterli- 
cher Argumentation in der Zeit. Jede Kommunikation, die Anspruch auf rechtliche Geltung erhebt, sich also am Rechtscode orientiert, ist Teil des juristischen Diskurses. Neben der richterlichen Urteilsbegründung, dem Rechtsgespräch vor Gericht, der rechtswissenschaftlichen Dogmatik in Aufsätzen und Büchern, Vorlesungen und Seminaren sowie der rechtlichen Diskussion zwischen Studenten, Anwälten, Wirtschaftsund Verwaltungsjuristen, sind auch Urteilsbesprechungen und rechtspolitische Diskussionen in den Medien und der Öffentlichkeit umfasst.

Dieser juristische Diskurs ist heterarchisch organisiert, spontan, unvorhersehbar und offen, da sich prinzipiell jede Kommunikation dem Diskurs durch Codebezug selbst zuordnen kann. Die Chancen, die Richtung des Diskurses zu bestimmen und damit auch die Rechtsstruktur zu beeinflussen, sind allerdings ungleich verteilt. Gemäß der Logik des Erinnerns und Vergessens haben im Strom der Rechtskommunikationen nur schriftlich fixierte und veröffentlichte Kommunikationen die Chance, dem Vergessen zu entrinnen, und nur die wenigsten Kommunikationen werden so oft erinnert, daß sie über den juristischen Diskurs den structural drift des Rechtssystems bestimmen oder gar selbst als Text zur Rechtsstruktur werden. So sind die Chancen wahrgenommen zu werden ungleich verteilt, indem der Zugang zur rechtsdogmatischen Diskussion an formale (Promotion und Habilitation) und materiale (Reputation) Kriterien gebunden ist, indem bestimmten politischen Kommunikationen strukturändernder Charakter zugeschrieben wird (Gesetzgebung) und indem der juristische Diskurs im Zentrum des Rechts hierarchisch organisiert wird, so daß klar ist, wer im Instanzenzug das letzte Wort behält (Rechtsprechung).

Dieser juristische Diskurs ist an verschiedenen Stellen in Rechtsverfahren eingebettet, die eine Entscheidung ermöglichen, obwohl der Diskurs selbst niemals abgeschlossen ist, sondern als unendlicher Lernprozess in der Zeit verläuft. In diesen rechtlich institutionalisierten Verfahren werden die Rechtsakte Gesetz, Satzung, Vertrag, Urteil etc. produziert, die aufgrund ihrer Einbettung in den fortlaufenden Diskurs zwar eine Vermutung für Vernünftigkeit in Anspruch nehmen können, sich aber jeweils nur als interrimistisches Zwischenergebnis des Diskurses darstellen, welches als vorläufige Arbeitsgrundlage gesellschaftsweit verbindlich gemacht wird.

Im Zentrum des Rechtssystems spricht deshalb eine Vermutung für die Vernünftigkeit richterlicher Urteile, soweit diese sich in ihrer Begründung durch das Anknüpfen an Gesetz, Dogmatik und Präjudiz, sowie im Bereich des innerhalb dieser juristischen Methoden diskursiv Möglichen durch allgemeine praktische Argumentation als Teil dieses Diskurses ausweisen. Dabei gilt als oberste Diskursregel, daß die Vermutung für Vernünftigkeit umso größer ist, je gründlicher sich das Urteil mit allen im juristischen Diskurs befindlichen Argumenten auseinandersetzt, also state of the art begründet ist. Kurz gesagt ist ein Urteil dann rational, wenn es den "Stand der Rechtswissenschaft" wiedergibt.

Prozedurales Recht meint also auf der Handlungs- und Kommunikationsebene, daß das Recht (bzw. rechtliches Entscheiden) sich nicht nur aus Normen, sondern auch aus deren Anwendung in einem Verfahren der rationalen juristischen Argumentation legitimiert. 


\section{Reflexion: ein prozedurales Rechtsparadigma}

Versteht sich der juristische Diskurs in diesem Sinne als Spezialfall des allgemeinen rationalen Diskurses, so besteht die Gefahr einer Selbstüberschätzung und Selbstüberforderung des Rechts: denn nur der "Richter Herkules" könnte tatsächlich die Bedingungen eines allgemeinen rationalen Diskurses erfüllen. Mit diesem unerfüllbaren Ideal des Herkules vor Augen ist das Recht blind gegenüber der Gesellschaft und gegenüber sich selbst und seinen Grenzen. Der Richter Herkules ist deshalb ein unreflektiertes ${ }^{498}$ Selbstbild des Rechts. Ein Rechtssystem, das sich Herkules zum Vorbild und Selbstbild machen würde, würde seine Funktion in der modernen Kommunikationsgesellschaft nicht erfüllen können. Auf einer Metaebene meint prozedurales Recht daher neben prozeduralen Normen und prozeduraler Rationalität der juristischen Argumentation ein prozedurales Paradigma des Rechts. Paradigma des Rechts meint ein Bild des Rechts von der Gesellschaft und von sich selbst, was beides zusammenhängt. Nur wer "Du" sagen kann, kann sich selbst in Abgrenzung von diesem "Du", dem anderen, als "Ich" bezeichnen, also eine Identität, ein Selbstbild entwickeln.

Reflexion bedeutet demnach, daß das Rechtssystem sich selbst als ein Teilsystem in der Gesellschaft versteht, und in Bezug auf sein Gesellschaftsbild seine eigene Funktion und Rolle in der Gesellschaft bestimmt. Reflexion meint dabei aber nicht, daß das Rechtssystem unbewußt ein "implizites Gesellschaftsbild" benutzt, wie dies von Wieakker für die Periode des bürgerlichen Formalrechts und des sozialstaatlich materialisierten Rechts nachgewiesen wurde. Reflexion meint vielmehr, daß das Recht sich seine impliziten, gleichsam unterbewußt verwendeten Gesellschaftsbilder bewußt macht und diese auf ihre Angemessenheit in der modernen Gesellschaft hin überprüft. Reflexion definieren wir deshalb als die bewußte Erstellung eines Paradigmas des Rechts, also als die bewußte Herstellung eines Selbstbildes des Rechts in Bezug auf ein Gesellschaftsbild des Rechts, wobei dieses Paradigma in jeder Operation des Rechts Wirksamkeit entfaltet und zugleich auf seine Angemessenheit hin überprüft wird.

Als der modemen Gesellschaft angemessen haben wir ein prozeduralistisches Rechtsparadigma bestimmt, das auf die zunehmende Entscheidungsabhängigkeit (Kontingenz) in der Gesellschaft, auf die zunehmende Abhängigkeit der Rationalität von Entscheidungen von Verfahren und auf die zunehmende Ausdifferenzierung der Gesellschaft in ganz unterschiedliche Verfahrensrationalitäten reflektiert. Der ideale, einheitliche Diskurs ist nicht institutionalisierbar. Er kann nur als dezentriert und gleichsam subjektlos in der Zeit voranschreitender Lernprozeß verstanden werden. ${ }^{499}$ Gleiches gilt für die Vielzahl hochspezialisierter Teildiskurse, die sich anhand bestimmter Themen ausdifferenziert haben. Solche Diskurse sind unter je unterschiedlichen sachlichen, zeitlichen und sozialen Bedingungen (Beschränkungen) in Verfahren eingebettet, die verbindliche Entscheidungen in der Gegenwart ermöglichen. Soweit solche Entscheidungen im Zweifelsfalle mit politischer Macht durchgesetzt werden sollen, sind diese Verfahren als Rechtsverfahren ausgestaltet, in denen Rechtsakte produziert werden.

Die Spezialdiskurse differenzieren sich aus, weil sie unter bestimmten Gesichtspunkten (Funktion) besonders leistungsfähig sind, da sie Informationen unter bestimmten

498 Im Sinne von "nicht auf hinreichender Reflexion auf die Funktionsbedingungen und Grenzen von Recht in der modernen Kommunikationsgesellschaft beruhend".

499 Als solcher kann er unter dem Stichwort "Ethik" aber in die ausdifferenzierten Kommunikationskreisläufe der Subsysteme einfließen. S.u. Kap. 3 zu den Ethikkommissionen. 
Gesichtspunkten (Code) vereinseitigt verarbeiten. Auch das Recht vereinseitigt im juristischen Diskurs gesellschaftliche Probleme anhand des Codes Recht/Unrecht. Ein Rechtssystem, welches der gesamten Gesellschaft sein spezifisches Verständnis von Rationalität aufzwingt (Herkulesmodell), und dabei den Eigenwert anderer Codes negiert, tut der Gesellschaft in einem metaphorischen Sinne Unrecht. Diese Einsicht kann als systemische Rekonstruktion der Lehren von der Natur der Sache begriffen werden. Auch das Recht selbst entwickelt als System eine Eigendynamik, die systemisch als "Normenhunger" oder "Rechtsimperialismus" verstanden werden kann und aus Sicht der Gesellschaft oder anderer Spezialdiskurse kontraproduktive Wirkungen (Kolonialisierung der Lebenswelt; negative externe Effekte der Verrechtlichung) zeitigen kann. Recht macht die Welt also nicht glücklich, aber ohne Recht gibt es die Gesellschaft nicht so, wie wir sie kennen. Wie jedes System ist Recht daher ein zweischneidiges Schwert, das Freiheit und Entfremdung gleichzeitig beinhaltet.

Über das prozedurale Rechtsparadigma soll das Recht auf die Gesellschaft und ihre Probleme, auf sich selbst, seine Vorteile und Grenzen reflektieren und sich in Bezug auf dieses Paradigma selbst limitieren. Ein prozedurales Rechtsparadigma betont die traditionelle Stärke des Rechtssystems auf dem Gebiet der Verfahrensgerechtigkeit, während es dem Recht auf dem Gebiet inhaltlich konkreter Entscheidungen eher seine Schranken (i.S.v. Beschränktheit) aufweist. So, wie dem Philosophen in der Diskurstheorie nicht mehr die Erkenntnis "objektiver Werte und Normen", sondern nur noch die Rolle eines Diskussionsleiters, der die Einhaltung der Verfahrensregeln überwacht, zukommt; so, wie der Psychiater nicht mehr objektive Lösungen vorgibt, sondern sich selbst als Teil des Problems versteht und nur noch Lernprozesse und Prozesse der Selbstveränderung anstößt und supervidiert; und so, wie der Unternehmensberater heute die Notwendigkeit der Einbeziehung aller Mitarbeiter in den Prozeß der Problemdefinition sieht und den Anstoß eines "kontinuierlichen (Selbst-) Verbesserungsprozesses" zum Ziel hat; so kann auch das Recht nicht mehr bis in jedes Detail hinein allgemeinverbindliche, inhaltliche Vorgaben für das Zusammenleben machen, sondern muß sich auf die Kompatibilisierung unterschiedlicher Teilrationalitäten sowie die Bevorratung gesamtgesellschaftlicher, struktureller Lernfähigkeit konzentrieren.

\section{Definition}

Im zusammenfassenden Rückblick auf die Abschnitte III und IV kann der Begriff Prozedurales Recht nunmehr wie folgt definiert werden:

"Prozedurales Recht" bezeichnet das Recht als ein Kommunikationssystem, dessen Komponenten darauf gerichtet sind, die Rationalität des Rechts durch Verfahren zu steigern. $\mathrm{Zu}$ den Komponenten eines prozedural-rationalen Rechts gehören (1) alle rationalitätsfördernden Normen, durch die das Recht sich als System konstituiert einschließlich derer, die die Kopplung des Rechts an seine Umwelt regeln (strukturelle Komponente), (2) alle Kommunikationen, die einen Anspruch auf richtige Verwendung des Rechtscodes erheben einschließlich derer, die sich auf die diskursive Einlösung dieses Anspruchs richten (operative Komponente) und (3) ein prozedurales Rechtsparadigma, das bei allen Rechtsoperationen zur Bestimmung von Identität und Grenzen des Rechts mitzuführen und beständig zu überarbeiten ist (reflexive Komponente). 